\title{
\#USGS
}

\section{Topographic Change Detection at Select Archeological Sites in Grand Canyon National Park, Arizona, 2006-2007}

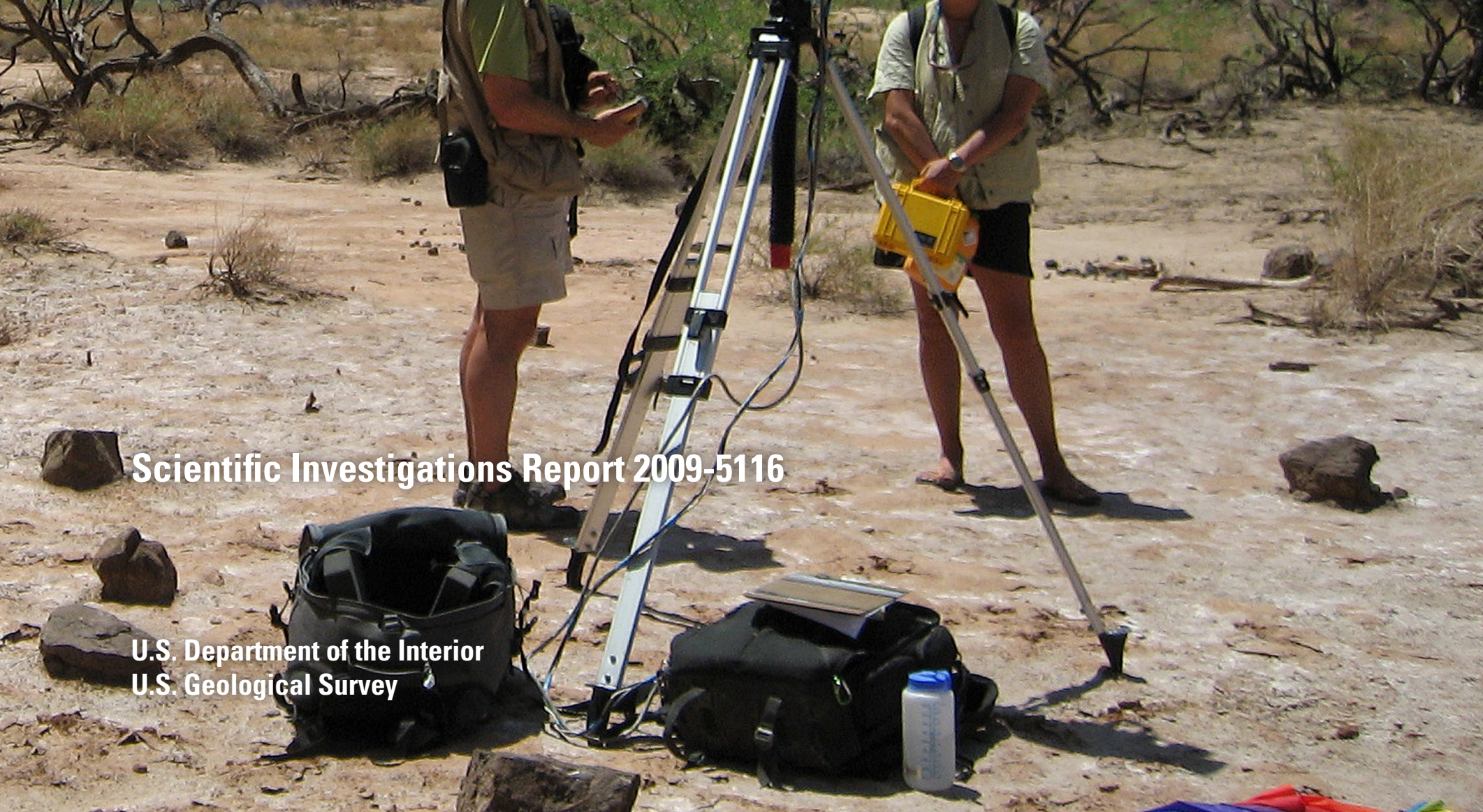


Front Cover: U.S. Geological Survey researchers collecting high-resolution topographic terrestrial lidar data near an archeological site in Grand Canyon National Park. 


\section{Topographic Change Detection at Select Archeological Sites in Grand Canyon National Park, Arizona, 2006-2007}

Brian D. Collins, Diane Minasian, and Robert Kayen

Scientific Investigations Report 2009-5116 


\section{U.S. Department of the Interior \\ KEN SALAZAR, Secretary \\ U.S. Geological Survey \\ Suzette M. Kimball, Acting Director}

\section{U.S. Geological Survey, Reston, Virginia: 2009}

This report and any updates to it are available at:

http://pubs.usgs.gov/sir/2009/5116/

For more information on the USGS - the Federal source for science about the Earth, its natural and living resources, natural hazards, and the environment, visit http://www.usgs.gov or call 1-888-ASK-USGS

For an overview of USGS information products, including maps, imagery, and publications, visit http://www.usgs.gov/pubprod

To order this and other USGS information products, visit http://store.usgs.gov

Any use of trade, product, or firm names is for descriptive purposes only and does not imply endorsement by the U.S. Government.

Although this report is in the public domain, permission must be secured from the individual copyright

owners to reproduce any copyrighted materials contained within this report.

Suggested citation:

Collins, B.D., Minasian, D., and Kayen, R., 2009, Topographic Change Detection at Select Archeological Sites in Grand Canyon National Park, Arizona, 2006-2007: U.S. Geological Survey Scientific Investigations Report 2009-5116, 58 p. [http://pubs.usgs.gov/sir/2009/5116/]. 


\section{Contents}

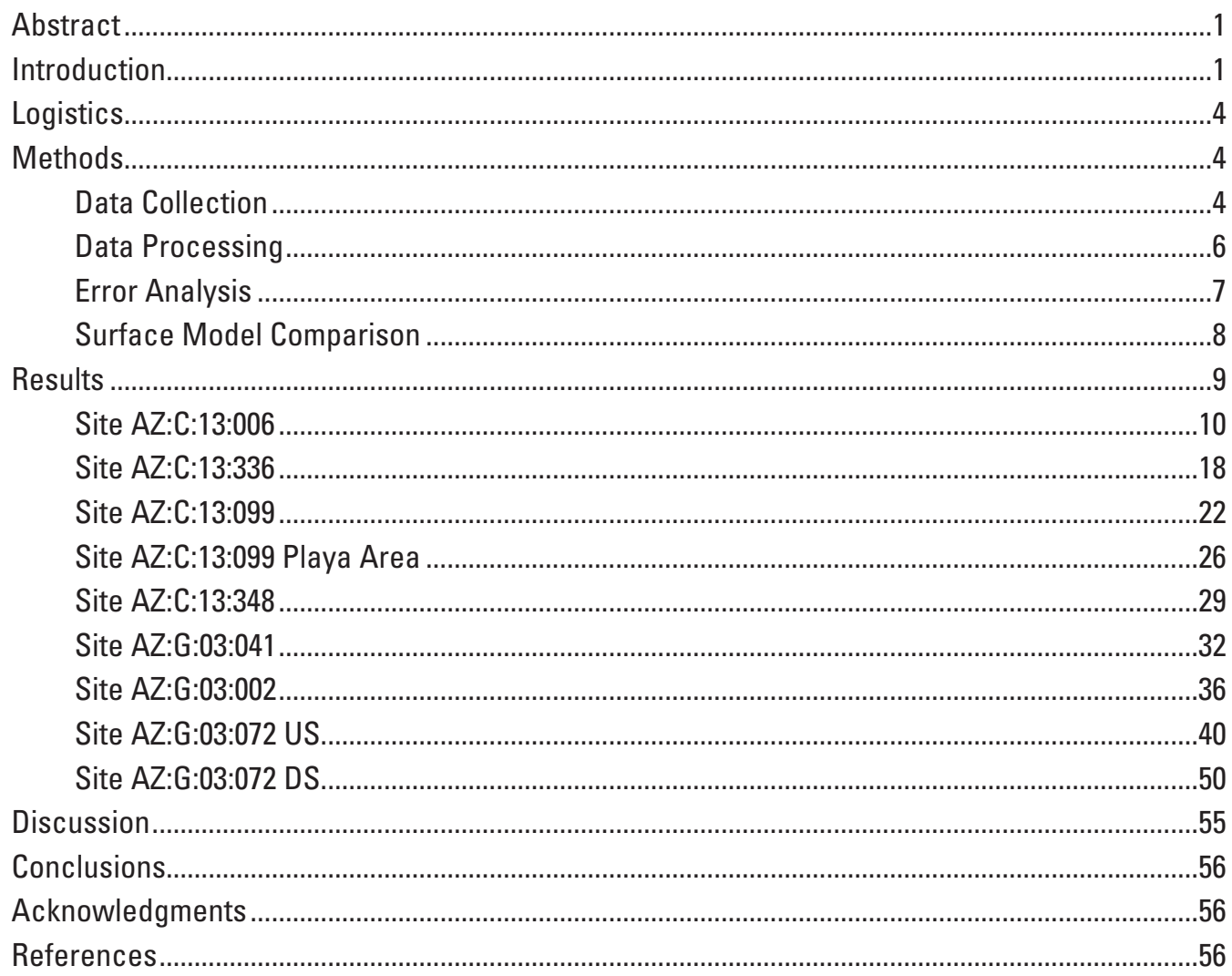

\section{Figures}

1. Gullying of an archeological site in Grand Canyon National Park and excavation of

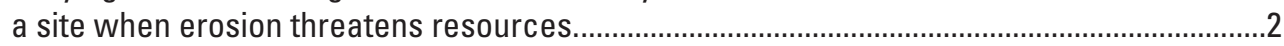

2. Regional map of northern Arizona and Grand Canyon National Park........................................3

3. Site map showing general location of sites included in this investigation and referenced by archeological identification number (ArchID) ..................................................

4. Terrestrial lidar data collection in Grand Canyon National Park.................................................

5. Site AZ:C:13:006 showing main gullies, general downhill flow direction, and laser scan and laser control point locations........................................................................

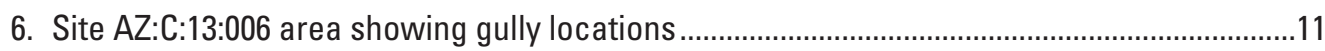

7. Site $A Z: C: 13: 006-5-\mathrm{cm}$ triangulated irregular network (TIN) output showing relative magnitude of surface comparison from May 2006 to September 2007......................12

8. Site AZ:C:13:006 - 10-cm gridded output showing erosion and deposition from May 2006 to September 2007 and approximate gully locations......................................13

9. Site AZ:C:13:006-10-cm gridded output showing erosion and deposition from May 2006 to May 2007 and approximate gully locations ................................................14

10. Site AZ:C:13:006 - 10-cm gridded output showing erosion and deposition from May 2007 to September 2007 and approximate gully locations. 
11. Site AZ:C:13:006 overview images showing area of as much as $30 \mathrm{~cm}$ deposition measured between May 2006 and September 2007.

12. Site AZ:C:13:006 overview images showing locations of erosion

13. Site $A Z: C: 13: 336$ and site $A Z: C: 13: 099$ playa areas showing main gullies, general downhill flow direction, and laser scan and laser control point locations.

14. Site AZ:C:13:336 showing confluence of two drainages and rock check dam structures in the upper area of the site.

15. Site AZ:C:13:336 - 5-cm triangulated irregular network (TIN) output showing relative magnitude of surface comparison from May 2006 to September 2007

16. Site AZ:C:13:336 - 10-cm gridded output showing erosion and deposition from May 2006 to September 2007 and approximate gully locations.....................................20

17. Site AZ:C:13:336—Photos of $G 2$ depositional area in September 2007 .....................................21

18. Site AZ:C:13:099 showing main gullies, general downhill flow direction, and laser scan and laser control point locations.

19. Site AZ:C:13:099 showing confluence of two smaller drainages into the main gully system...

20. Site AZ:C:13:099—5-cm triangulated irregular network (TIN) output showing relative magnitude of surface comparison from May 2006 to September 2007

21. Site AZ:C:13:099—10-cm gridded output showing erosion and deposition from May 2006 to September 2007 and approximate gully locations

22. Site AZ:C:13:099 - Site overview images showing locations of as much as $20 \mathrm{~cm}$ measured erosion and location of gullies...

23. Site $A Z: C: 13: 099$ playa area showing location of main gully .26

24. Site AZ:C:13:099 playa area-5-cm triangulated irregular network (TIN) output showing location and relative magnitude of surface comparison from May 2006 to September 2007

25. Site AZ:C:13:099 playa area-10-cm gridded output showing erosion and deposition, positive) from May 2006 to September 2007 and approximate gully location

26. Site AZ:C:13:099 playa area-Image and inset showing area of as much as $12 \mathrm{~cm}$ measured erosion and location of major gully.

27. Site AZ:C:13:348 area showing main gullies, general downhill flow direction, and laser scan and laser control point locations.

28. Site $A Z: C: 13: 348$ area showing gully locations

29. Site AZ:C:13:348-5-cm triangulated irregular network (TIN) output showing relative magnitude of surface comparison from May 2007 to September 2007

30. Site AZ:C:13:348-10-cm gridded output showing erosion and deposition from May 2007 to September 2007 and approximate gully locations.

31. Site AZ:C:13:348-Images of gully $G 1$ and gully $G 2$ from September 2007 showing possible locations of minor erosion.

33. Site AZ:G:03:041 area showing gully locations.

32. Site AZ:G:03:041 area showing main gullies, general downhill flow direction, and laser scan and laser control point locations.

34. Site AZ:G:03:041—5-cm triangulated irregular network (TIN) output showing relative magnitude of surface comparison from May 2006 to September 2007

35. Site AZ:G:03:041-10-cm gridded output showing erosion and deposition from May 2006 to September 2007 and approximate gully locations...

36. Site AZ:G:03:041—Images of gully G2 bottom slope area from May 2006 and September 2007. 
37. Site AZ:G:03:002 showing main gullies, general downhill flow direction, and laser scan crosses) and laser control point locations.

38. Site $A Z: G: 03: 002$ area showing gully locations upper $G 1$ and $G 2$ and lower $G 1$

39. Site AZ:G:03:002—5-cm triangulated irregular network (TIN) output showing location and relative magnitude of surface comparison from May 2006 to September 2007.

40. Site AZ:G:03:002 - 10-cm gridded output showing erosion and deposition from May 2006 to September 2007

41. Site AZ:G:03:002 — Cross-section analysis of lower G1 area from manual filtered point data, and image showing cross-section location

42. Site $A Z: G: 03: 072$ showing main gullies, general downhill flow direction, and laser scan and control point locations for both upstream and downstream sites...........40

43. Site $A Z: G: 03: 072$ US area showing gully locations.

44. Site AZ:G:03:072 US-5-cm triangulated irregular network (TIN) output showing location and relative magnitude of surface comparison from May 2006 to May 2007

45. Site AZ:G:03:072 US-10-cm gridded output showing erosion and deposition from May 2006 to May 2007 and approximate gully locations.

46. Site AZ:G:03:072 US—Photo comparison of G3 erosional area between May 2006 and May 2007.

47. Site AZ:G:03:072 US - 10-cm contour map comparison of G3 erosional area between May 2006 and May 2007.

48. Site AZ:G:03:072 US - 5-cm triangulated irregular network (TIN) output showing location and relative magnitude of surface comparison from May 2007 to September 2007.

49. Site AZ:G:03:072 US - 10-cm gridded output showing erosion and deposition from May 2007 to September 2007 and approximate gully locations.......................46

50. Site AZ:G:03:072 US_Photo of G1 erosional area in September 2007.

51. Site AZ:G:03:072 US—Photo comparison of G2 erosional area between May 2007 looking updrainage and September 2007 looking downdrainage . .48

52. Site AZ:G:03:072 US_Photo of G2 slope erosional area in September 2007...........................48

53. Site AZ:G:03:072 US—Photo of G1 dune erosional area in September 2007............................49

54. Site AZ:G:03:072 US—Photo comparison of G3 erosional area between May 2007 looking downdrainage and September 2007 looking updrainage

55. Site AZ:G:03:072 US-10-cm contour map comparison of G3 erosional area between May 2007 and September 2007

56. Site $A Z: G: 03: 072$ DS area showing gully locations in May 2006 and May 2007.

57. Site AZ:G:03:072 DS—-5-cm triangulated irregular network (TIN) output showing location and relative magnitude of surface comparison from May 2006 to May 2007

58. Site AZ:G:03:072 DS—10-cm gridded output showing erosion and deposition from May 2006 to May 2007 and approximate gully locations

59. Site AZ:G:03:072 DS—5-cm triangulated irregular network (TIN) output showing location and relative magnitude of surface comparison from May 2007 to September 2007

60. Site AZ:G:03:072 DS - 10-cm gridded output showing erosion and deposition from May 2007 to September 2007 and approximate gully locations 


\section{Tables}

1. Lidar data collection at archeological sites in Grand Canyon National Park . .4

2. Summary of data collection and surface modeling at each archeologic site .9

3. Summary of net topographic change between May 2006 and September 2007 55

\section{Datum Information}

Vertical coordinate information is referenced to the North American Datum of 1983

(NAD83) ellipsoid height, expressed in meters.

Horizontal coordinate information was collected referenced to the North American Datum of 1983 (NAD83) and projected to Arizona Central Zone 0202 State Plane coordinates expressed in meters. For the purpose of protecting the sensitive nature of the archeological sites, all coordinates have been reoriented about a fictitious origin, still expressed in meters.

Elevation, as used in this report, refers to distance above the vertical datum.

Metadata for the products described in this report are available at: http://walrus.wr.usgs.gov/infobank/1/lg106gc/html/1-g1-06-gc.meta.html http://walrus.wr.usgs.gov/infobank/1/lg107gc/html/1-g1-07-gc.meta.html http://walrus.wr.usgs.gov/infobank/l/lg207gc/html/l-g2-07-gc.meta.html. 


\title{
Topographic Change Detection at Select Archeological Sites in Grand Canyon National Park, Arizona, 2006-2007
}

\author{
By Brian D. Collins ${ }^{1}$, Diane Minasian², and Robert Kayen²
}

\section{Abstract}

Topographic change of archeological sites within the Colorado River corridor of Grand Canyon National Park (GCNP) is a subject of interest to National Park Service managers and other stakeholders in the Glen Canyon Dam Adaptive Management Program. Although long-term topographic change resulting from a variety of natural processes is typical in the Grand Canyon region, a continuing debate exists on whether and how controlled releases from Glen Canyon Dam, located immediately upstream of GCNP, are impacting rates of site erosion, artifact transport, and the preservation of archeological resources. Continued erosion of archeological sites threatens both the archeological resources and our future ability to study evidence of past cultural habitation. Understanding the causes and effects of archaeological site erosion requires a knowledge of several factors including the location and magnitude of the changes occurring in relation to archeological resources, the rate of the changes, and the relative contribution of several potential causes, including sediment depletion associated with managed flows from Glen Canyon Dam, site-specific weather patterns, visitor impacts, and long-term climate change. To obtain this information, highly accurate, spatially specific data are needed from sites undergoing change. Using terrestrial lidar data collection techniques and novel TIN- and GRID-based change-detection post-processing methods, we analyzed topographic data for nine archeological sites. The data were collected using three separate data collection efforts spanning 16 months (May 2006 to September 2007). Our results documented positive evidence of erosion, deposition, or both at six of the nine sites investigated during this time interval. In addition, we observed possible signs of change at two of the other sites. Erosion was concentrated in established gully drainages and averaged $12 \mathrm{~cm}$ to $17 \mathrm{~cm}$ in depth with maximum depths of $50 \mathrm{~cm}$. Deposition was concentrated at specific locations outside of drainages but generally was spread over larger areas (tens to hundreds of square meters). Maximum depths of deposition averaged $12 \mathrm{~cm}$ to $15 \mathrm{~cm}$ and reached as much as $35 \mathrm{~cm}$. Overall, we found that the spatial distribution and magnitudes of surface change are specific to each site and that

\footnotetext{
${ }^{1}$ U.S. Geological Survey, Western Earth Surface Processes Team, Menlo Park, California ${ }^{2}$ U.S. Geological Survey, Western Coastal and Marine Geology Team, Menlo Park, California
}

a thorough understanding of the geomorphology, weather, and sand supply is requisite for a complete understanding of the data. Additional work in combining these results with site-specific weather, hydrology, and geomorphology data will assist in the development of working models for determining the causes of the documented topographic changes

\section{Introduction}

Topographic change of archeological sites within the Colorado River corridor of Grand Canyon National Park (GCNP) is a subject of interest to National Park Service (NPS) managers and other stakeholders in the Glen Canyon Dam Adaptive Management Program. Although long-term topographic change resulting from a variety of natural processes is typical in the Grand Canyon region, a continuing debate exists on whether and how controlled releases from Glen Canyon Dam, located immediately upstream of GCNP, are affecting rates of site erosion, artifact transport, and the preservation of archeological resources. Archeological sites in Grand Canyon represent an irreplaceable cultural and scientific resource. Studies of these sites have shown that human occupation in Grand Canyon dates to 11,000 years before the present (Fairley, 2005). Continued erosion of archeological sites threatens both the archeological resources and our future ability to study evidence of past cultural habitation (fig. 1). Many sites are located in alluvial terrace deposits that are prone to erosion (Hereford, 1996; Hereford and others, 1993, 1998). Among the potential causes of continued site erosion may be a lack of renewed sandbars at river level which are thought to replenish sediment covering many archeological sites in the river corridor through aeolian transport. Wright and others $(2005,2008)$ provide reviews of post-dam sediment budgets balancing the amount of sand supplied by tributaries downstream of the dam and the capacity of the river to transport the input. Without replenishment, gullying in the form of new and increasingly incised drainage channels leads to the potential loss of artifacts to the river system and loss of the archeological sites' overall physical integrity. This hypothesis was first suggested by Hereford and others (1991, 1993); recent 

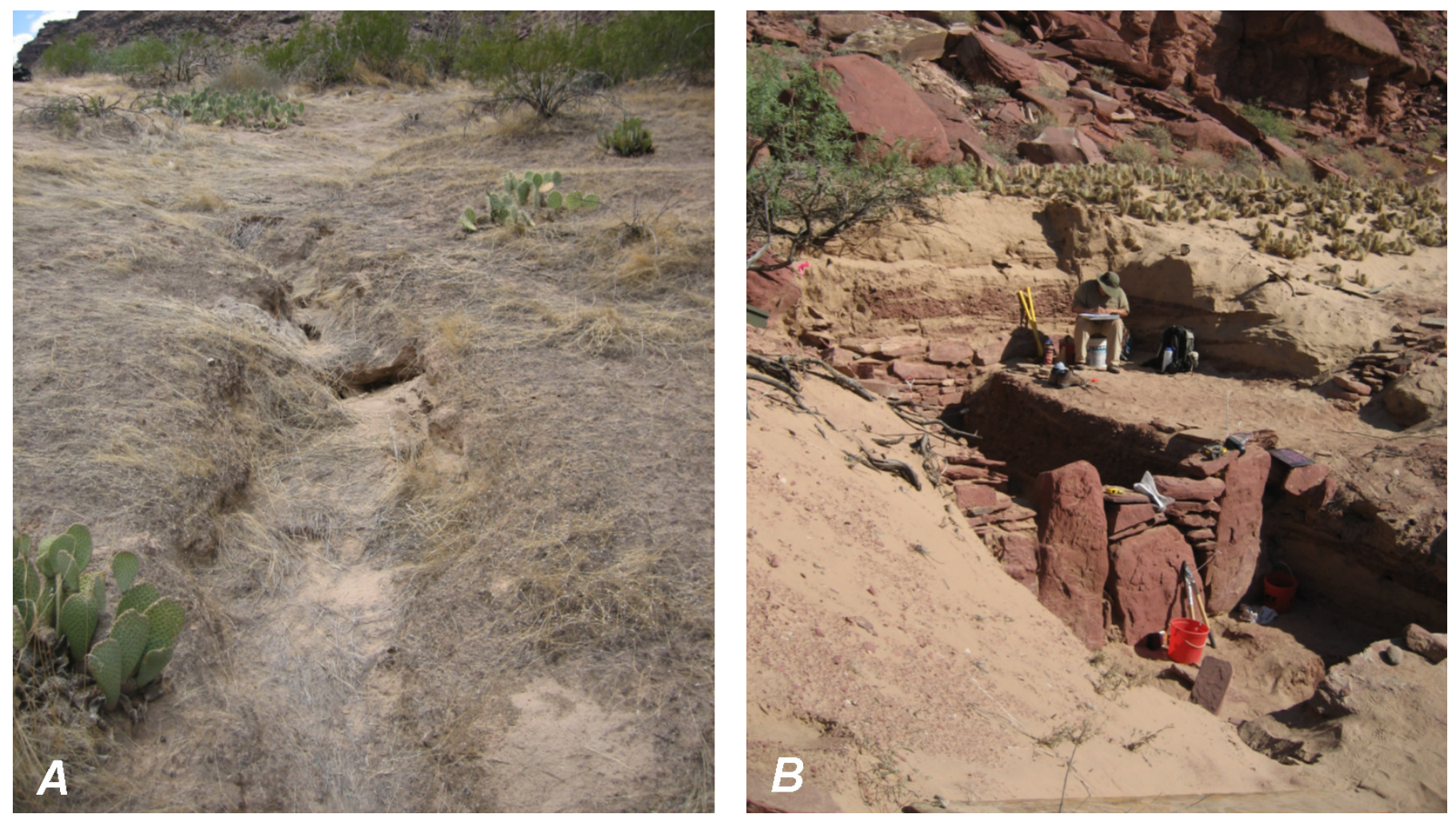

Figure 1. A, Gullying of an archeological site in Grand Canyon National Park and $B$, excavation of a site when erosion threatens resources. The area in $B$ was previously buried by aeolian deposition and emerged as precipitation runoff and wind deflation exposed small features of the habitation site.

follow up studies by Draut and Rubin (2008), for example, have begun to quantitatively evaluate these linkages.

Studies documenting the erosion of archeological sites were first performed by Hereford and others $(1991,1993)$ using comparative photography following the 1983 flood release from Glen Canyon Dam. Additional studies by Fairley and others (1994) on an inventory of approximately 475 sites located throughout the Colorado River corridor (fig. 2) showed that a variety of erosion-related impacts were occurring to these sites including surface deflation, gullying, bank slumpage, and animal- and human-caused erosion due to trailing (that is, the creation and repeated use of trails) and bioturbation. Following passage of the Grand Canyon Protection Act in 1992, the NPS initiated a monitoring program using conventional total station surveying at more than 70 sites to systematically document potential erosion-induced changes to site topography affecting archeological sites in the river corridor (for example, Leap and others, 1996, 1997). For a variety of reasons, this effort was halted before a change-detection study could be completed (Leap and others, 2000). From 2001 to 2003, both low-altitude photogrammetry (1:1600 scale) and conventional total station surveying were used by Pederson and others (2003, 2006) in a study focused on evaluating the evolution of drainage channels (gullies) through nine archeological sites in the river corridor and to monitor the effectiveness of check dams for stabilizing gully erosion at these sites. During this time, NPS resource managers became increasingly concerned that research and monitoring activities using total station surveying may be having a detrimental impact, through trailing-induced erosion, on the resources that researchers are trying to protect. Partly in response to these concerns, remote-sensing survey techniques were investigated (Davis, 2004) in the hopes that their use would prevent potentially damaging site effects caused by repeated direct access at the sites required by conventional methods. A variety of techniques were investigated, including the use of airborne light detection and ranging (aerial lidar) for remote collection of topographic data. In both the Pederson and others $(2003,2006)$ and Davis (2004) studies, it was determined that the lower-than-desired accuracy of the remotely sensed data (that is, photogrammetry and aerial lidar), coupled with its high cost, limited its applicability as a site-specific, long-term monitoring tool.

In response to these studies, researchers from the U.S. Geological Survey (USGS) Grand Canyon Monitoring and Research Center (GCMRC), in collaboration with the NPS, initiated a project to explore other remote sensing technologies that potentially would be more efficient, more accurate, and less intrusive for monitoring geomorphic change (Fairley and others, 2007). One of these - terrestrial lidar — was selected for testing because of its recent proven track record for documenting site conditions with high resolution (hundreds of points per square meter) and accuracy (centimeter level) in a variety of applications (for example, Bellian and others, 2005; Collins and Sitar, 2002, 2008; Doneus and Neubauer, 2005; Kayen and Collins, 
2005; Labourdette and Jones, 2007; Nagihara and others, 2004; Wawrzyniec and others, 2007). Although terrestrial lidar had been used in previous studies in GCNP and other NPS units to document existing conditions of archeological structures and resources (for example, Hough and Brennan, 2008), data collection was limited to single temporal data sets of archeological structures rather than being focused on collecting multiple, temporally distinct data sets for centimeter-scale change detection of geomorphic features. Thus, use of terrestrial lidar as a change detection tool at archeological sites had not been previously tested, nor had its utility as a monitoring tool applied to resources within the logistically challenging confines of the inner Grand Canyon been previously evaluated.

The use of terrestrial lidar as a remote-sensing survey technique for geomorphologic studies in the Colorado River corridor was first investigated by Collins and Kayen (2006) during the 2004 high- flow experiment from Glen Canyon Dam. They collected high-resolution survey data of hydrologic, biologic, and archeologic features and sites, several thousands of square meters in size, and created three-dimensional models of the topography for future change detection studies. Unfortunately, owing to excessive rain and fog creating false returns from water droplets in the atmosphere, they were unable to prove its effectiveness for archeological site topographic change detection monitoring at that time and suggested that its future use required additional evaluation. As a result, the GCMRC Sociocultural Program initiated a study in 2006 to assess the applicability of terrestrial lidar for monitoring physical change at archeological sites and to compare its use to total station surveying (Collins and others, 2008). One focus of this study was to compare site impacts of the two techniques, measured in terms of survey time and foot step counts within archeological site boundaries. The results showed that whereas the two techniques were quantitatively approximately the same, they were spatially different, with terrestrial lidar able to collect data from a much larger area at each site with approximately the same level of field effort. The main component of the study focused on the ability of each method to collect accurate long profile sections of drainage gullies that cross archeological sites. The study showed that although terrestrial lidar could remotely model an accurate gully long profile, in this particular application it was no more accurate than total station data, required additional post-processing effort, and was limited in its ability to identify

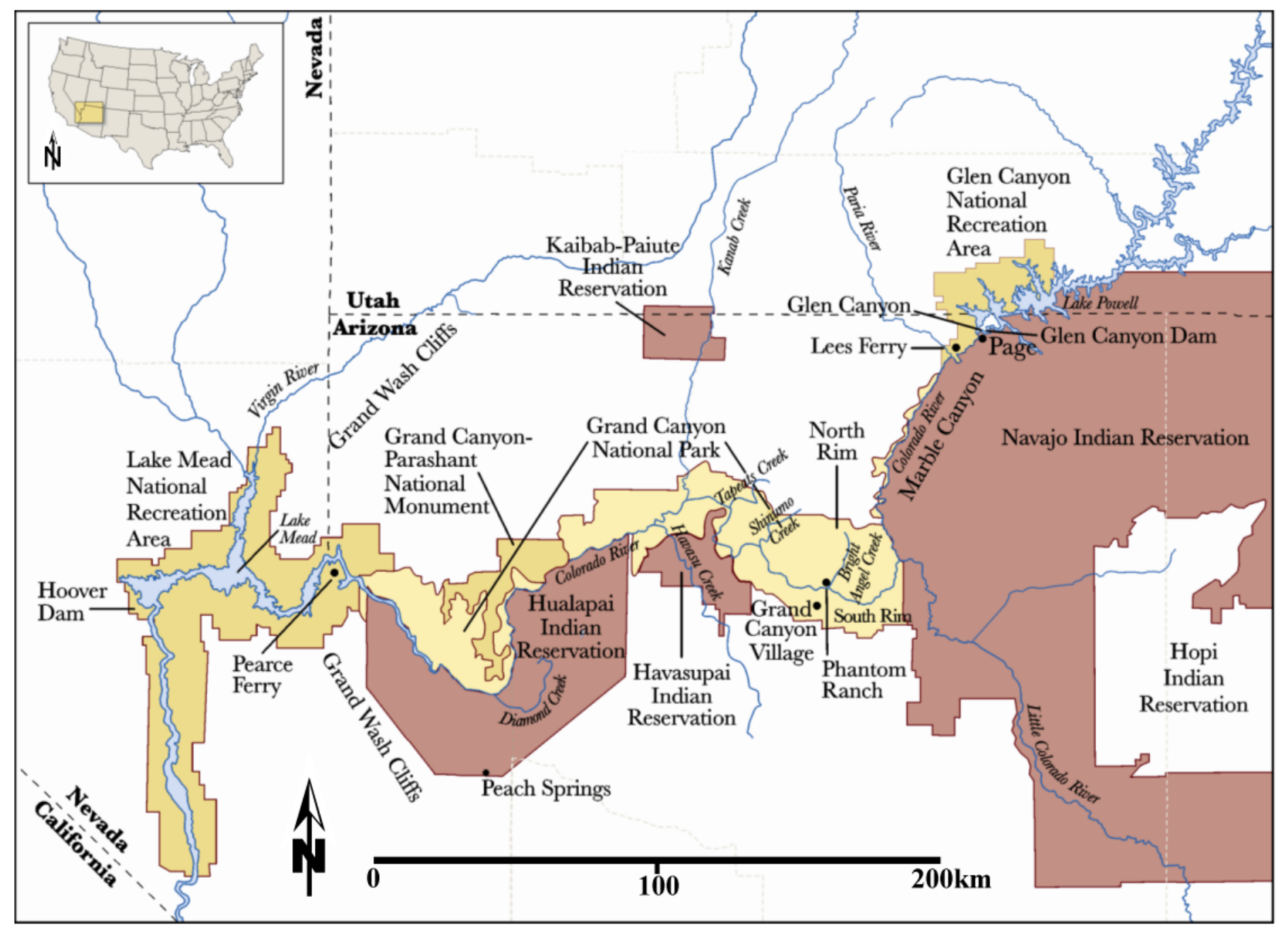

Figure 2. Regional map of northern Arizona and Grand Canyon National Park. 
centimeter-scale, field-visible features such as small knickpoints in the thalweg. However, the study also showed that terrestrial lidar could efficiently collect accurate topographic data of whole site areas rather than just localized feature topography such as small-scale drainage systems - a capability that would permit researchers to monitor sediment aggradation and deflation over much broader areas of sites with highly precise, densely spaced data points that simply could not be collected efficiently using total station methods.

Thus, the Collins and others (2008) study showed promising results for high-accuracy (subdecimeter) change detection over the entire area of an archeological site. Coincidentally, a data review panel independently reviewing cultural monitoring legacy data at the GCMRC also recommended that terrestrial lidar be pursued for temporal change monitoring of archeological sites (Kintigh and others, 2007). As a result of these initial results and recommendations, the GCMRC Sociocultural Program continued the study in 2007 with a specific focus on the potential utility of terrestrial lidar for whole site change detection monitoring of archeological sites within Grand Canyon. This report presents the results of that study and compares the terrestrial lidar data sets collected in 2006 with those collected in 2007. Data for a total of nine sites situated throughout the length of the Colorado River corridor are presented and compared for three data sets collected in May 2006, May 2007, and September 2007. We present a full description of terrestrial lidar methods in this report because the technique is relatively new and because post-processing methods are still in their infancy. The results indicate areas of both erosion and deposition at specific archeological sites. Although we present interpretations of the likely geomorphologic processes causing these changes, this report does not try to relate them either directly or indirectly to the controlled flow regime from Glen Canyon Dam. Instead, we focus on presenting the highest resolution topographic change detection data yet available for monitoring the geomorphic controls at archeological sites in GCNP, with the intention that these data may then be used for future dam- and river-process related studies.

\section{Logistics}

Three data collection efforts were made in Grand Canyon National Park between 2006 and 2007 (table 1). For simplicity, we refer to each effort as either the May 2006, May 2007, or September 2007 surveys. During the surveys, data were collected at nine localities (fig. 3), each encompassing an archeological area of interest where erosion has been identified as having a potential impact on site resources. To protect the sensitive nature of the sites, specific site location information is omitted, and the GCNP archeological site identification number is used for reference. At each site, data collection was focused on the terrain surrounding and including one or more drainage systems, colloquially termed "gullies," that are referred to in this report as G1, G2, and so on, and numbered sequentially moving from upstream to downstream along the river corridor or contributing side drainage.
Table 1. Lidar data collection at archeological sites in Grand Canyon National Park.

\begin{tabular}{lccc}
\hline \multicolumn{1}{c}{ Site name } & May 2006 & May 2007 & Sept. 2007 \\
\hline C:13:006 & $5 / 6 / 2006$ & $4 / 28 / 2007$ & $9 / 15 / 2007$ \\
C:13:336 & $5 / 7 / 2006$ & $4 / 29 / 2007$ & $9 / 16 / 2007$ \\
C:13:099 & $5 / 8 / 2006$ & $4 / 29 / 2007$ & $9 / 16 / 2007$ \\
C:13:099 playa area & $5 / 7 / 2006$ & $4 / 29 / 2007$ & $9 / 16 / 2007$ \\
C:13:348 & $5 / 8 / 2006$ & $4 / 30 / 2007$ & $9 / 17 / 2007$ \\
G:03:041 & $5 / 14 / 2006$ & $5 / 7 / 2007$ & $9 / 24 / 2007$ \\
G:03:002 & $5 / 15 / 2006$ & $5 / 8 / 2007$ & $9 / 25 / 2007$ \\
G:03:072 US & $5 / 17 / 2006$ & $5 / 9 / 2007$ & $9 / 26 / 2007$ \\
$\quad$ (upstream site) & & & \\
G:03:072 DS & $5 / 16 / 2006$ & $5 / 10 / 2007$ & $9 / 26 / 2007$ \\
$\quad$ (downstream site) & & & \\
\hline
\end{tabular}

Each survey effort consisted of two GCMRC-supported motor rafts carrying all personnel and equipment for trips lasting from 16 to 18 days. Equipment consisted of camping gear and food supplies, a battery charging system for all electronics, and survey equipment, including the USGS Coastal and Marine Geology (CMG) Program's terrestrial lidar unit, GCMRC's total station unit, and CMG's pair of differential GPS receivers. Personnel consisted of researchers from the USGS in Menlo Park, California, and researchers and staff from the GCMRC in Flagstaff, Arizona. Assistance in mobilization of equipment was provided by a team from Utah State University performing concurrent geomorphologic assessments of the same sites. Additional trip personnel included archeologists from NPS and the Zuni Tribe and raft pilots (boatmen).

\section{Methods}

\section{Data Collection}

The terrestrial lidar technique (three-dimensional, or 3-D, laser scanning) consists of sending and receiving laser pulses to build a point file of 3-D coordinates of virtually any surface. A laser scanning device is set up at a fixed location with an open field of view and aimed at the ground surface. The time of travel and/or phase-shift for a single laser pulse reflection is measured along a known trajectory such that the distance from the laser scanner, and consequently the location of a point of interest, is computed. In the present study, a Riegl Z210 laser scanner was used as a tripod-mounted survey instrument (fig. 4). The Riegl Z210 uses a Class 1 (eye safe under normal operating conditions), near-infrared ( $900 \mathrm{~nm})$, pulsed laser diode with beam divergence of $0.172^{\circ}$ (approximately $3 \mathrm{~cm}$ at $10 \mathrm{~m}$ range). Typical maximum range for natural targets with 10 percent and 80 percent reflectivity is $150 \mathrm{~m}$ and $350 \mathrm{~m}$, respectively, with $25 \mathrm{~mm}$ accuracy. The laser system consumes relatively low 


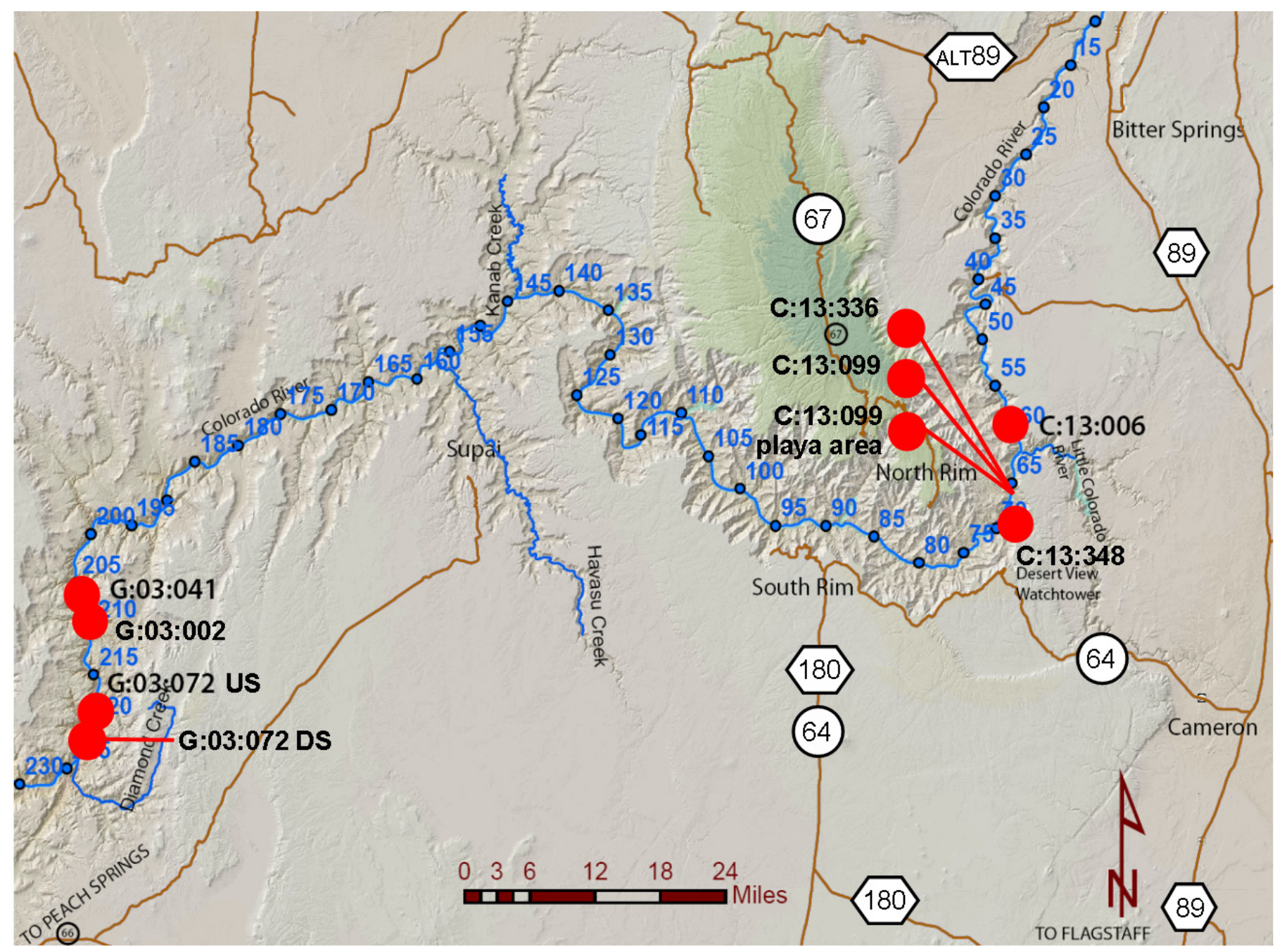

Figure 3. Site map showing general location of sites included in this investigation and referenced by archeological identification number (ArchID). Exact locations are not shown to protect the archeological resources of interest. Numbers in blue represent river mile measured downstream from Glen Canyon Dam.

power (typically $35 \mathrm{~W}$ ) compared to similar laser systems, using 12-volt, sealed, gel-cell, lead-acid batteries.

Most laser scanners operate using some combination of precisely aligned rotating polygonal mirrors and extremely smallstepping motors to guide the laser paths over the area of interest. With the Riegl Z210, laser pulses are reflected from a triangular mirror, rotating around the horizontal axis (with minimum angle step width of $0.072^{\circ}$ ), while the entire head of the scanner pans around the vertical axis of the laser diode origin (also with minimum angle step width of $0.072^{\circ}$ ). The technology, specifically developed for rapid topographic surveys, allows data to be collected at rates of thousands of points per second, generating a "point cloud" of 3-D coordinates. Acquisition of sufficiently dense point clouds (that is, point-to-point spacing on the order of $5 \mathrm{~cm}$ or less) can, in most cases, fully describe site topography. The point files from data collection are transformed into 3-D surfaces for cross-section and volumetric analyses.

At each survey location, we transported the laser from the raft to the archeological site by backpack. We used an elevated tripod (to $2.3 \mathrm{~m}$ ) to position the laser above each site to capture a wide range and more direct line of sight to the area topography. We collected multiple scans from different locations during each survey to fill in "shadow zones" of areas not directly in the line of sight of the laser and to expand the range and density of the point data. Data with the Riegl Z210 were collected at a rate of 8,000 points per second using a single, last return for each point and scanning over a $333^{\circ}$ range in the horizontal direction and $\pm 40^{\circ}$ from the horizontal range in the vertical direction. This provided approximately 2.3 million points for each scan, although only a portion (about 50 percent) of those actually defined the site topography of interest.

The major challenge in the terrestrial lidar method is in combining the multiple scans collected into a single, georeferenced, point-cloud model. Although many methods exist, all rely on the accurate collection of georeferenced survey points on either the laser itself, a network of visible reflectors within the scans, or both (Collins and others, 2006). For each survey effort, we collected high accuracy ( $<1 \mathrm{~cm}$ RMS error) survey 


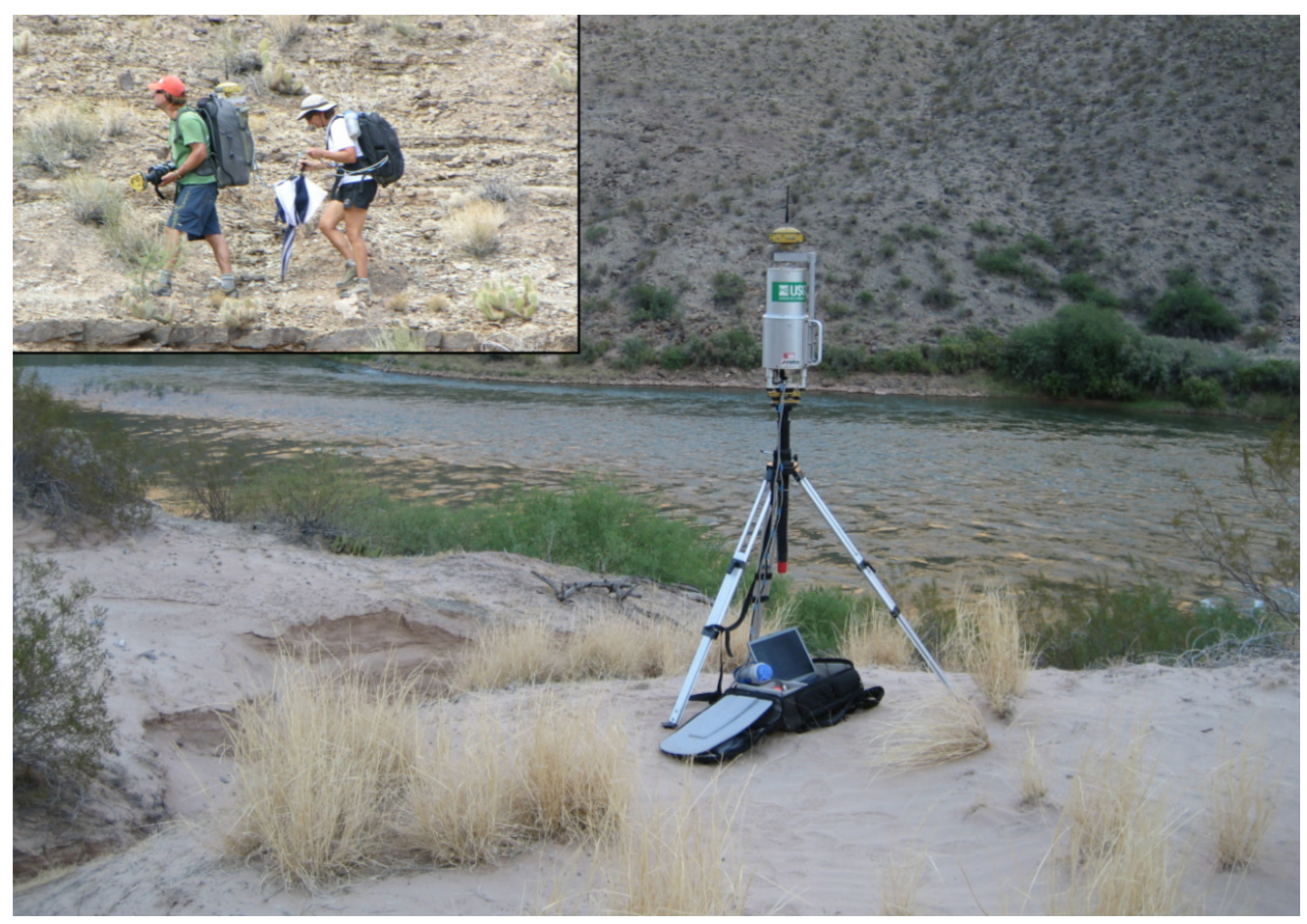

Figure 4. Terrestrial lidar data collection in Grand Canyon National Park. The extendable tripod allows a larger area of data collection and less oblique laser returns from areas of flat topography. Differential global positioning system (GPS) with a fixed radio-linked base station is used to georeference the instrument location. Inset shows typical transportation of the equipment.

control on all scanner origins and a network of three to six control targets. Coordinates were determined by either locating the instrument over known survey benchmarks or by collecting either total station or global positioning system (GPS) positions on the laser and target locations. We note that the RMS survey control error represents a relative level of horizontal and vertical control in georeferenced space since the control points used in the survey are only known to a three-dimensional accuracy of $5 \mathrm{~cm}$ to $8 \mathrm{~cm}$ (Grand Canyon Monitoring and Research Center, 2008). However, since identical control points were used throughout the study, this component of error is not included in the subsequently outlined error analysis.

In 2006, we collected georeferenced survey data for our laser instrument locations using a Topcon total station survey device. In 2007, we collected this data using a pair of surveygrade, real-time kinematic differential Topcon Hyper+ GPS receivers. Metadata for the data collection efforts are available at http://walrus.wr.usgs.gov/infobank/1/lg106gc/html/1g1-06-gc.meta.html, http://walrus.wr.usgs.gov/infobank/1/ lg107gc/html/1-g1-07-gc.meta.html, and http://walrus.wr.usgs. gov/infobank/1/lg207gc/html/l-g2-07-gc.meta.html (U.S. Geological Survey, 2008a).

\section{Data Processing}

We processed the lidar data through an integrated suite of registration, georeferencing, filtering, and surface-model generation techniques specific to terrestrial lidar data. Because each scan contains data of only a part of each site, the data from all scans must be combined (registered) and spatially located (georeferenced) to a common geographic coordinate system. To obtain a continuous bare ground surface model of a site, the data must be filtered of extraneous data such as vegetation and atmospheric interference (birds, bugs, dust, and others), and then a surface is built from the remaining data. These steps involve the mathematical translation and rotation of the data from local coordinates centered about each scan origin to geographic coordinates specific to the survey data and also the categorization of points both within and outside of the bare earth (without vegetation) model. The scan and surface model files, which typically contain several million points each, require specific software to handle the large number of matrix transformation equations applied to the files. Among the several software programs available, we used I-SiTE Studio software (I-SiTE, 2008) for all data filtering, registration, georeferencing, and initial surface-model building.

We used an integrated processing workflow that ensures that data quality and accuracy are maximized and that the data are properly archived following each major processing step. The workflow is outlined here for reference:

1. Raw Data Archiving - The data are archived in raw field format to ensure a backup copy. 
2. Survey Data Processing - The survey data provided by total station or GPS are processed to determine accurate georeferenced positions for the scanner and reflectors and to eliminate common field errors such as incorrectly recorded tripod or antenna heights.

3. Preliminary Scan Filtering - Extraneous points that define such items as people, equipment, dust, or birds are removed from the raw scan files. Distant points outside the overall study area are also removed.

4. Georeferencing-Each scan is located to geographic coordinates through a matrix transformation of the scan origin.

5. Registration-Each scan is rotated about its now fixed, georeferenced origin until the best fit of the scan to all neighboring scans is achieved. Best fit is measured by direct comparison and minimization of error between nearest-neighbor point pairs within each scan's point cloud (that is "cloud-tocloud" registration). This requires the manual selection of the best overlapping data within each scans' point cloud, such that poorly fitting data points (for example, vegetation) are deselected and well-fitting items (for example, bare ground, cliff faces, boulders) remain. Initial registration of a site is achieved by registering three scans with origins that form an approximately equilateral triangle on the ground, thus forming a plane with a single geometric solution. Additional scans are registered to this georeferenced group of point clouds.

The order of the registration process of the scans is set by the triangular layout of the scan locations, which are carefully and specifically selected in the field. Control reflector points, located outside the archeological site areas, were also sometimes used to constrain the number of degrees of motion when cloud-to-cloud registration did not achieve the required registration accuracy.

6. Topographic Filtering-Points representing anything other than the ground surface are removed from each scan using a sequence of topographic filtering steps. Following a rough, manual removal of tall vegetation points, the lowest point within each $0.5-\mathrm{m}$-square grid cell is first selected. A surface is then constructed of these points. All points within $10 \mathrm{~cm}$ of this surface are added back to the scan data. The lowest point within each 5-cm-square grid cell is then selected. These steps generally achieve a well-refined, highresolution ground point data file, although some additional manual manipulation of the data is sometimes required for particularly small and large vegetation.

7. Surface Model Generation-The final surface model is created using a triangulated irregular network (TIN). Minor filtering of the TIN is sometimes needed to remove obvious remaining extraneous high points from tall vegetation. In some cases, difficulties in manual filtering larger vegetation led to inconsistencies in the final surface models, for example, when a large boulder was mistaken as a similar-sized bush or tree. These instances are discussed on a case-by-case basis in the presentation of the data and results.

\section{Error Analysis}

Terrestrial lidar data, similar to any other survey data, are subject to errors originating from both the data collection and post-processing methodologies. We include a detailed analysis of the errors associated with the data to allow the objective presentation of limitations in detecting topographic change. Although terrestrial lidar data provide a three-dimensional basis for surface modeling, we focus our results on the calculation of erosion and depositional change in only the vertical dimension as this is the most obvious way to understand and interpret surface change. Thus, the following error analysis was developed over a framework that focuses on the vertical component of error, unless otherwise noted.

Error introduced to the final terrestrial lidar surface models $E_{\text {total }}$, is a result of the summation of three independent errors: (1) the error associated with the position of the origin of the scanner $\left(E_{\text {survey }}\right),(2)$ error associated with the pulse and reflection of the laser beam $\left(E_{\text {laser }}\right)$, and (3) error associated with the registration of the laser point data $\left(E_{\text {reg }}\right)$. However, as previously discussed, registration occurs through the alignment of a generally equilateral triangle created by the origins of three individual scans - from one scan to the next, and from these two scans to the third, and the vertical component of registration error must be included twice - once each for each registration step. Calculation of TIN surface models technically can introduce a fourth source of error $\left(E_{\text {tin }}\right)$ through interpolation between the modeled surface and the true bare ground surface. This error is primarily dependent on the data density (point spacing) used in TIN generation and the relative change in slope (actual surface roughness) between data points. In this study, we assume negligible error from surface generation (that is, $E_{\text {tin }} \approx 0$ ) due to the close $(5 \mathrm{~cm})$ spacing of the points forming the TIN and observation that the majority of the areas investigated are of subtle topography (that is, few "sharp" edges within the site area). This error source is therefore not included in the subsequent calculations.

The sum of a series of independent errors are typically calculated as a root mean square error (RMSE):

$$
E_{\text {total }}=\sqrt{E_{\text {survey }}^{2}+E_{\text {laser }}^{2}+E_{\text {reg } 1}^{2}+E_{\text {reg } 2}^{2}}
$$

In this study, we determined the origin of the scanner position by either total station surveying (May 2006) or differential GPS surveying (May and September 2007). For both statistical significance and mathematical simplicity, the vertical component of error in positioning was estimated as the average single standard deviation calculated from each group of vertical measurements. In May 2006, the vertical component of error from the total station data for 80 independent survey points at one standard deviation (1) was $5 \mathrm{~mm}$. In 2007, the vertical component of error (1) from the GPS data was $5 \mathrm{~mm}$ for 114 survey points in May and $4 \mathrm{~mm}$ for 117 survey points in September. We therefore estimate the vertical survey position error $E_{\text {survey }}$, of all models as the average value $(4.6 \mathrm{~mm})$. We note again that the final error budget will be that for a relative calculation in georeferenced space as errors 
because of GPS benchmark location (typically between $5 \mathrm{~cm}$ and $8 \mathrm{~cm}$ positional accuracy; Grand Canyon Monitoring and Research Center, 2008) are not included in the analysis. In calculating differences between each data set, any additional benchmark-related error can be ignored, however, because the same identical benchmark control point locations were used for both total station and GPS base station positioning between the 2006 and 2007 survey efforts. Although this requires assumptions of maximum point stability and minimal differential tectonic movement between control point benchmarks and site areas, these are both valid for short duration surveys in Grand Canyon.

Laser beam pulse and reflection error can be measured by either absolute (maximum possible) or empirical (actual measured) methods. For calculating the vertical component of error in the laser beam, we use the average results $\left(E_{\text {laser }}=7.2 \mathrm{~mm}\right)$ of two sophisticated, third-party empirical calibration tests performed on the Riegl Z210 laser system (4.1 mm by Lichti and others, 2002; $10.2 \mathrm{~mm}$ by Boehler and others, 2003). Both of these tests were performed at relatively close range, consistent with the data gathered in this study (typically less than $15 \mathrm{~m}$ ).

The registration error is associated with the numerical alignment of the point clouds (scans). The scans are aligned with one another in such a way that the error between all points used in the registration of each cloud (typically between 100,000 and $1,000,000$ points) is minimized. The following equation presents this calculation in terms of the horizontal $(x, y)$ and vertical $(z)$ dimensions for two positions, 1 and 2, calculated for $N$ pairs of points, each delineated between $i$ and $N$ :

$R M S E_{3 D}=\sqrt{\frac{1}{N} \sum_{i=1}^{N}\left(x_{1}-x_{2}\right)_{i}^{2}+\left(y_{1}-y_{2}\right)_{i}^{2}+\left(z_{1}-z_{2}\right)_{i}^{2}}$

In general, our data processing resulted in a maximum, threedimensional $(x, y$, and $z)$, point-matching error not greater than $5 \mathrm{~cm}$. For simplicity, we assume that errors are evenly distributed between the three dimensions due to the threedimensional nature and equivalent point spacing of the data. However, this should be noted as a conservative error estimate because most of the sites are not very steep $\left(<45^{\circ}\right)$ in slope, and it is only at a $45^{\circ}$ inclination that the errors can be assumed evenly distributed. For increasingly flat surfaces, the error associated with the $z$ dimension diminishes to zero.

Using the evenly distributed error assumption, the vertical error component can be simplified as only a portion of the point-matching error and we can equate the $x, y$, and $z$ error components:

$$
5 \mathrm{~cm}=\sqrt{\frac{1}{N} \sum_{i=1}^{N}\left[3\left(z_{1}-z_{2}\right)_{i}^{2}\right]}
$$

Calculating through the sum, and simplifying, we solve for the vertical component of error of a single registration between two point clouds $\left(\Delta z=E_{\text {reg } 1}=E_{\text {reg } 2}\right)$ as:

$$
5 \mathrm{~cm}=\sqrt{3} \Delta z
$$

Solving for $\Delta z$, the error estimate is $29 \mathrm{~mm}$ each for $E_{\text {regl }}$ and $E_{\text {reg2 } 2}$.
From equation 1, the total vertical error estimate in a single constructed model surface is:

$$
E_{\text {total }}=\sqrt{4.6^{2}+7.2^{2}+29^{2}+29^{2}}=41.9 \mathrm{~mm}
$$

Note that the meaning of $E_{\text {total }}$ is that all points on the final surface are within $41.9 \mathrm{~mm}$ of their true position in relative georeferenced space. When calculating vertical distances between two surfaces, the error estimate must be accounted for in each case, because each surface could potentially be in error by $E_{\text {total }}$. Although the errors could be treated independently, as it is highly unlikely that the errors between two surfaces are exactly opposite of one another, we used an error bound of $83.8 \mathrm{~mm}(\approx 8 \mathrm{~cm})$ that is double the single surface error. This error limit serves as the distinguishing bound between areas of actual measured change and that potentially caused by data collection and processing errors. However, in the absence of any errors in the data collection and processing, smaller scale changes may have occurred at some sites. Thus, it can be considered conservative in the context of detection of only significant topographic change; that is, vertical change that has the potential for greater impact on archeological sites.

\section{Surface Model Comparison}

For each site, three surface models were created - one each for the May 2006, May 2007, and September 2007 field efforts. We analyzed the surface models methodically, first comparing the May 2006 and September 2007 surfaces. If no change was detected outside the survey error bounds, no additional analysis was undertaken. If change was detected, we compared the shorter surface change intervals from May 2006 to May 2007 and May to September 2007 to identify the time period in which the change occurred. However, because of this analysis method, the possibility exists that cycles of erosion and deposition may have occurred within a single time period and gone undetected. Given the relatively short time period between data collection (between 3 and 12 months), it is probable that only one additional cycle of erosion and deposition may have occurred (between May 2006 and May 2007). Regardless, the results still present measurements of actual measured change and provide definitive results for the time period in which monitoring occurred.

We note here the use of the generalized terms "erosion" and "deposition" to indicate surface lowering and surface rising, respectively. Thus, these may, at times, capture such processes as surface compaction and aeolian dune inflation, which are technically neither erosion nor depositional processes. When a more specific geomorphic process is known, we identify this within the results for each site.

Two types of surface change maps were used to detect vertical change - a three-dimensional TIN surface change map and a two-dimensional grid of the surface change. The threedimensional surface change map was constructed by coloring the more recent surface by the elevation difference with the previous surface (with orange equaling negative change representing 
erosion; and blue equaling positive change representing deposition). In the results, the number of points reported for each surface construction indicates the number of points used in TIN model construction - the actual number of points collected is typically an order of magnitude greater but were removed as per the filtering and post-processing methodologies previously outlined. The three-dimensional TIN allowed in-depth analysis of both the statistics and locations of the change. A histogram of the differences between every TIN triangle to the previous complementary surface provided the distribution of the change over the maximum range of expected change $( \pm 50 \mathrm{~cm})$. The histogram was normally distributed in all cases and we therefore calculated the average, standard deviation, and $2 \sigma(95.4$ percent confidence interval) differences between each pair of compared surfaces. All TINs were retriangulated using a consistent triangle-edge size $(5 \mathrm{~cm})$ so that the area of the histogram outside the error limits $( \pm 8 \mathrm{~cm})$ could be calculated. Further, when confirmed change was detected, we calculated the two-dimensional area of affected ground. When available, we used and present photographs of the sites to confirm and highlight the exact location and extent of each area of positively detected change.

Two-dimensional grid maps were constructed from the 5 -cm surface-change TIN data using Surfer software (Golden Software, 2008) to perform regular kriging on a $10-\mathrm{cm}$-square grid. Kriging technically introduces a new error term, the error associated with gridding $\left(E_{\text {grid }}\right)$ to the analysis, but because of the close spacing of the TIN $(5 \mathrm{~cm})$ and grid $(10 \mathrm{~cm})$, we found these errors to be negligible for the change detection presented here. Comparisons of a subset of the data for sites where the greatest site change occurred show an average TINgrid mean surface difference of only $3.7 \mathrm{~mm}$.

Using the grid data, vertical change was contoured and colored according to the same orange (erosion) to blue (deposition) gradient scheme. The grid provided us with direct maps of the magnitude of the recorded change throughout the surface. We colored areas within the $\pm 8 \mathrm{~cm}$ error bounds gray as a way to highlight those areas outside this range where change did occur. In some cases, the maps indicated change that was due to difficult-to-filter vegetation or poor overlap between consecutive surfaces. These areas are indicated as such in the figures presented with the results.

When change was significant at a site, we performed more detailed volumetric and cross-sectional analyses using the TIN data. This provided additional pertinent data for those sites, such as the exact vertical magnitude of the change (as opposed to the range of change from the grid map), the spatial location of those changes, and the volume of material mobilized either into or out of the site.

\section{Results}

The results for each of the nine sites are presented separately and include brief descriptions of the topography, geomorphology, hydrology, archeology, and general vegetation ecology at each site. Additional details for some of the sites have also been summarized by Pederson and others (2003). Base maps were developed from the USGS GCMRC Internet Map Server (U.S. Geological Survey, 2008b) but to protect the sensitivity of each site they do not contain georeferenced identifiable features. Change detection results highlight areas of significant erosion and deposition measured between the three surface models of the 2006-2007 data sets. Where no change was detected between the earliest (May 2006) and latest (September 2007) data sets, no further discussion is included for the mid-range (May 2007) data set. As a reference, table 2

Table 2. Summary of data collection and surface modeling at each archeologic site.

\begin{tabular}{|c|c|c|c|c|}
\hline Site Number & $\begin{array}{c}\text { Number of } \\
\text { scan locations }\end{array}$ & $\begin{array}{l}\text { Approximate } \\
\text { surface area of } \\
\text { data collection } \\
\qquad\left(\mathrm{m}^{2}\right)\end{array}$ & $\begin{array}{l}\text { Number of points used } \\
\text { in each surface model }\end{array}$ & $\begin{array}{l}\text { Approximate surface } \\
\text { area modeled for } \\
\text { change detection } \\
\left(\mathrm{m}^{2}\right)\end{array}$ \\
\hline AZ:C:13:006 & 6 & 2,730 & 600,000 & 1,280 \\
\hline AZ:C:13:336 & 5 to 6 & 3,120 & 450,000 & 1,250 \\
\hline AZ:C:13:099 & 4 & 1,700 & 400,000 & 770 \\
\hline AZ:C:13:099 playa area & 4 to 7 & 6,900 & $1,400,000$ & 3,300 \\
\hline $\mathrm{AZ}: \mathrm{C}: 13: 348^{1}$ & 4 to 14 & 3,210 to 6,110 & 300,000 to $1,000,000$ & 920 to 3,020 \\
\hline AZ:G:03:041 ${ }^{2}$ & 9 to 16 & 1,000 to 1,380 & 195,000 to 290,000 & 600 to 800 \\
\hline AZ:G:03:002 & 11 to 13 & 3,470 & 380,000 & 1,020 \\
\hline AZ:G:03:072 US ${ }^{3}$ & 8 to 13 & 1,090 to 1,490 & 290,000 to 440,000 & 870 to 1,210 \\
\hline AZ:G:03:072 $\mathrm{DS}^{4}$ & 6 to 7 & 1,100 & 150,000 & 450 to 460 \\
\hline \multicolumn{5}{|c|}{$\begin{array}{l}{ }^{1} \text { In May } 2006 \text { data from only four scan locations of a smaller area were collected. } \\
2 \text { In May } 2007 \text { the digital data from six scans were corrupt and only a smaller area could be modeled. } \\
{ }^{3} \text { Following the May } 2006 \text { data collection, the number of scan locations was increased. } \\
{ }^{4} \text { The modeled surface region represents a neighboring but slightly different area between the May } 2006 \text { to May } 2007 \text { and }\end{array}$} \\
\hline
\end{tabular}


provides a summary of the number of scan locations and measured area where data were collected and area and number of points used in the creation of each surface model for the presented results. The collected and modeled surface areas are different in size because of the lack of overlap between some data, the inability to accurately analyze change at the boundaries of the site area or in areas of dense vegetation, and the effort to avoid analyzing outside the area of interest.

\section{Site AZ:C:13:006}

Site AZ:C:13:006 consists of a raised alluvial terrace that overlooks the confluence of a deeply incised arroyo with the Colorado River (fig. 5). The area is composed of overwash cliff deposits and aeolian dune sands stabilized with biological soil crust and is of increasingly convex profile moving down in elevation towards the arroyo and the river. Four small, shallow drainages (G1a, G1b, G2, and G3) traverse the site (fig. 6), and all but G3 appear to be nearing a state of incipient entrenchment. The remaining drainage (G3) has already formed an approximately $10-\mathrm{cm}$-deep incised gully. Vegetation cover consists of a mix of bunch grasses and small cacti, chiefly prickly pear (for example, Opuntia polyacantha var. erinacea), generally averaging less than $20 \mathrm{~cm}$ in height with a few larger mesquite trees (Prosopis glandulosa var. torreyana) near the boundaries of the site (fig. 6). The site is archeologically important as an area of Puebloan II (about A.D. 900 to 1100) habitation (Fairley and others, 1994). Although there

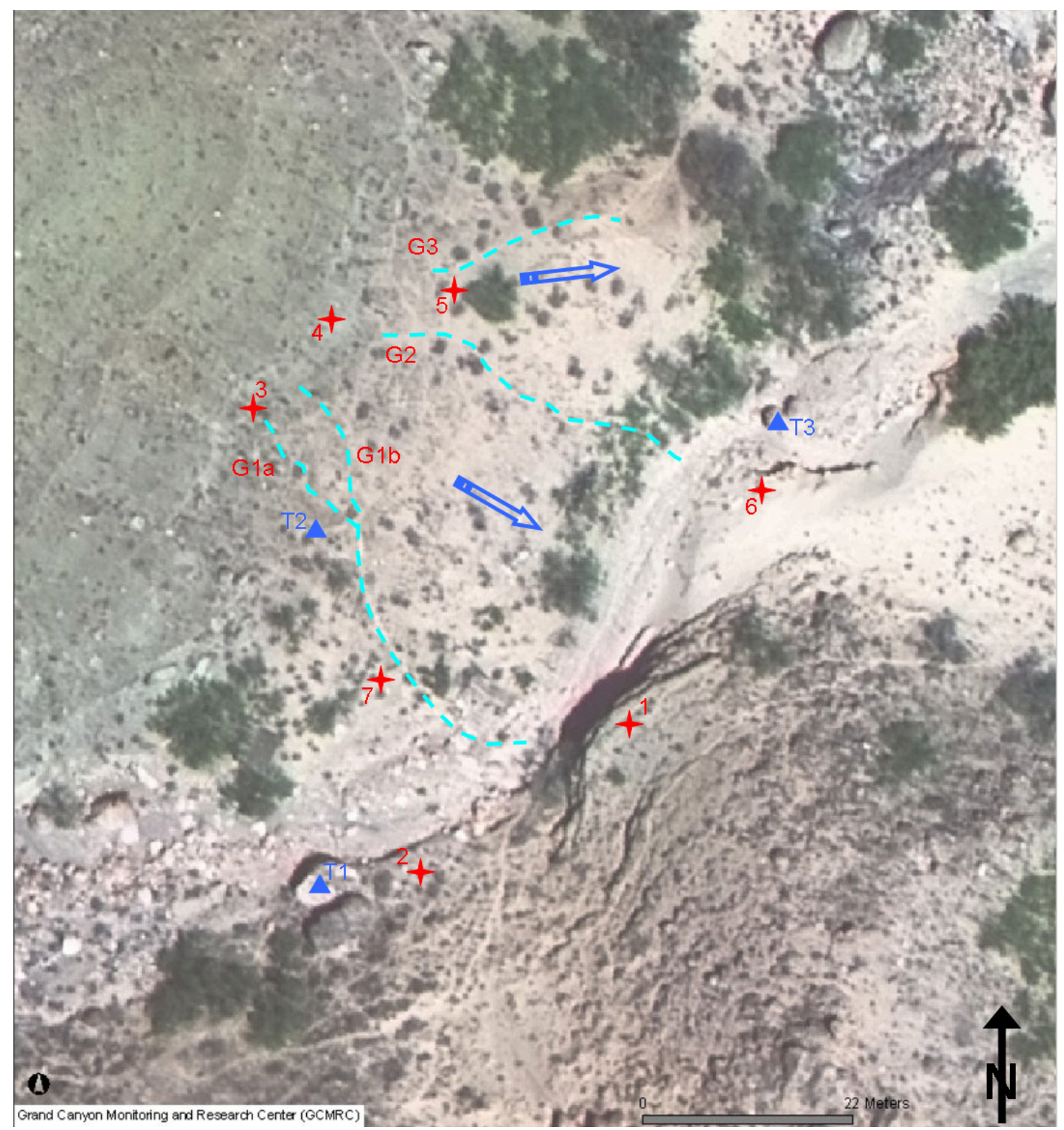

Figure 5. Site AZ:C:13:006 showing main gullies (dashed lines), general downhill flow direction (blue arrows), and laser scan (red crosses) and laser control point (blue triangles) locations. 
are no visible habitation structures, the types and varieties of artifacts visible on the site surface suggest that structures may be buried beneath the dune sands in this area (H. Fairley, pers. comm., 2006)

Surface comparison between May 2006 and September 2007 shows both areas of deposition and erosion throughout the site (fig. 7). The average distance between the two modeled surfaces is $3.3 \mathrm{~cm}$ with a standard deviation of $6.4 \mathrm{~cm}$. Given that the surface change is normally distributed (fig. $7 C$ ), the $2 \sigma$ confidence intervals (about 95 percent) can be calculated $(-9.5 \mathrm{~cm}$ and $16.1 \mathrm{~cm})$ which are greater than the vertical error bound estimates $( \pm 8 \mathrm{~cm})$. Likewise, the histogram distribution identifies a total of 21.4 percent of the data outside the range of the error bounds (that is, indicating actual topographic change) with 2.7 percent $\left(35 \mathrm{~m}^{2}\right)$ of the site showing erosion and 18.7 percent $\left(240 \mathrm{~m}^{2}\right)$ showing deposition.

The largest identifiable change within the site boundary is a deposition area located between gullies G2 and G3 (fig. 6). Here, we calculated deposition as great as $30 \mathrm{~cm}$ in isolated areas, averaging between $8 \mathrm{~cm}$ and $15 \mathrm{~cm}$ over an area encompassing approximately $160 \mathrm{~m}^{2}$ (fig. 8). Overall, a total of $26.9 \mathrm{~m}^{3}$ of sediment was transported to this area. Additional analysis was performed using surface comparisons between May 2006 and May 2007, and May 2007 and September 2007. The results show that all deposition occurred between May 2006 and May 2007, over a slightly larger area $\left(260 \mathrm{~m}^{2}\right)$ and with greater depth (fig. 9). Between May 2007 and September 2007, erosion on the order of $8 \mathrm{~cm}$ to $15 \mathrm{~cm}$ occurred throughout a large part $\left(220 \mathrm{~m}^{2}\right)$ of the area (fig. 10). Analysis of photographs taken in May 2006 and September 2007 (fig. 11) shows that this area aggraded due to aeolian deposition. Partial to complete burial of prickly pear cacti and grasses is shown in the September 2007 images (fig. 11B).

The detailed comparison also shows two positively identifiable areas of erosion. The first is located in the lower portion of Gully 1 , below the confluence of Gully $1 \mathrm{a}$ and $1 \mathrm{~b}$ (fig. 9). Here, isolated erosion of as much as $30 \mathrm{~cm}$ in depth and $0.2 \mathrm{~m}^{3}$ in volume has affected a small $\left(<2 \mathrm{~m}^{2}\right)$ area of the drainage (fig. 12). Although surface water runoff may be the cause of this erosion, we note that this drainage also serves as an unofficial access trail leading up to the site; thus, an anthropogenic source for this topographic change cannot be ruled out.

We also found statistically significant erosion along a 10-m length (over an approximately $10 \mathrm{~m}^{2}$ area) of the upper portion of G3 (figs. 10 and 12) totaling $0.5 \mathrm{~m}^{3}$ in volume. Although the calculated surface change is on the order of 10 $\mathrm{cm}$ to $30 \mathrm{~cm}$ in places, we suspect that vegetation that is difficult to filter (that is, small prickly pear cacti) is responsible for at least a part of the measured change. However, an erosion signature is present for a majority of the drainage in this area, and therefore we conclude that the gully is actively eroding, albeit at the lower end of the detected change (on the order of $10 \mathrm{~cm}$ ). Our observations indicate that channelized overland flow is responsible for this erosion.

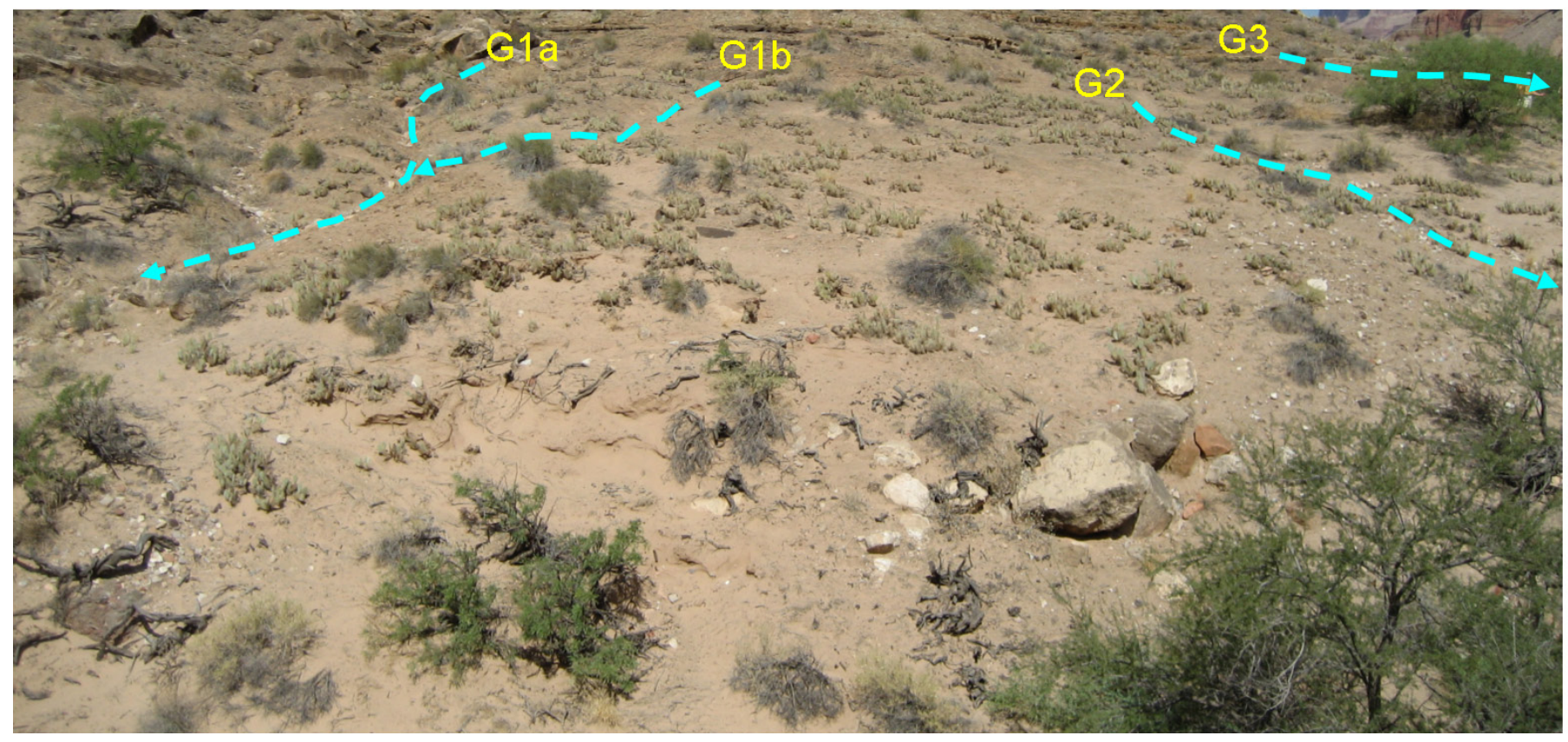

Figure 6. Site AZ:C:13:006 area showing gully locations (dashed lines). 

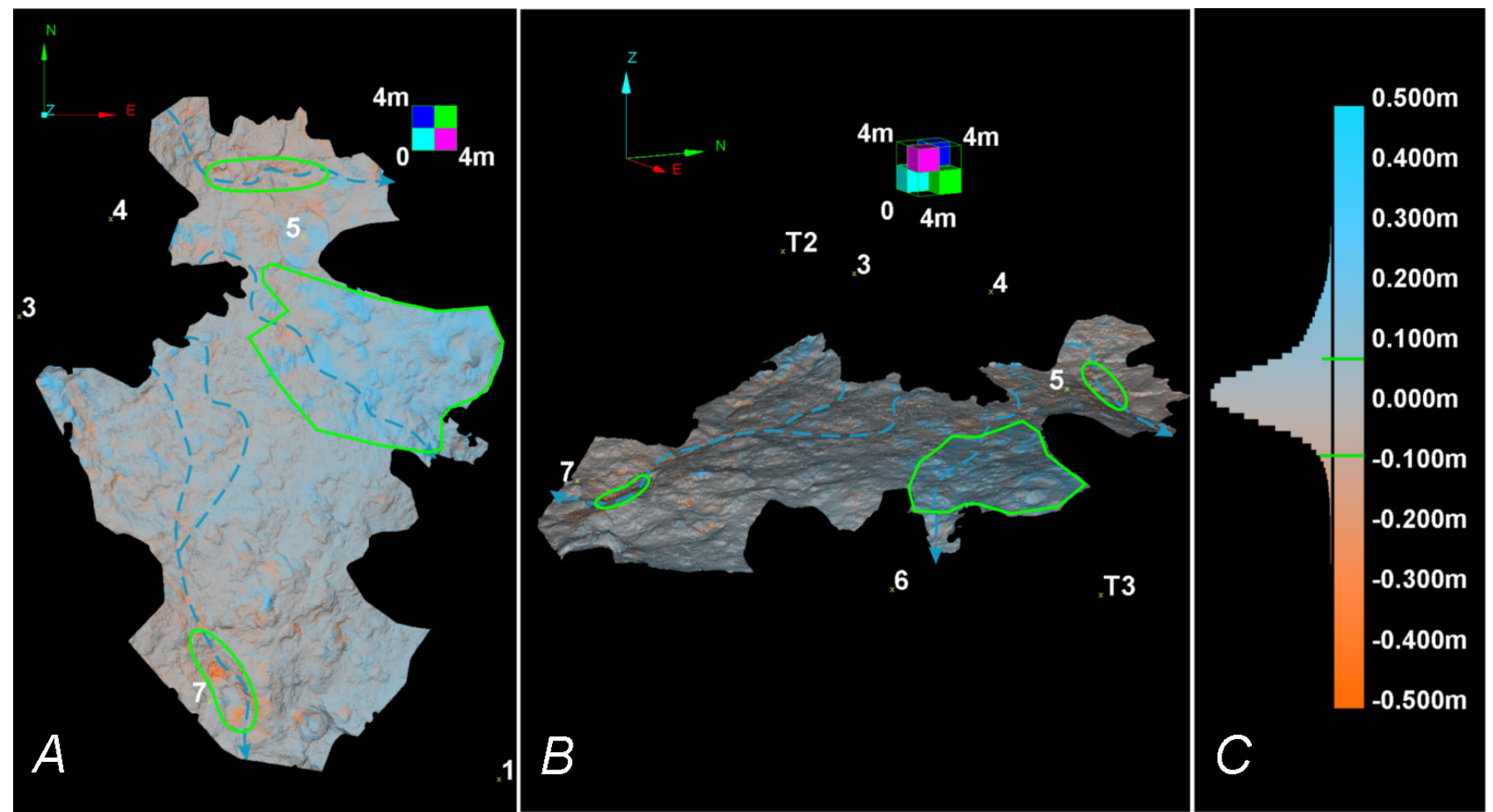

Figure 7. Site AZ:C:13:006-5-cm triangulated irregular network (TIN) output showing relative magnitude of surface comparison from May 2006 to September 2007. Laser scan and control point locations coincide with figure 5 . Identified change is outlined by polygon areas. $A$, plan view; $B$, oblique view; and $C$, vertical change histogram distribution and color scale. 


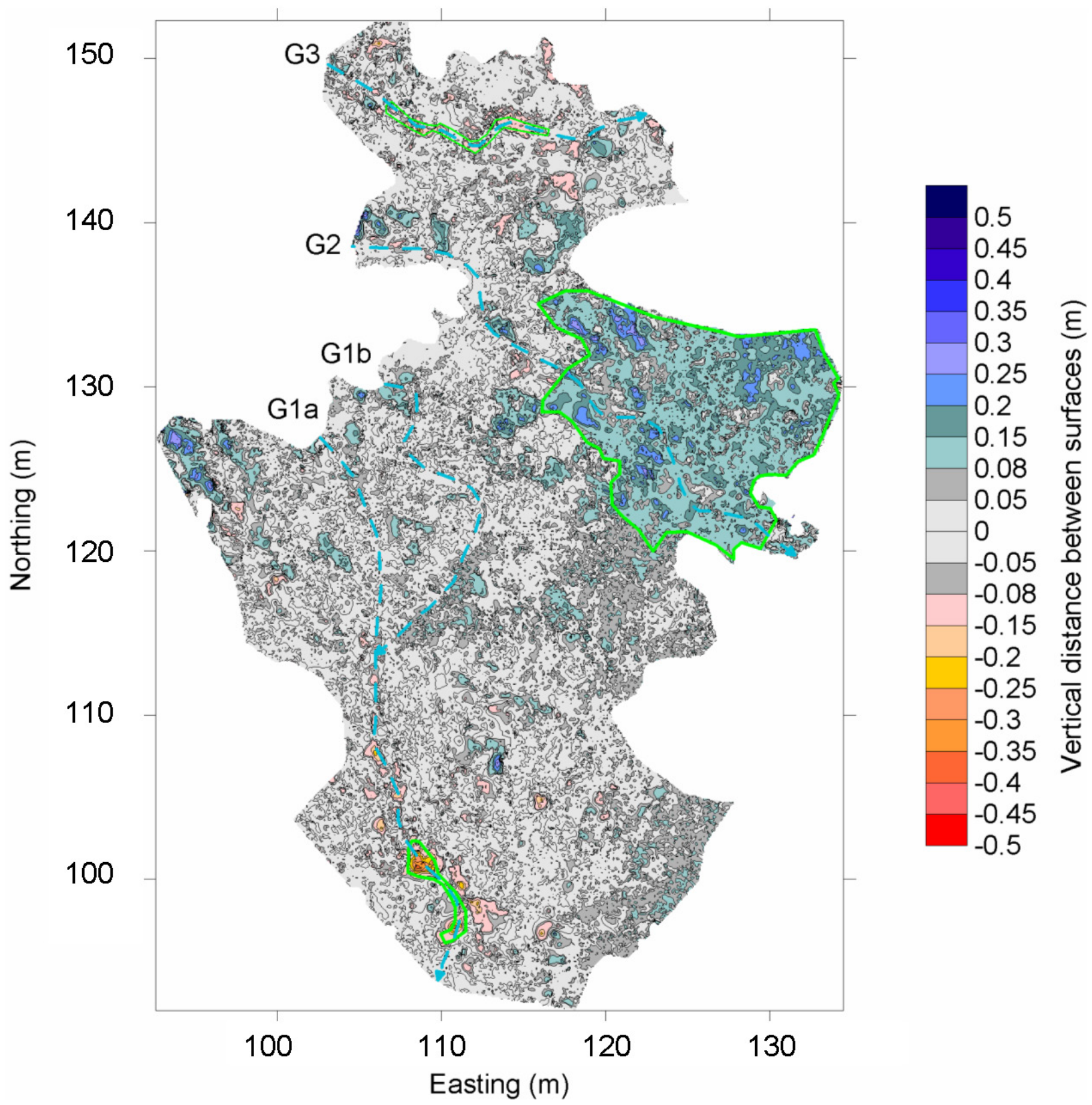

Figure 8. Site AZ:C:13:006 - 10-cm gridded output showing erosion (red, negative) and deposition (blue, positive) from May 2006 to September 2007 and approximate gully locations (dashed lines). Identified change is outlined by polygons. 


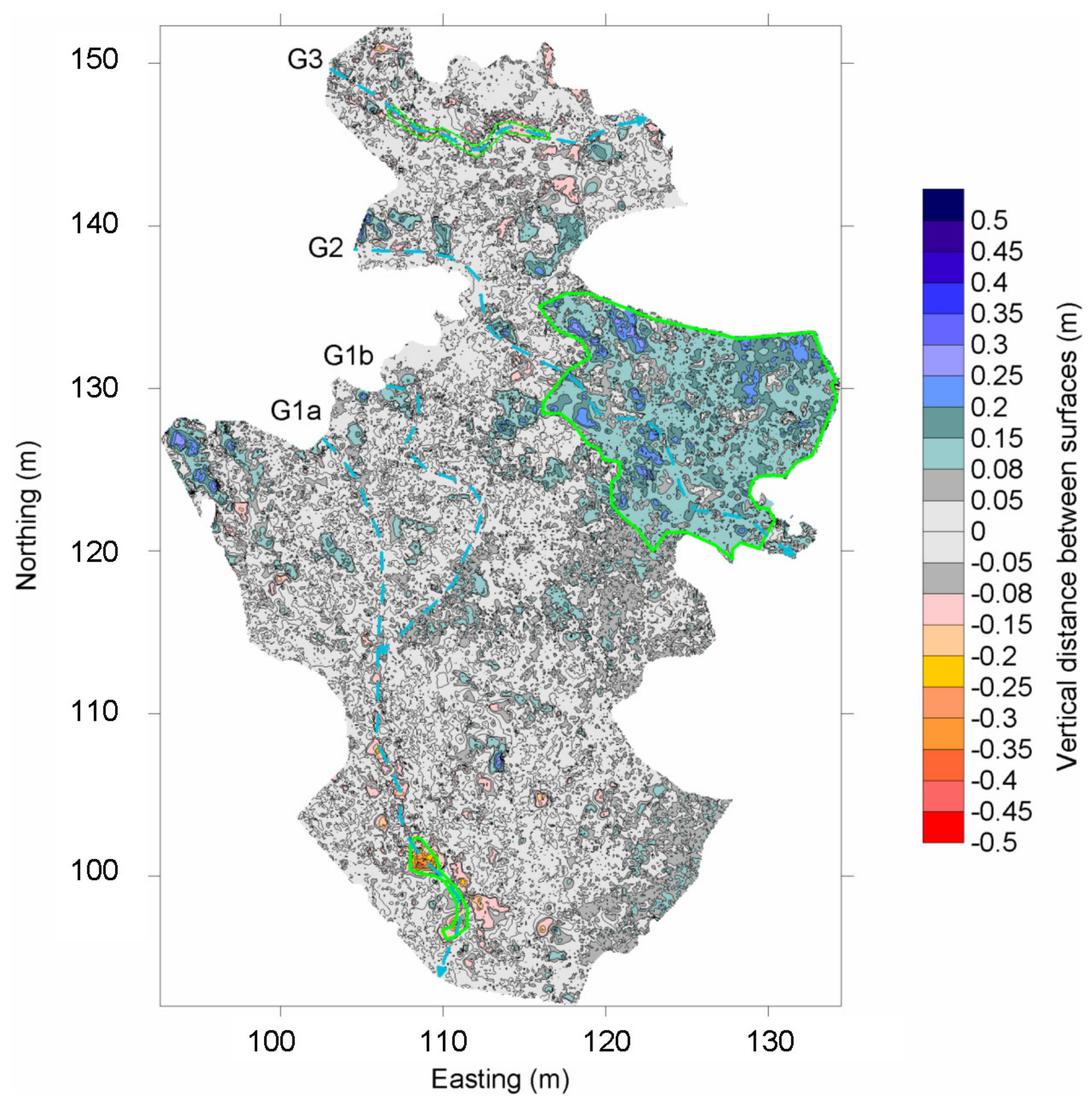

Figure 9. Site AZ:C:13:006 - 10-cm gridded output showing erosion (red, negative) and deposition (blue, positive) from May 2006 to May 2007 and approximate gully locations (dashed lines). Identified change is outlined by polygons. 


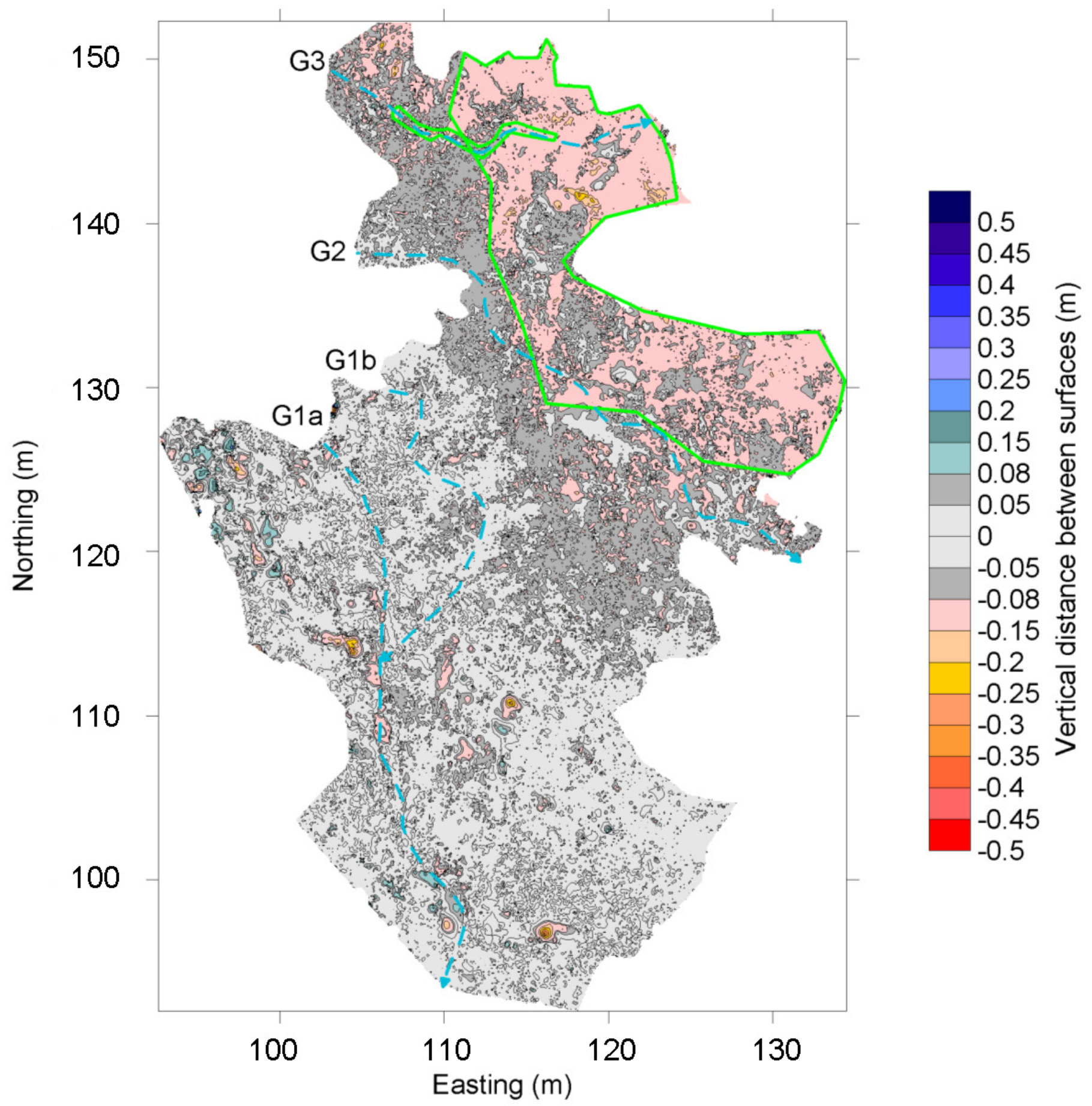

Figure 10. Site $A Z: C: 13: 006-10-\mathrm{cm}$ gridded output showing erosion (red, negative) and deposition (blue, positive) from May 2007 to September 2007 and approximate gully locations (dashed lines). Identified change is outlined by polygons. 

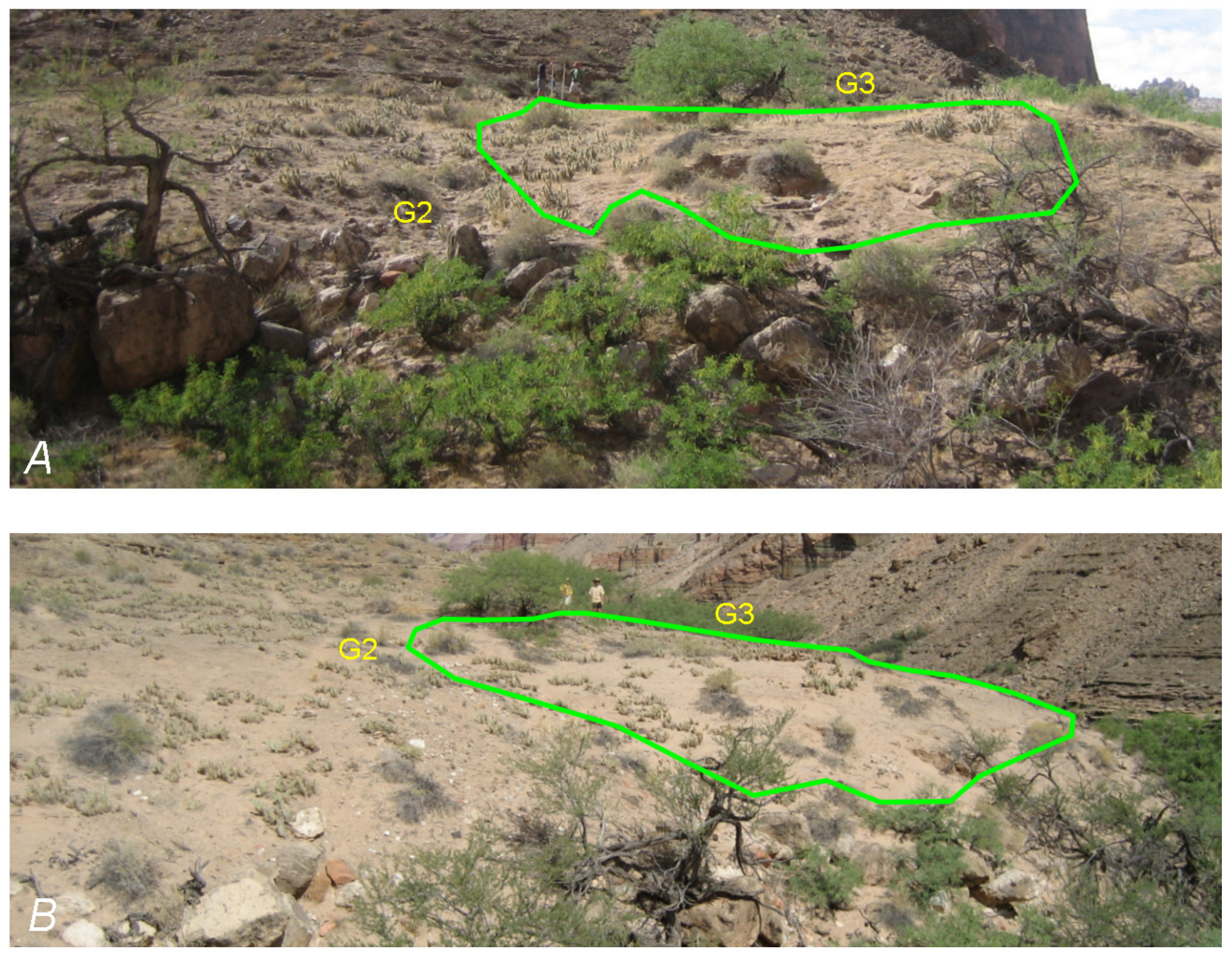

Figure 11. Site AZ:C:13:006 overview images showing area of as much as $30 \mathrm{~cm}$ deposition (polygons) measured between ( $A$ ) May 2006 and $(B)$ September 2007. Note grasses in $A$ are buried in $B$. 

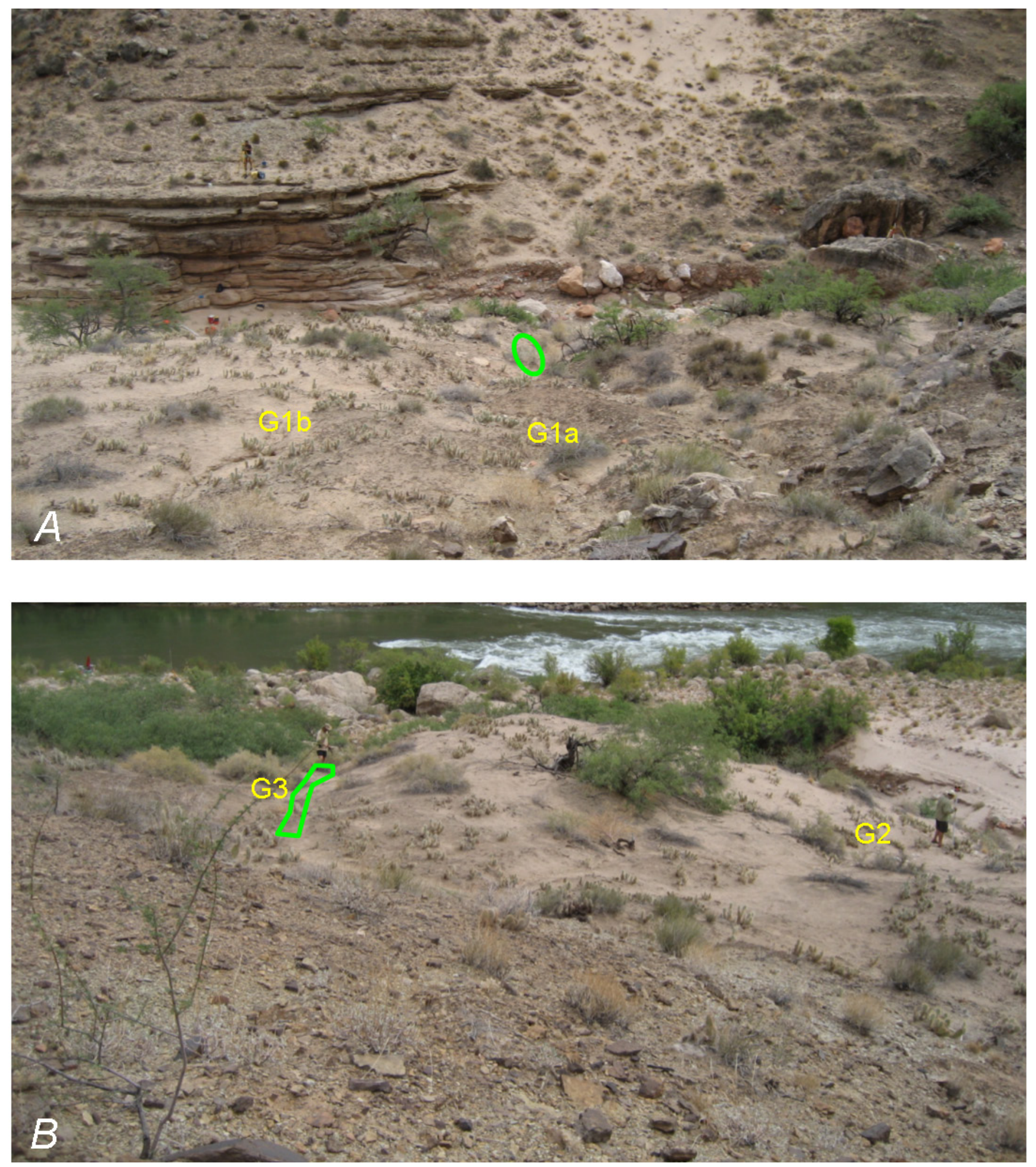

Figure 12. Site AZ:C:13:006 overview images showing locations of erosion (oval and polygon). The majority of change in $A$ occurred between May 2006 and May 2007, whereas the majority of change in B occurred between May 2007 and September 2007. 


\section{Site AZ:C:13:336}

In the Palisades region, we investigated three separate areas for topographic change. This area consists of a pre-Glen Canyon Dam flood level alluvial terrace (that is, an alluvial terrace formed from high-flows of the Colorado River prior to impoundment of the river by Glen Canyon Dam in the early 1960's) that has been subject to aeolian deposition and subsequent erosion by channelized flows. Drainages with channel widths ranging from less than a decimeter to more than a meter traverse the site, with the largest of these causing significant incision and headward retreat. This area hosts a major concentration of prehistoric habitation sites, agricultural areas, and artifacts, generally related to middle Puebloan II (about A.D. 1050 to 1100) occupation (Fairley and others, 1994). Several major archeological sites have been identified in the area. We performed topographic change detection data collection and analysis at two of them.

The first, site AZ:C:13:336, consists of an area of low relief situated among several vegetation-stabilized coppice mounds (fig. 13). A single gully crosses this area but bifurcates in the middle of the site (fig. 14). Each fork of the gully

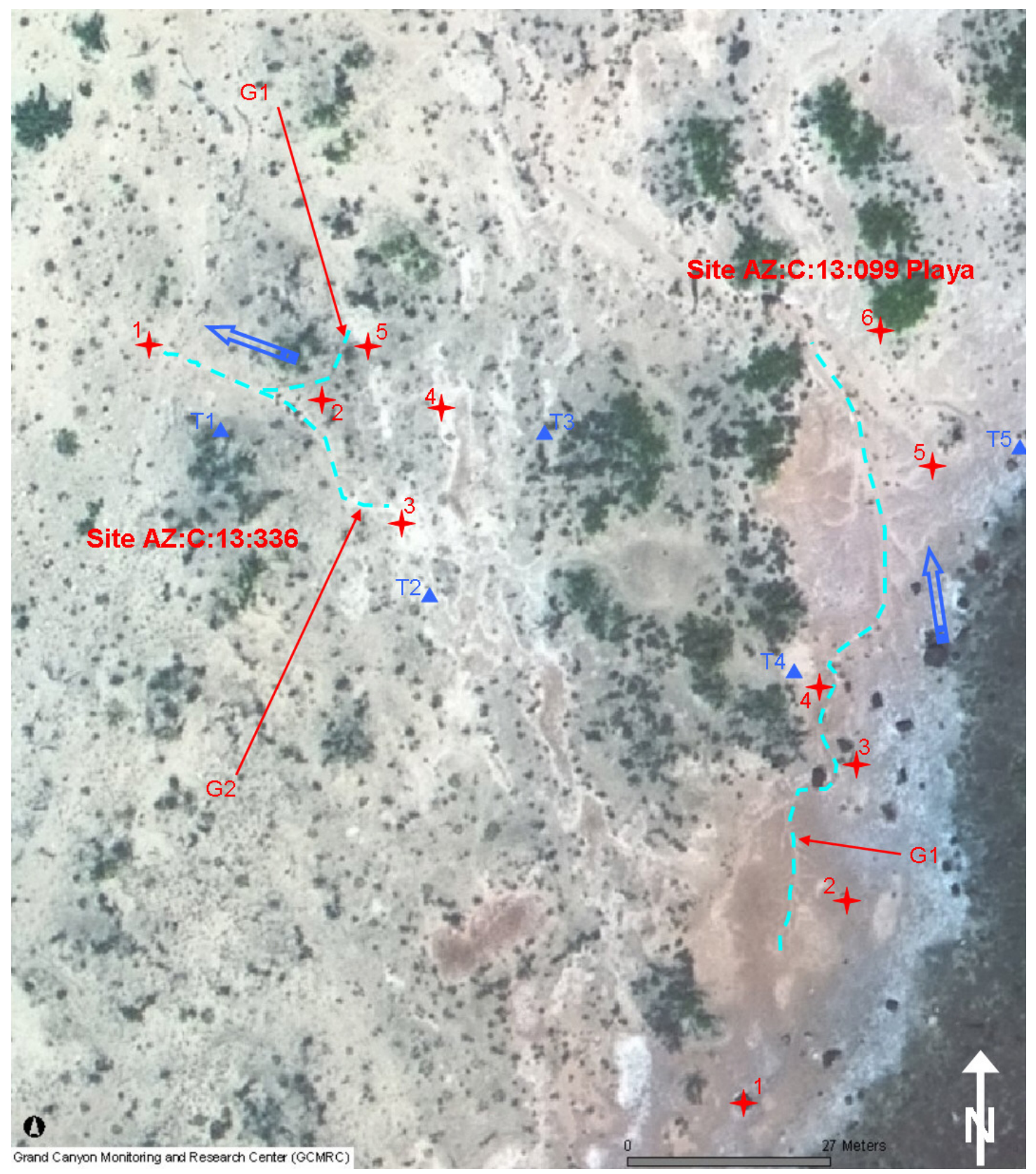

Figure 13. Site AZ:C:13:336 and site AZ:C:13:099 playa areas showing main gullies (dashed lines), general downhill flow direction (blue arrows), and laser scan (red crosses) and laser control point (blue triangles) locations. 


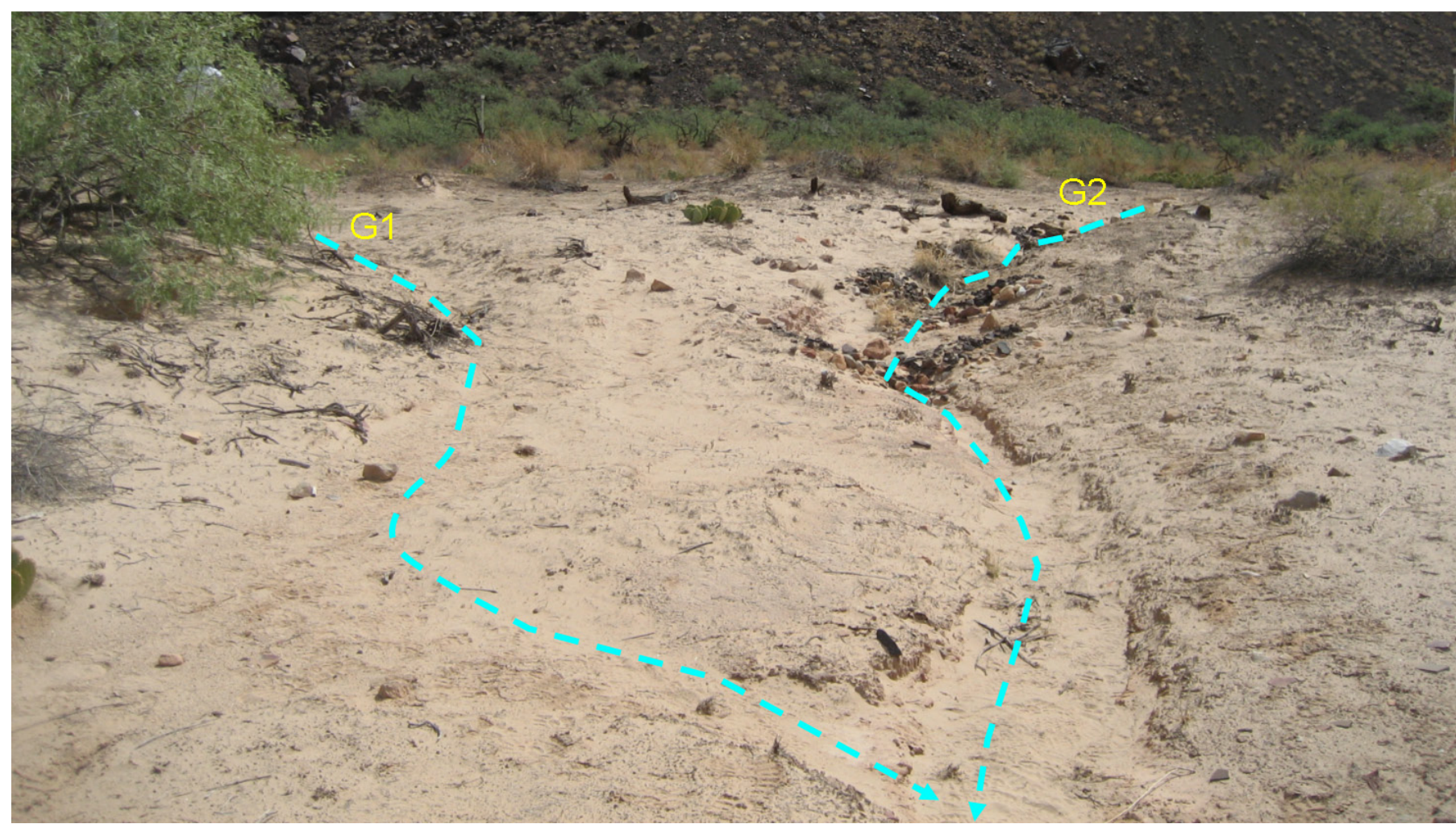

Figure 14. Site AZ:C:13:336 showing confluence of two drainages (dashed lines, G1 and G2) and rock check dam structures in the upper area of the site.

transitions into an area of very flat topography immediately adjacent to but topographically divided from the AZ:C:13:099 playa area (discussed subsequently). The gully has been the subject of an erosion mitigation study (Pederson and others, 2003), and both vegetation and rock-type check dams have been installed in various portions of the main channel. Although the main gully area is not heavily vegetated, the flatter upper portion of the drainage contains irregularly spaced grasses, shrubs, and prickly pear cacti (for example, Opuntia polyacantha var. erinacea), with mesquite trees (Prosopis glandulosa var. torreyana) several meters in height located at the edges of the site. All vegetation within the site is generally no larger than $0.5 \mathrm{~m}$ in diameter and $0.5 \mathrm{~m}$ in height, and individuals are separated from one another by several meters.

Surface comparison between May 2006 and September 2007 indicates that one area of statistically significant deposition occurred at this site (figs. 15 and 16). However, the overall statistics show that the majority of the site remained unchanged. The average distance between the two modeled surfaces is $0.6 \mathrm{~cm}$ with a standard deviation of $2.9 \mathrm{~cm}$. The $2 \sigma$ confidence intervals (about 95 percent) are $-5.2 \mathrm{~cm}$ and $6.4 \mathrm{~cm}$ and are both within the vertical error bound estimates $( \pm 8 \mathrm{~cm}$ ). The histogram distribution (fig. $15 \mathrm{C}$ ) identifies a total of 1.8 percent of the data outside the range of the error bounds with 0.5 percent $\left(6 \mathrm{~m}^{2}\right)$ of the site showing erosion and 1.3 percent $\left(16 \mathrm{~m}^{2}\right)$ showing deposition. With the exception of the noted deposition, we correlated each of these areas to processing difficulties with vegetation.

Within gully G2 and below the confluence of the two upper branches, we identified a 3.3-m-length of the gully with up to $15 \mathrm{~cm}$ of deposition between May 2006 and September 2007 (fig. 17). Analysis of the May 2007 surface shows that deposition of this magnitude began along a 1.8-m-length of the gully between May 2006 and May 2007 and expanded an additional $1.5 \mathrm{~m}$ updrainage between May 2007 and September 2007. The total volume change ( 0.1 $\mathrm{m}^{3}$ ) occurred over a $0.9-\mathrm{m}^{2}$ area located immediately above a brush check dam built to mitigate continued erosion of the site. The deposit is composed mainly of sandy material and infilled the brush check dam nearly to its crest. Because similar deposition did not occur outside the gully banks, we propose that the sand was transported and deposited by surface water rather than wind. However, because an upstream erosion source could not be positively identified, an aeolian deposition mode cannot be ruled out-aeolian transport could have infilled an isolated section of the gully. 

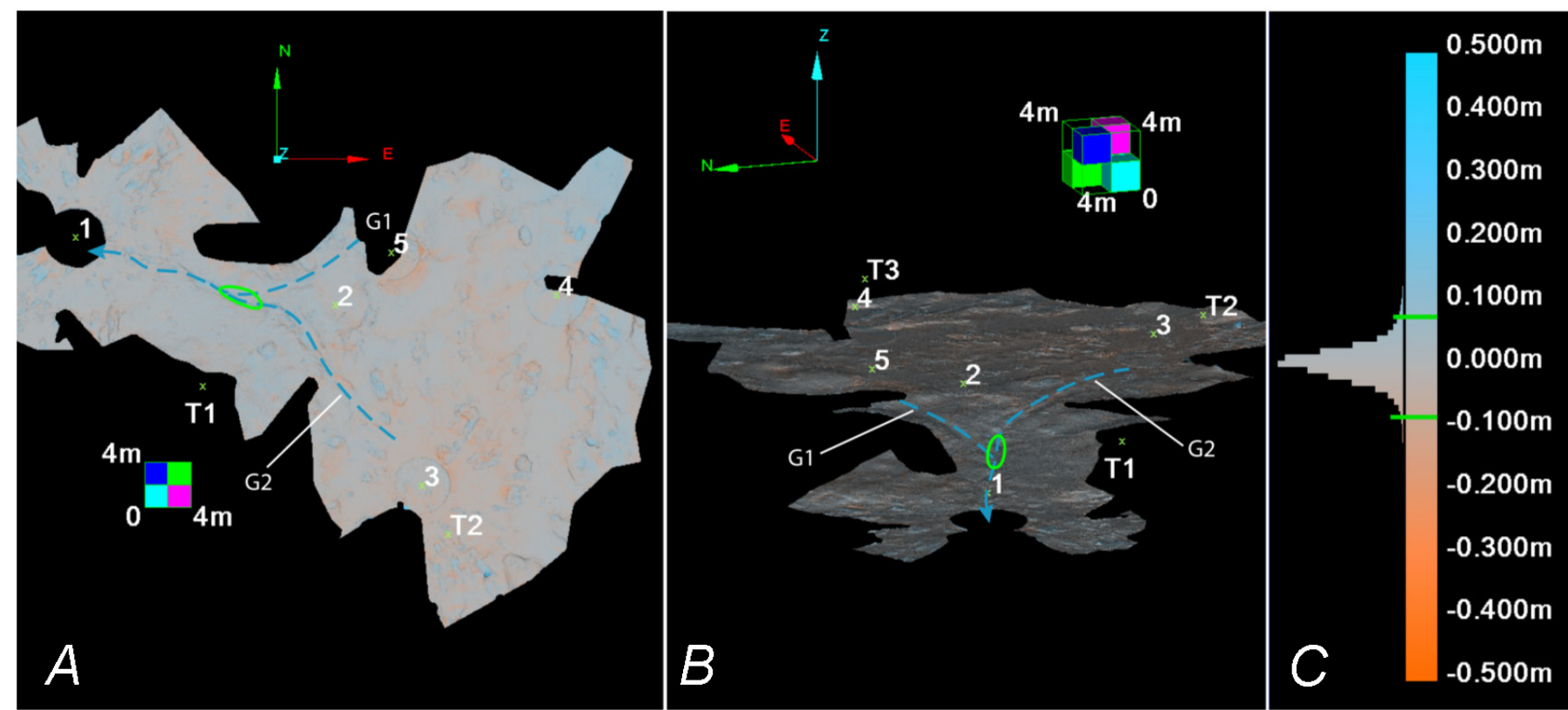

Figure 15. Site AZ:C:13:336 - 5-cm triangulated irregular network (TIN) output showing relative magnitude of surface comparison from May 2006 to September 2007. Laser scan and control point locations coincide with figure 13. One area of deposition in gully $\mathrm{G} 2$ was identified (ovals). $A$, plan view; $B$, oblique view; and $C$, vertical change histogram distribution and color scale.

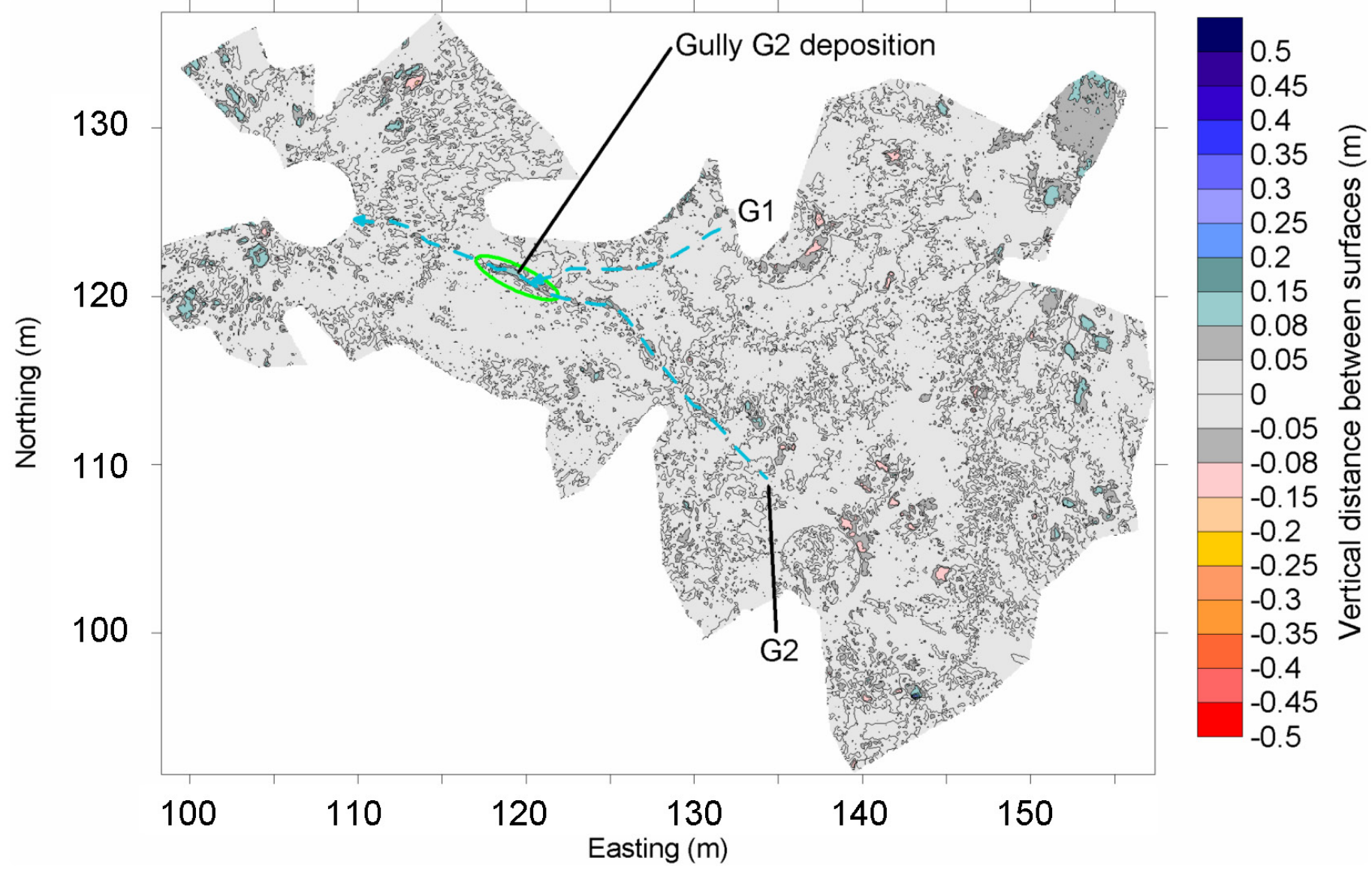

Figure 16. Site AZ:C:13:336 - 10-cm gridded output showing erosion (red, negative) and deposition (blue, positive) from May 2006 to September 2007 and approximate gully locations (dashed lines). One area of deposition (oval) in G2 was identified. 


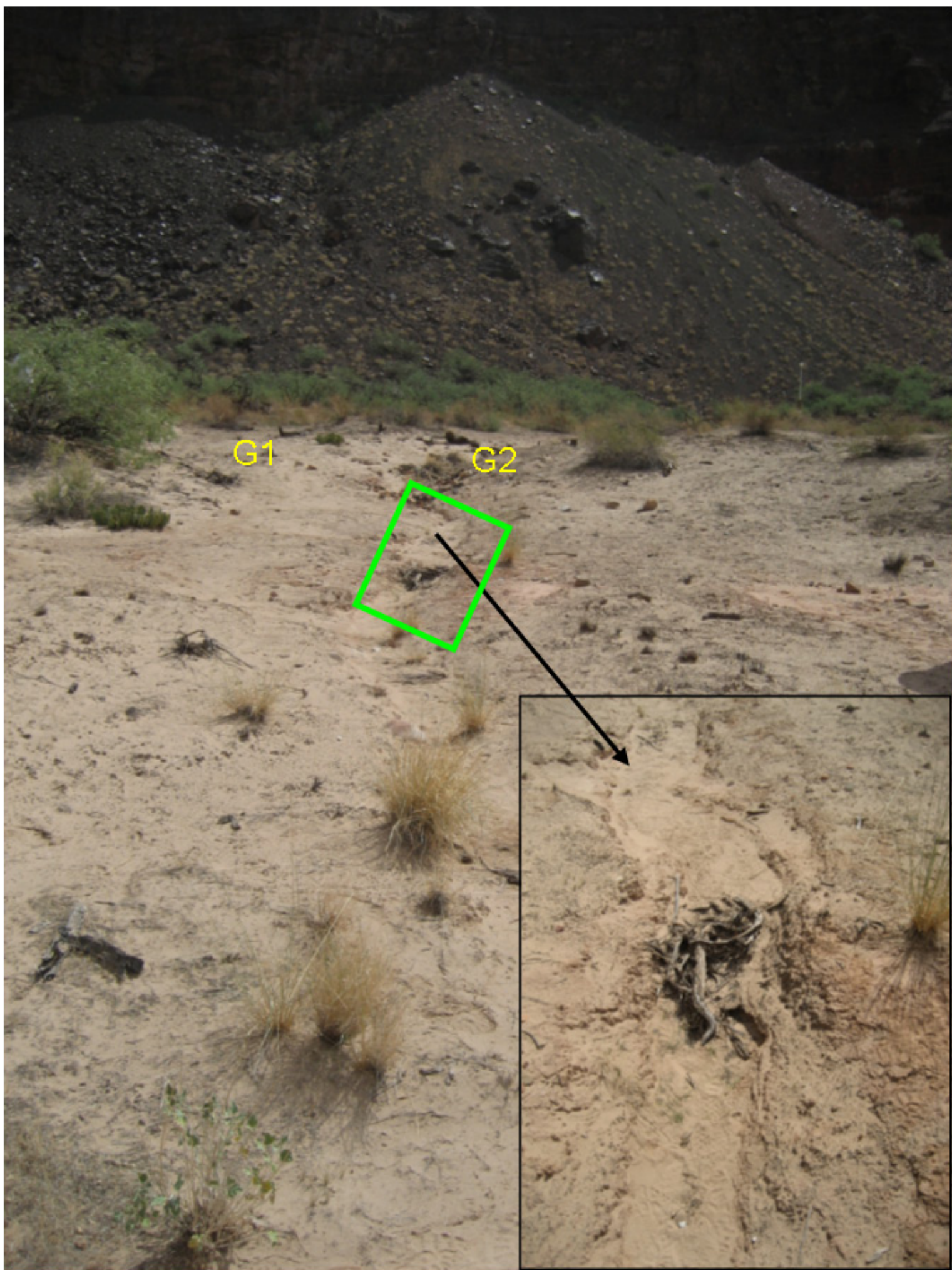

Figure 17. Site $A Z: C: 13: 336$ - Photos of $G 2$ depositional area (rectangle) in September 2007. Note brush check dam located immediately below area of deposition. 


\section{Site AZ:C:13:099}

The second major archeological site investigated in the Palisades region (site AZ:C:13:099) is located north of site AZ:C:13:336, in and around an incised gully system (fig. 18). The drainage system begins to the east of the site as a series of very shallow channels near the "playa" area, which forms the third site investigated in the Palisades region (discussed subsequently). As the shallow channels converge, they form ever deepening gullies until two channels located north and south of the site join to form a single larger drainage in the main portion of the site (fig. 19). Artifacts, including several varieties of sherds of middle Pueblo II origin, have been exposed by gully sidewall erosion near this area (H. Fairley, pers. comm.). Below this point, the gully passes through existing aeolian and alluvial terrace deposits, forming an approximately 1-m-deep channel, until draining into the Colorado River. This particular drainage and the associated archeological remains have been the focus of intensive research by archeologists and geomorphologists for more than two decades (Hereford and others 1991, 1993; Hereford 1996; Leap and others, 2000; Draut and others, 2005; Yeatts, 1996; Hazel and others, 2008).

Vegetation occurs throughout the site, consisting mainly of small diameter (about $0.5 \mathrm{~m}$ ) shrubs, grasses, and several

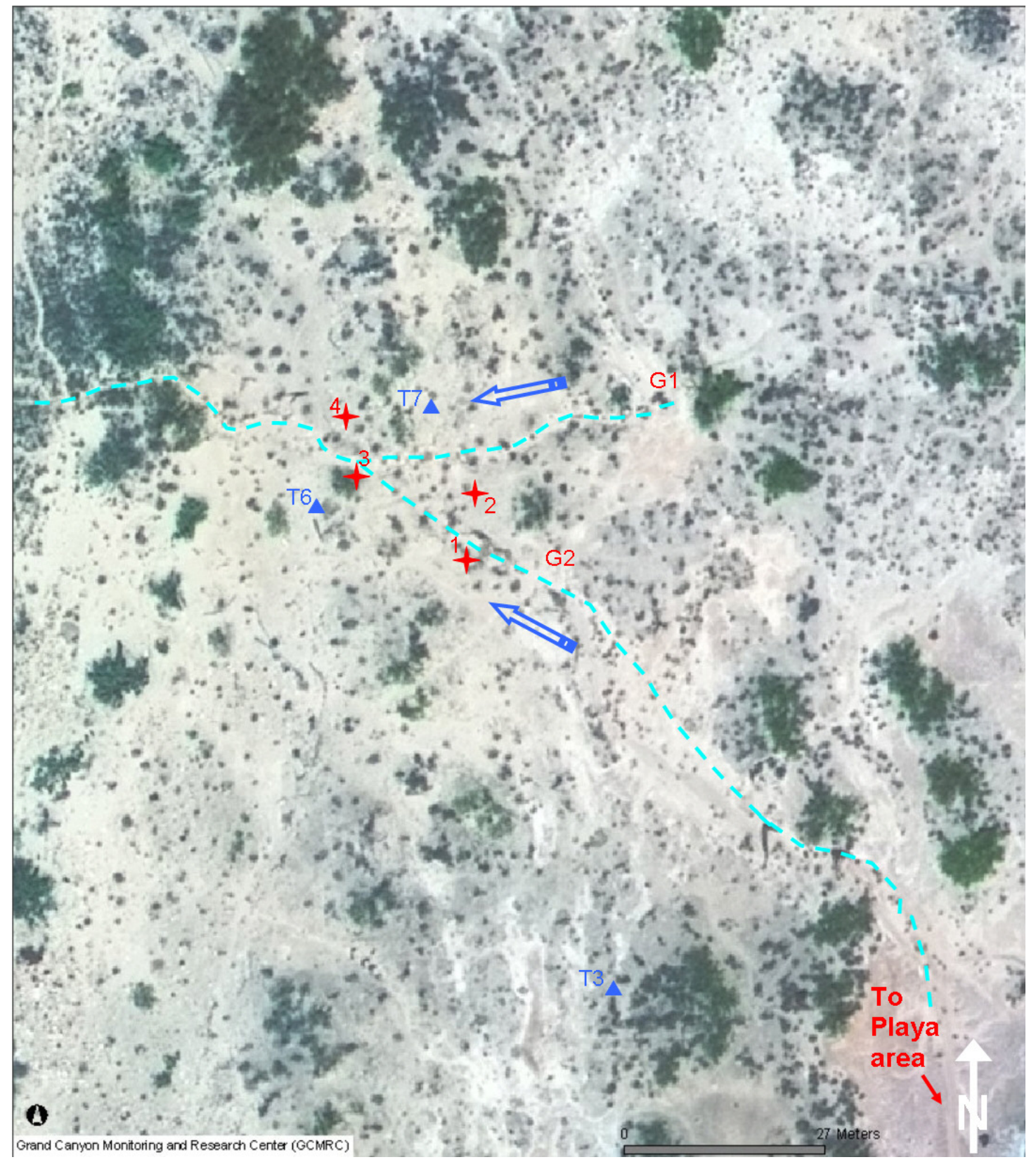

Figure 18. Site AZ:C:13:099 showing main gullies (dashed lines), general downhill flow direction (blue arrows), and laser scan (red crosses) and laser control point (blue triangles) locations. 


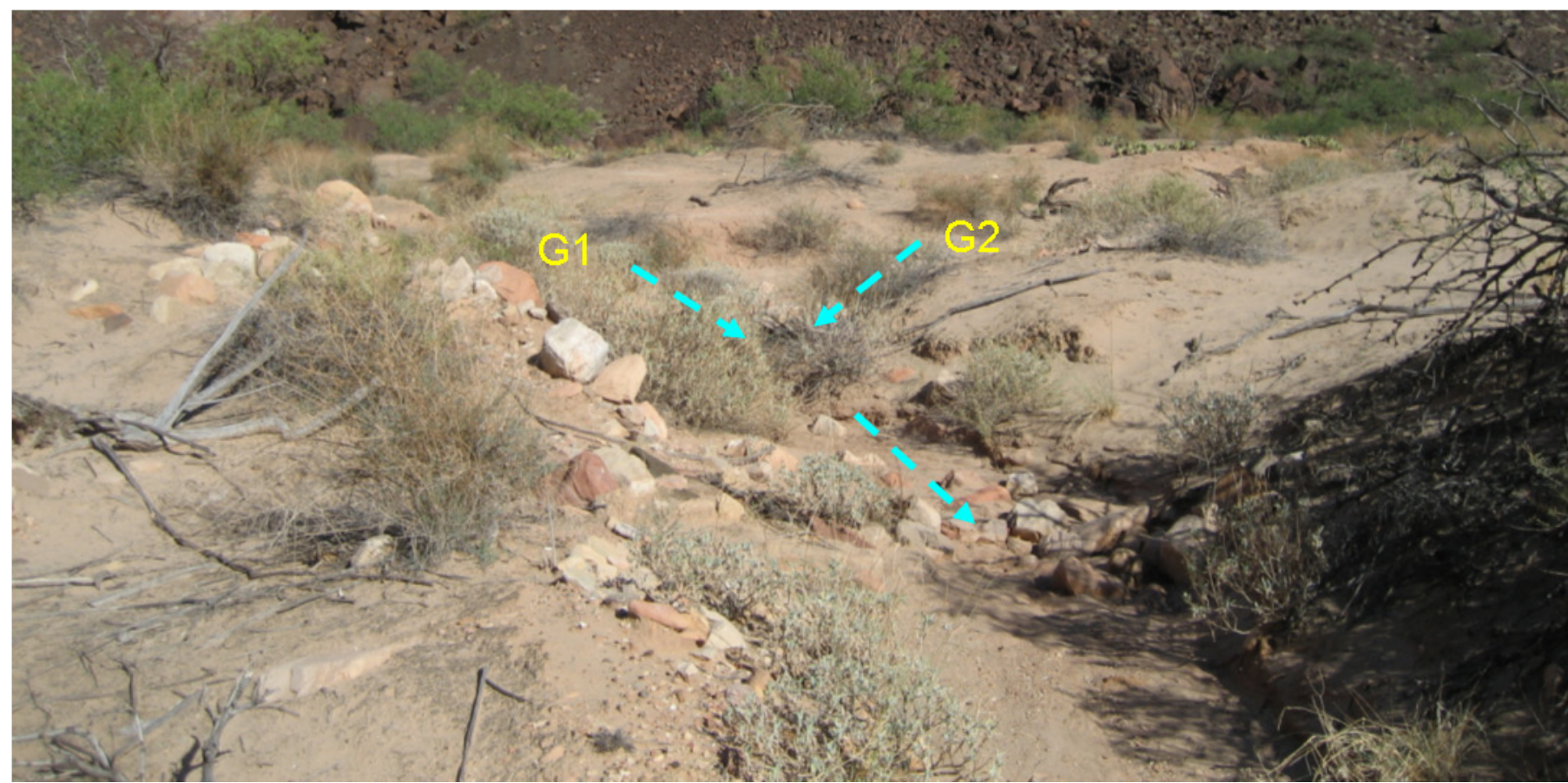

Figure 19. Site $A Z: C: 13: 099$ showing confluence of two smaller drainages (dashed lines, $G 1$ and $G 2$ ) into the main gully system
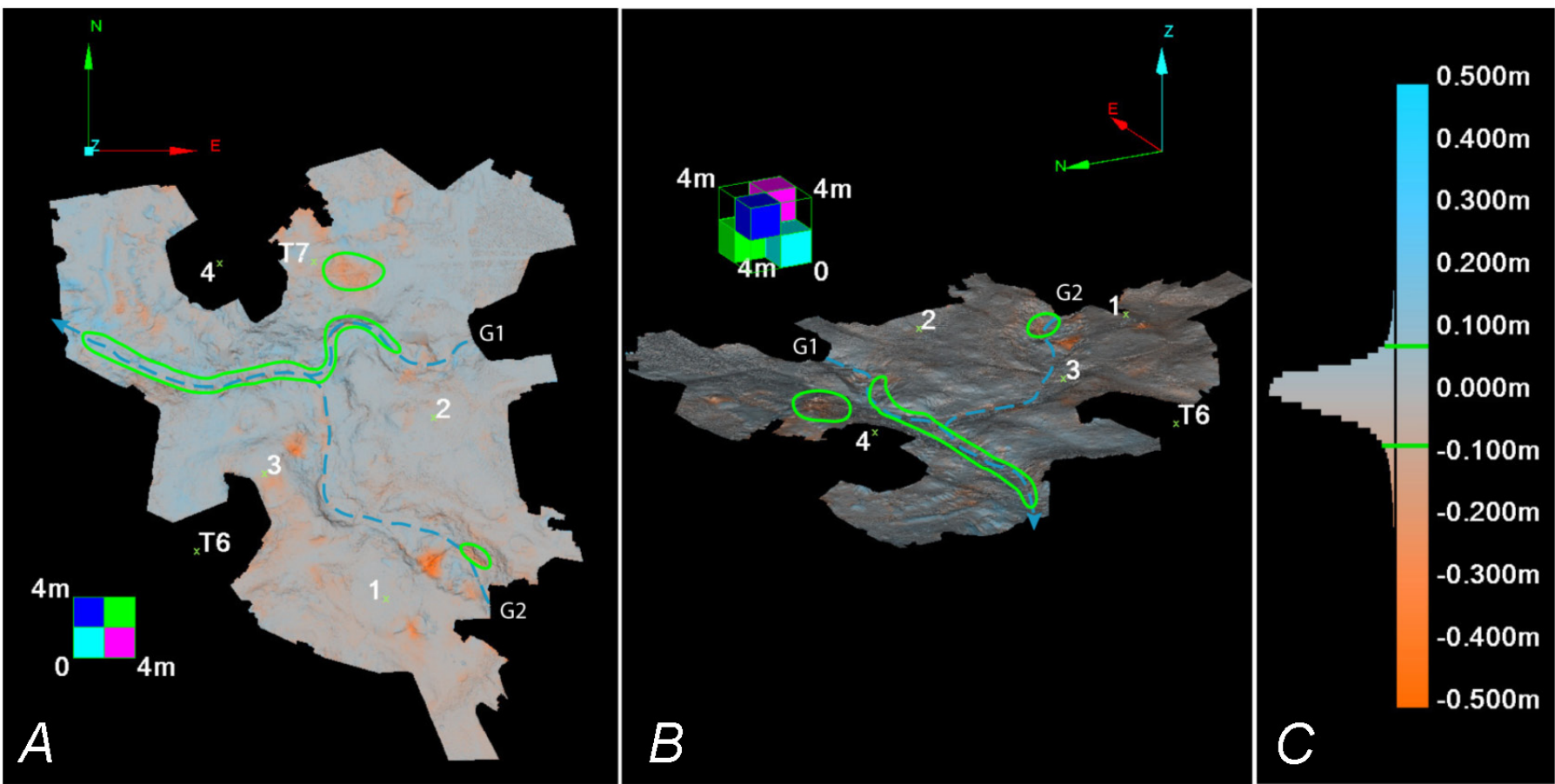

Figure 20. Site AZ:C:13:099 - 5-cm triangulated irregular network (TIN) output showing relative magnitude of surface comparison from May 2006 to September 2007. Laser scan and control point locations coincide with figure 18. Identified change is outlined by ovals and polygons. $A$, plan view; $B$, oblique view; and $C$, vertical change histogram distribution and color scale. 
larger (several meters in canopy diameter) mesquite trees (Prosopis glandulosa var. torreyana). In addition, small woody debris is scattered throughout the site, and check dams have been constructed to slow erosion in the most susceptible gully locations.

The surface comparison between May 2006 and September 2007 shows that several areas of the site have either eroded or been subject to deposition (fig. 20). The average distance between the two modeled surfaces is $0.4 \mathrm{~cm}$ with a standard deviation of $4.6 \mathrm{~cm}$. The $2 \sigma$ confidence intervals (about 95 percent) are $-8.8 \mathrm{~cm}$ and $9.6 \mathrm{~cm}$ and are both greater than the vertical error bound estimates $( \pm 8 \mathrm{~cm})$. Thus, at least 5 percent of the modeled surface shows evidence of change above the error bounds. The histogram distribution (fig. 20C) identifies a total of 6.5 percent of the data outside the range of the error bounds with 4.0 percent $\left(31 \mathrm{~m}^{2}\right)$ of the site showing erosion and 2.5 percent $\left(19 \mathrm{~m}^{2}\right)$ showing deposition.

We positively identified two areas of erosion that encompass 1.4 percent of the total surface area (fig. 21, ovals) and show changes as great as $20 \mathrm{~cm}$. One area is located in a section of the south fork of the drainage above

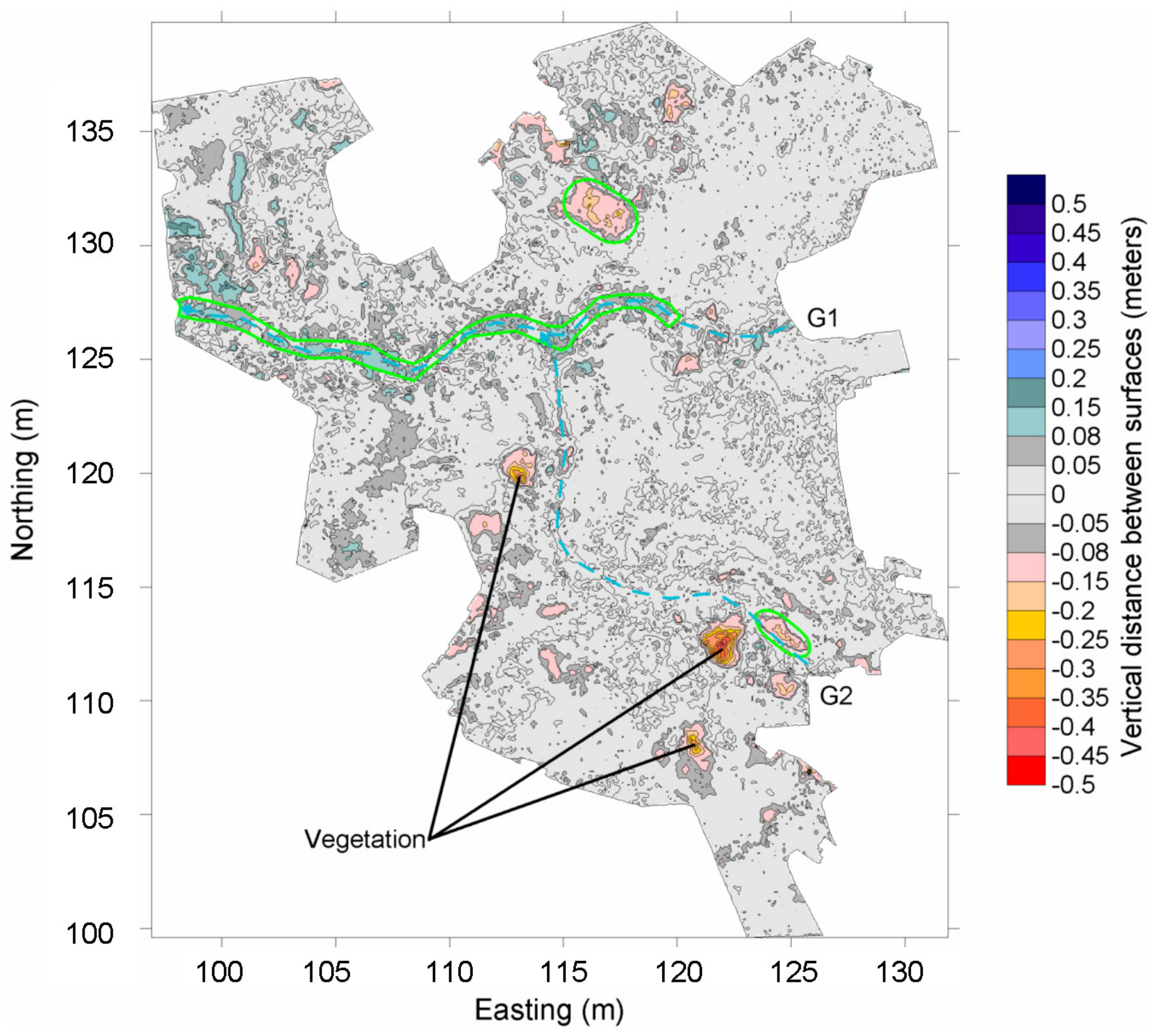

Figure 21. Site AZ:C:13:099 - 10-cm gridded output showing erosion (red, negative) and deposition (blue, positive) from May 2006 to September 2007 and approximate gully locations (dashed lines). Identified change is outlined by ovals and polygon. Orange areas identified as vegetation occurred because of inconsistent filtering of the point-cloud data. 
the confluence with the main gully (fig. 22). At this location, channel sidewall stabilization has been attempted with rock armoring, thus this area is of particular importance. Analysis of the May 2007 data indicates that $0.3 \mathrm{~m}^{3}$ of sediment eroded from this area between May and September 2007; the change is not visible when the May 2006 and May 2007 surfaces are compared. The other erosion area is located immediately adjacent to the north gully (G1) within aeolian sediments (fig. 22). As such, it is a likely area for potential change. Our analysis of the May 2006 to May 2007 surfaces shows that the area experienced the most erosion during that time, although the change continued to become more pronounced by September 2007, for a total of $0.5 \mathrm{~m}^{3}$ of sediment removed. The remaining 2.6 percent of denudation (of the total site) could not be positively associated with erosion processes. Although we identified a part (1.0 percent) of the area related to errors associated with difficult-to-remove, unfiltered vegetation in the bare-ground model, the remaining 1.6 percent of the total area associated with erosion could not be linked to any one source.

We found that the 2.5 percent $\left(19 \mathrm{~m}^{2}\right)$ of the total area of measured deposition is attributed to infilling of the bottom of the channel of the north fork of the drainage and the confluence below the site (figs. 20 and 21). Here, deposition is as great as $15 \mathrm{~cm}$ and totals $2.3 \mathrm{~m}^{3}$. Although some areas of erosion are visible immediately adjacent to the areas of deposition, they are of small $(<10 \mathrm{~cm})$ magnitude and area (about $1 \mathrm{~m}^{2}$ ), and it is therefore not possible to conclude whether the deposition is due to aeolian infilling or gully bank slumpage.
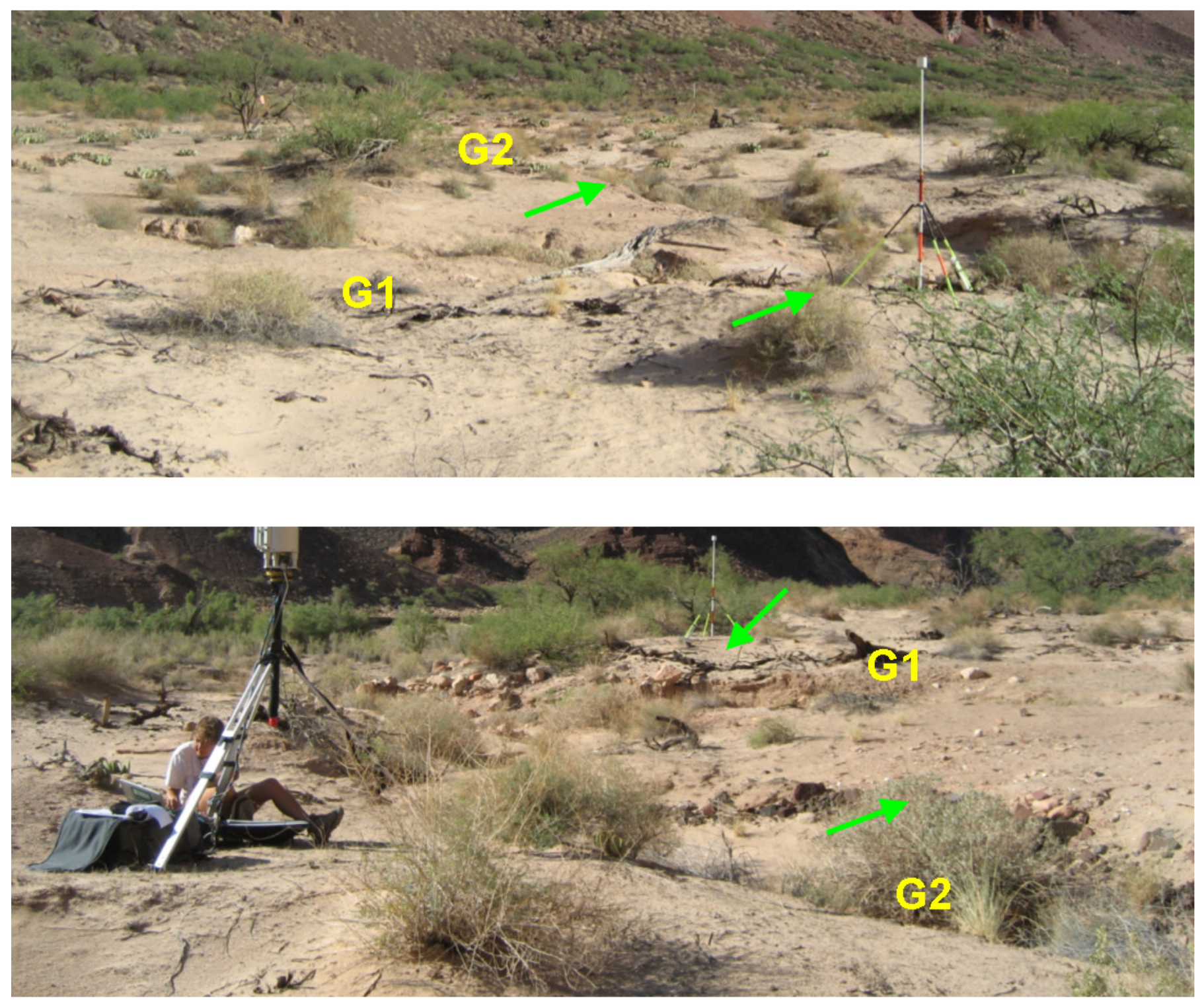

Figure 22. Site AZ:C:13:099-Site overview images showing locations of as much as $20 \mathrm{~cm}$ measured erosion (arrows) and location of gullies ( $\mathrm{G} 1$ and $\mathrm{G} 2$ ). 


\section{Site AZ:C:13:099 Playa Area}

The playa area near site AZ:C:13:099 is the third study site in the Palisades region that we investigated for topographic change (fig. 13). This area is named because it resembles a dry lakebed. Although the playa area does not constitute an archeological site in itself, its close proximity to adjacent sites of Puebloan age, and the incipient state of the existing drainages that could propagate into these archeological areas, makes this an important target site for topographic monitoring.
Of the three sites investigated in the Palisades region, this area is located farthest from the Colorado River. The site consists of a formerly ponded area of sand, silt, and clays with very flat topography, backed immediately by talus slopes formed from canyon wall rockfall (fig. 23). Rockfall events have deposited boulders approximately 1 to $2 \mathrm{~m}$ in diameter sporadically throughout the site. Site soils consist mainly of abiotic cruststabilized sands, although cryptobiotic soils are also present; the hard crust has most likely formed due to precipitation of cementing agents from evaporation of surface water caught in

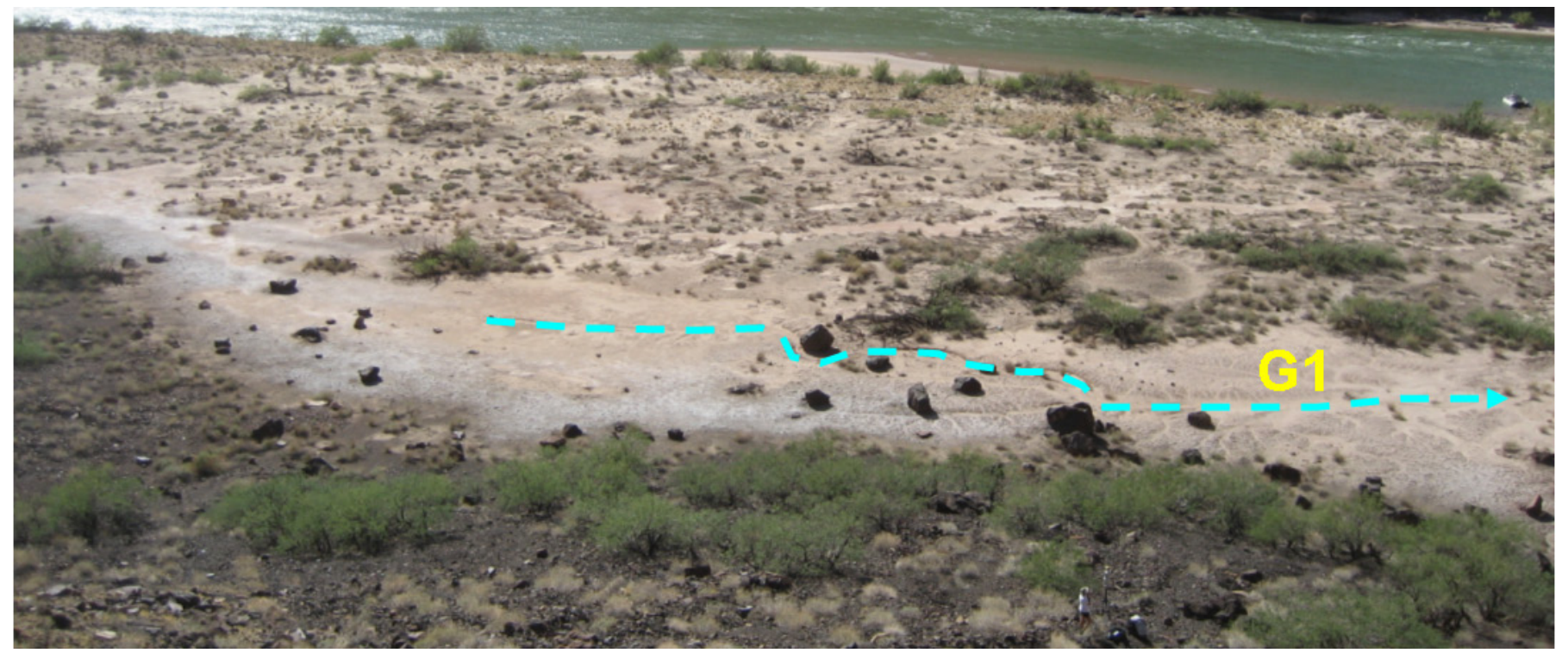

Figure 23. Site AZ:C:13:099 playa area showing location of main gully (dashed line, G1).
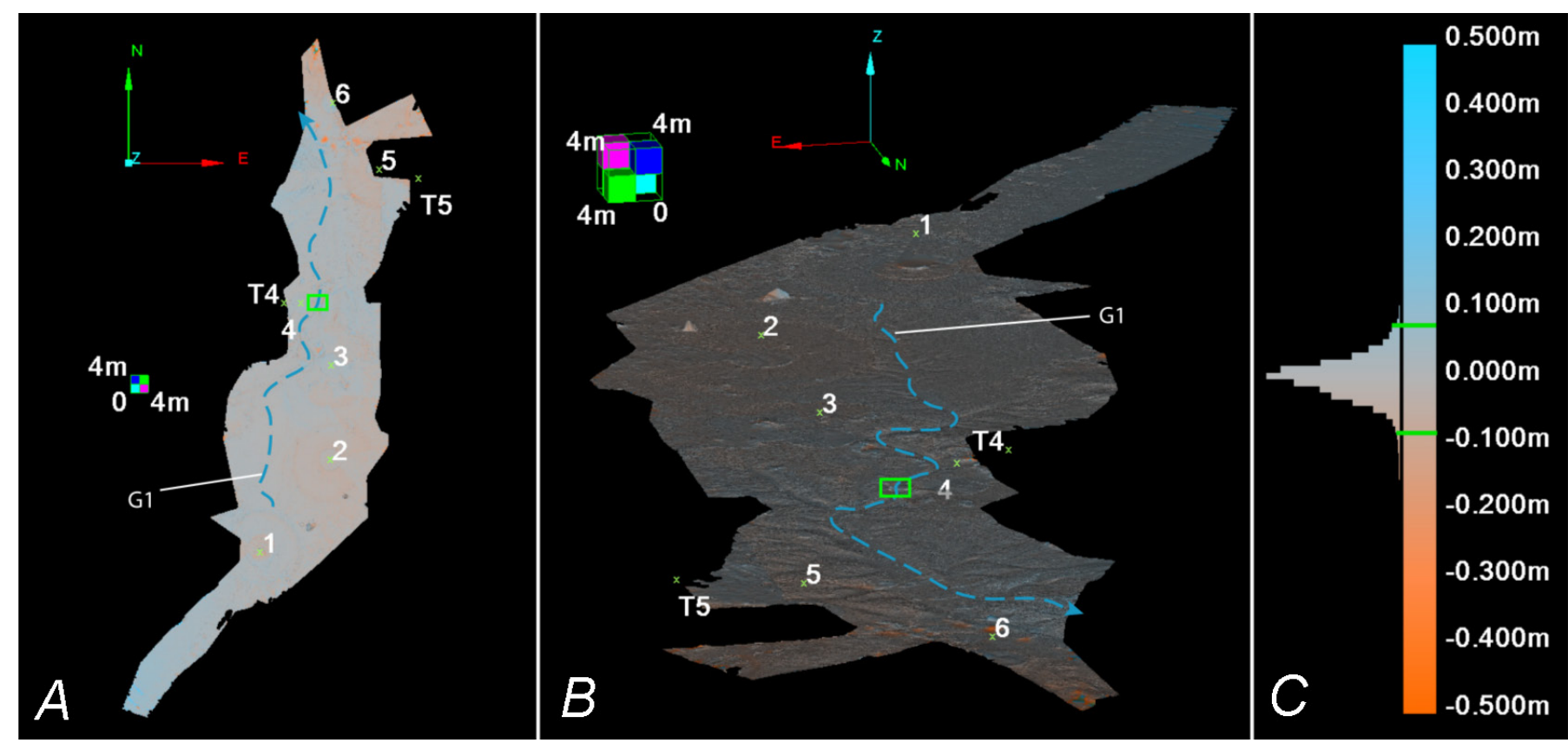

Figure 24. Site AZ:C:13:099 playa area-5-cm triangulated irregular network (TIN) output showing location and relative magnitude of surface comparison from May 2006 to September 2007. Laser scan and control point locations coincide with figure 13. Identified erosion is outlined by dashed area. $A$, plan view; $B$, oblique view; and $C$, vertical change histogram distribution and color scale. 


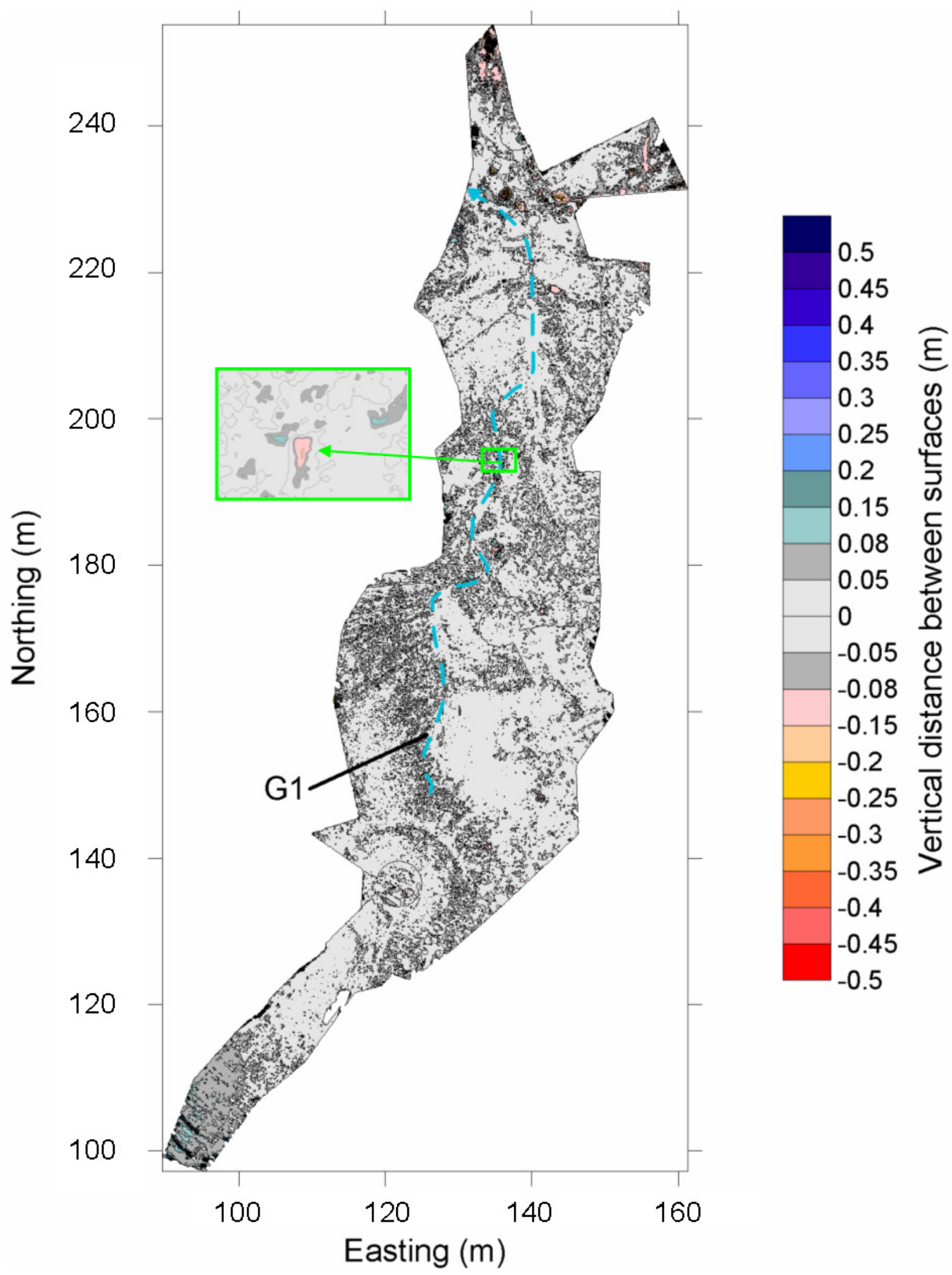

Figure 25. Site AZ:C:13:099 playa area-10-cm gridded output showing erosion (red, negative) and deposition (blue, positive) from May 2006 to September 2007 and approximate gully location (dashed line). Rectangle shows area of identified erosion. Inset is shown with $4 \mathrm{x}$ magnification. 
the area. A major concern at this site is that large rainfall events may lead to surface water flow that will break through the overlying crust and cause massive gullying of the underlying sands. With the exception of a few larger mesquite trees (Prosopis glandulosa var. torreyana) around the periphery of the "playa" and a few small bushes in the central and northern areas, the site is relatively bare of vegetation. A single primary drainage traverses the site (G1), but has incised less than $10 \mathrm{~cm}$ into the underlying soils thus far. Many other smaller channels form a dendritic pattern stemming from the primary channel such that maximum drainage distances for the transition from initial overland flow to channelized flow are only about 15 meters.

Our comparison of the topography at this site between May 2006 and September 2007 shows only one minor area (about $0.4 \mathrm{~m}^{2}$ ) of change (erosion) within the modeled site boundary (figs. 24 and 25). The average distance between the two modeled surfaces is $0.1 \mathrm{~cm}$ with a standard deviation of $3.8 \mathrm{~cm}$. The $2 \sigma$ confidence intervals $(-7.5 \mathrm{~cm}$ and $7.7 \mathrm{~cm})$, representing 95 percent of the data, are within the error range
( $\pm 8 \mathrm{~cm}$ ). According to the histogram distribution (fig. 24C), 1.5 percent of the total surface area (about $50 \mathrm{~m}^{2}$ ) underwent more than $8 \mathrm{~cm}$ of vertical erosion and 0.9 percent (about $30 \mathrm{~m}^{2}$ ) underwent more than $8 \mathrm{~cm}$ of vertical deposition. However, on additional investigation of the May 2007 model data, we attributed nearly all of these areas either to edge boundary effects of the models or poor data density caused by a single faulty scan from May 2006. The single area of erosion that was identified (about $0.4 \mathrm{~m}^{2}$ ) represents only 0.01 percent of the entire surface, but is located immediately in the main drainage of the site (fig. 26). Our comparisons of the three surfaces identify that the change occurred between May 2006 and May 2007. Though the change detection values show possible change that is as much as $20 \mathrm{~cm}$, additional analysis shows that a majority of this change is within the $( \pm 8 \mathrm{~cm})$ error bounds. We conclude, therefore, that statistically significant erosion of as much as $12 \mathrm{~cm}$ occurred in this location. On the basis of the relative location and shape of the eroded area within the channel, we also propose that the change is likely due to channel widening rather than deepening.

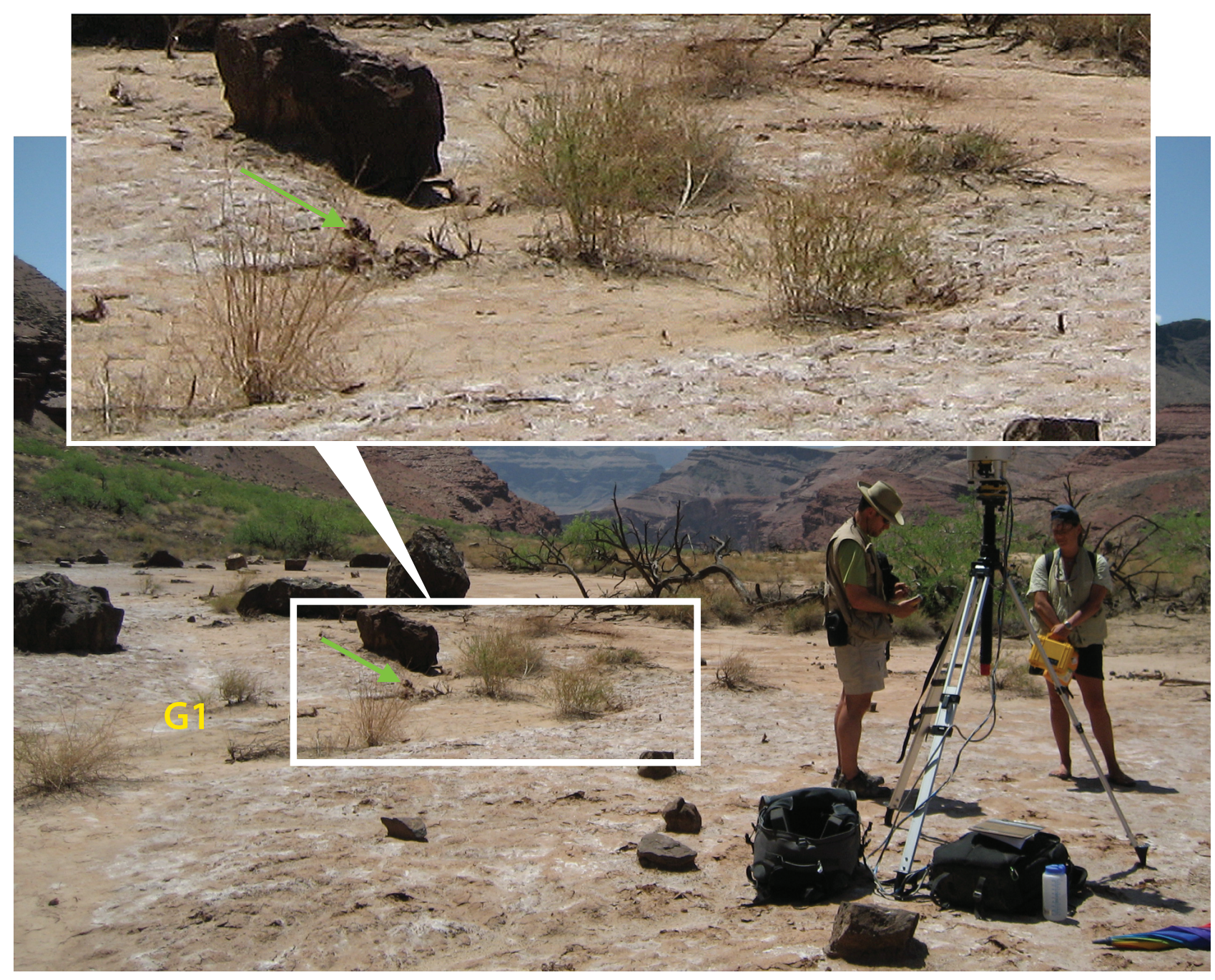

Figure 26. Site AZ:C:13:099 playa area-Image and inset showing area of as much as $12 \mathrm{~cm}$ measured erosion (arrows) and location of major gully (G1). 


\section{Site AZ:C:13:348}

Site AZ:C:13:348 consists of a broad alluvial fan of slope wash deposits grading into an alluvial terrace that adjoins a former flood plain of the Colorado River. Sand dunes several meters in height are located immediately downstream from the area, providing a potential source for aeolian transport to the site. Three small gullies traverse the site (G1, G2, and G3); G1 is composed of two smaller drainages (G1a, G1b) that join together at the top of the terrace and gullies G2 and G3 are separated from one another by a large coppice mound/ sand dune as they descend from the terrace to river level (fig. 27). All the gullies appear to be actively downcutting through the slope wash deposits as they move across this steeper slope. Vegetation consists of irregularly spaced, small desert seepweed bushes (Suaeda moquinii) and larger mesquite trees (Prosopis glandulosa var. torreyana), which in some cases are sufficiently dense to partially obscure the gullies from overhead observation (fig. 28).

This area is archeologically important as an area of Puebloan II habitation; first occupation has been generally constrained to approximately A.D. 1100 (Fairley and others, 1994). Two separate archeological sites are located here but are similar in age and setting. They consist of the remains of jacal-type structures, built by planting wood posts in the ground, weaving sticks between the posts, and plastering the

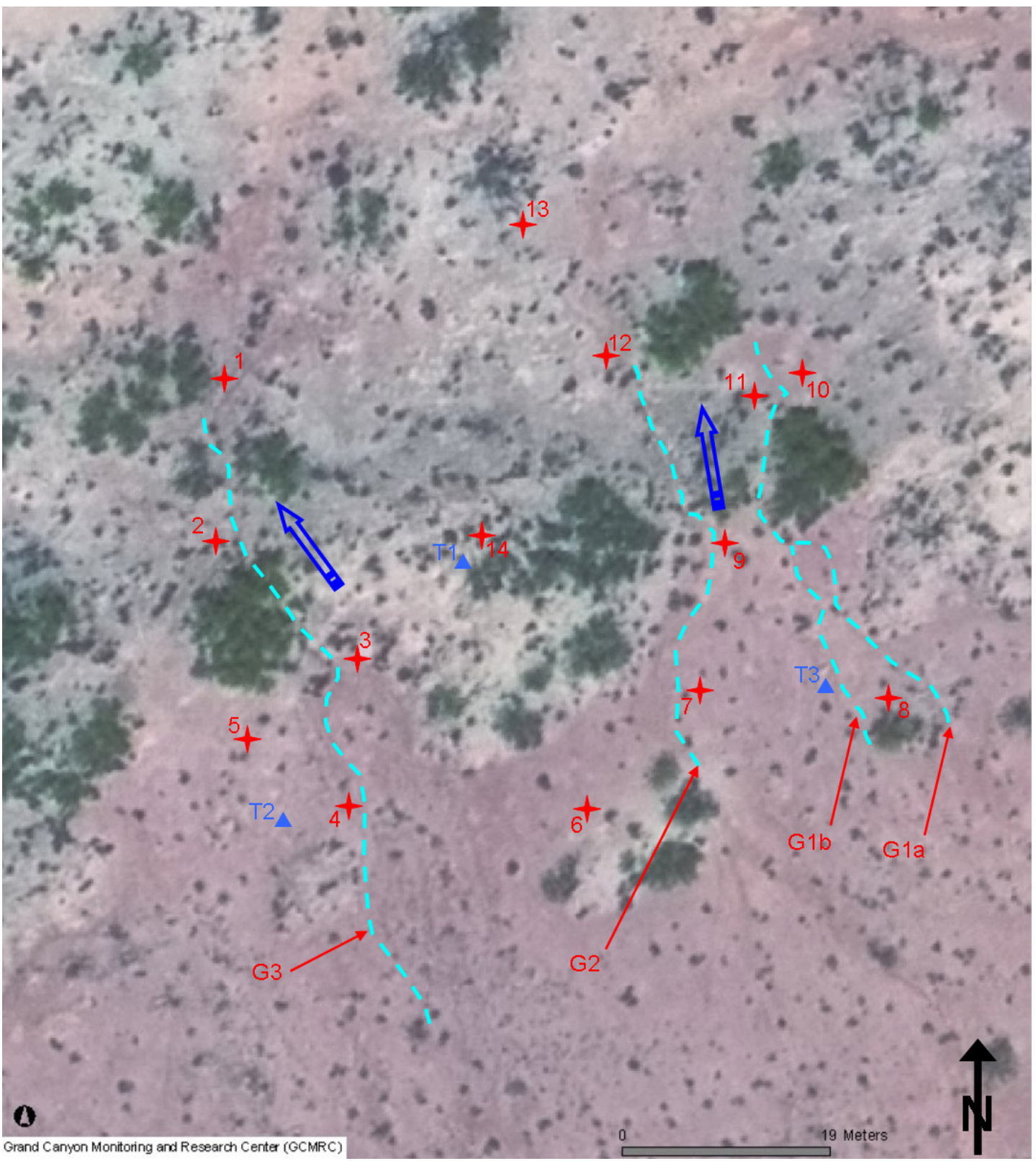

Figure 27. Site AZ:C:13:348 area showing main gullies (dashed lines), general downhill flow direction (blue arrows), and laser scan (red crosses) and laser control point (blue triangles) locations. 
wooden framework with mud. Given the surface proximity of the structural remains, it is thought that some structures extend below the current ground level. The area is also dense with surface artifacts, consisting mainly of sherds, although complete arrowheads have also been found.

Because of data collection (software) problems in May 2006, surface comparisons between May 2006 and May 2007 were performed on only a smaller area of the site $\left(920 \mathrm{~m}^{2}\right.$; table 2) containing a single gully (G3). The May 2007 to September 2007 surface comparison was performed on a larger area $\left(3,020 \mathrm{~m}^{2}\right)$ containing all three gullies.

The surface comparison between May 2006 and May 2007 shows that no identifiable change occurred throughout the site. The average distance between the two modeled surfaces is $0.4 \mathrm{~cm}$ with a standard deviation of $3.3 \mathrm{~cm}$. The $2 \sigma$ confidence intervals (about 95 percent) are therefore $-6.2 \mathrm{~cm}$ and $7.0 \mathrm{~cm}$ and are both within the vertical error bound estimates $( \pm 8 \mathrm{~cm})$. Analysis of the surface change histogram distribution (not shown) identified only 2.1 percent of the data outside these error bounds; we associated this entirely with lack of overlapping data due to vegetation shadows.

The surface comparison between May 2007 and September 2007 identifies two small areas associated with gullies G1 and G2 that may have eroded during this time (figs. 29 and 30). The majority of the site was unchanged. The average distance between the two modeled surfaces is $-0.9 \mathrm{~cm}$ with a standard deviation of $2.5 \mathrm{~cm}$. The $2 \sigma$ confidence intervals (about 95 percent) are $-5.9 \mathrm{~cm}$ and $4.1 \mathrm{~cm}$, both well within
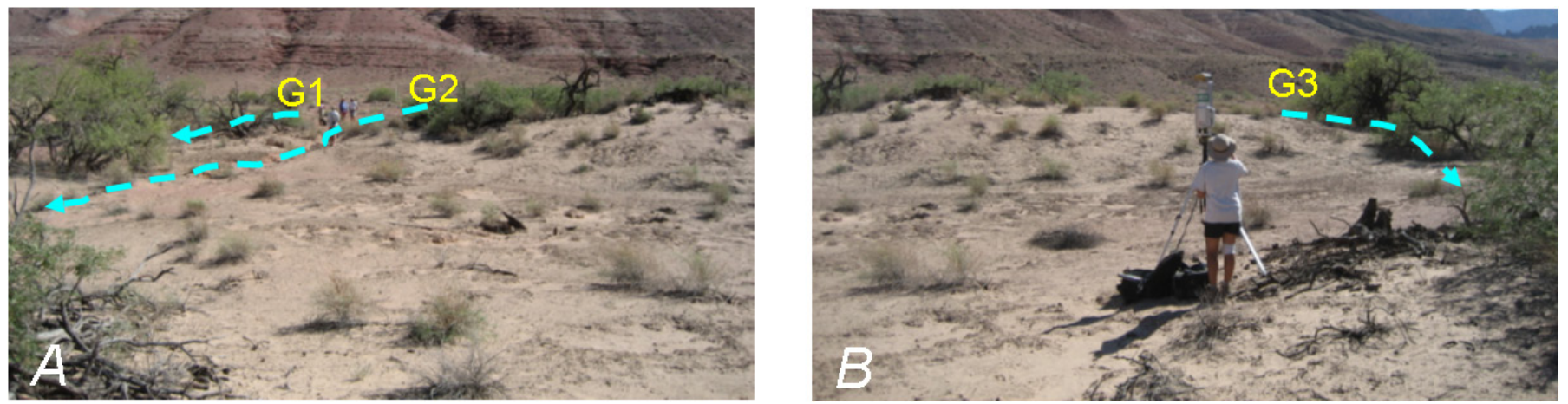

Figure 28. Site $\mathrm{AZ}: \mathrm{C}: 13: 348$ area showing gully locations (dashed lines): $A, \mathrm{G} 1$ and $\mathrm{G} 2 ; B, \mathrm{G} 3$.
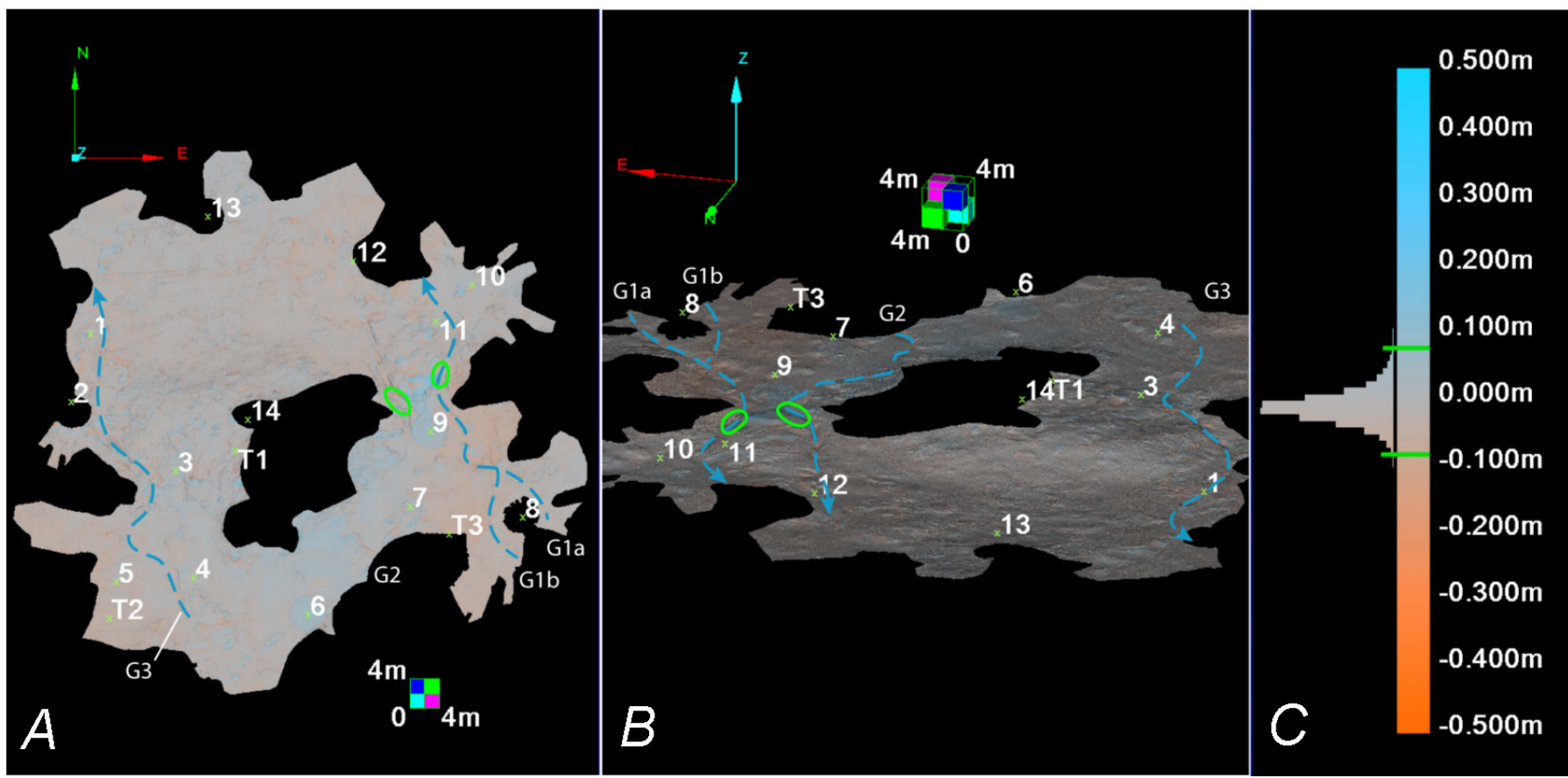

Figure 29. Site AZ:C:13:348 - 5-cm triangulated irregular network (TIN) output showing relative magnitude of surface comparison from May 2007 to September 2007. Laser scan and control point locations coincide with figure 27. Two small areas of possible erosion were identified in gullies $\mathrm{G} 1$ and $\mathrm{G} 2$ (ovals). $A$, plan view; $B$, oblique view; and $C$, vertical change histogram distribution and color scale. 
the vertical error bound estimates $( \pm 8 \mathrm{~cm})$. From the histogram distribution (fig. 29C) only 0.7 percent of the area is outside the range of error bounds. Analysis of these areas shows that with the exception of two small areas, the majority of the presumed detected change areas was due to difficult-to-filter vegetation.

The two areas of erosion are each very small (about $\left.0.2 \mathrm{~m}^{2}\right)$ and near the detectable change limits $( \pm 8 \mathrm{~cm})$ of this study. Although comparative photos from May 2007 are not available, photos from September 2007 indicate the likelihood of erosion in these areas (fig. 31). However, given the small footprint of the areas and the proximity of the detected change to the error bound estimates, we were not able to definitely identify these as erosion areas. We identify them here as possible locations for future monitoring. If erosion is occurring, we propose it is caused either by surface-water sediment transport or trailing from the use of these gullies as access routes by archeologists and geomorphologists.

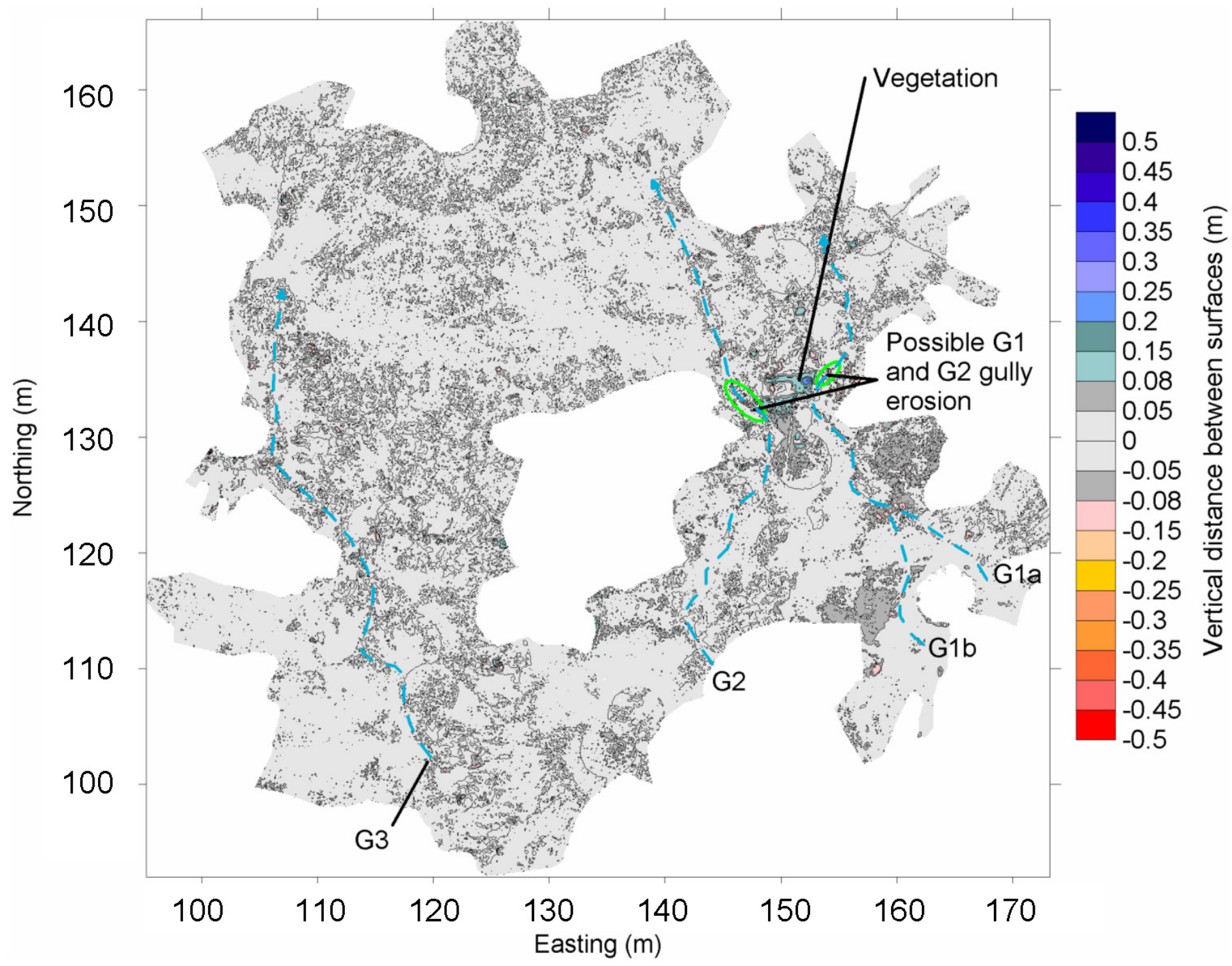

Figure 30. Site AZ:C:13:348 - 10-cm gridded output showing erosion (red, negative) and deposition (blue, positive) from May 2007 to September 2007 and approximate gully locations (dashed lines). Two small areas of possible erosion (ovals) were identified in gullies G1 and G2. 

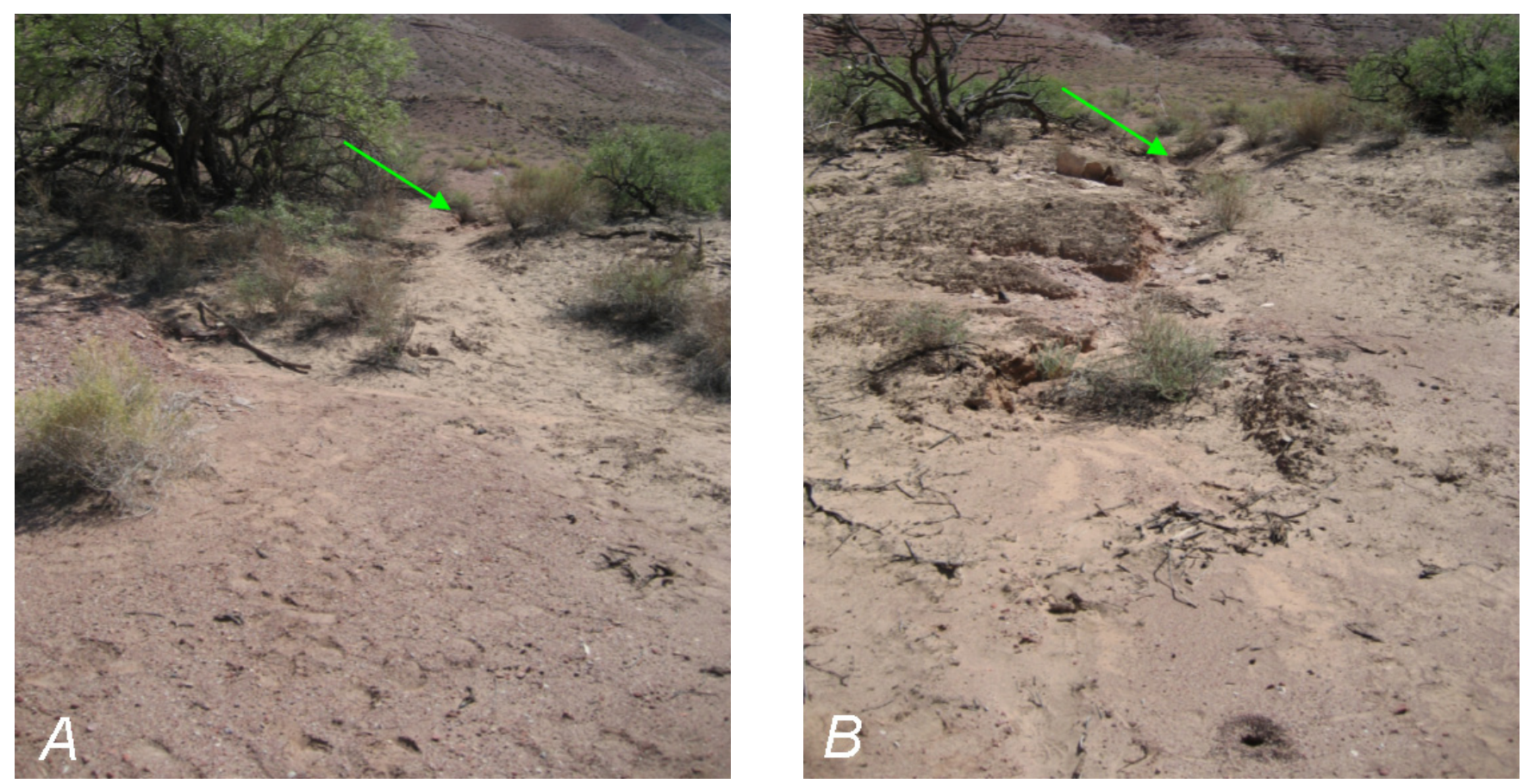

Figure 31. Site AZ:C:13:348 — Images of $(A)$ gully $G 1$ and $(B)$ gully $G 2$ from September 2007 showing possible locations (arrows) of minor (about $8 \mathrm{~cm}$ ) erosion.

\section{Site AZ:G:03:041}

Site AZ:G:03:041 is located in an area of slope wash deposits covered by aeolian sands. The site contains evidence of prehistoric habitation and includes roasting pit features, associated fire-cracked rock, and sparse but identifiable lithic objects. Roasting pits are more generally found in the lower, western portion of Grand Canyon and are often associated with protohistoric and prehistoric occupations (about A.D. 1500 to 1850) although this site has not been precisely dated (Fairley and others, 1994).

A large arroyo, several meters in width with bank height of about 1 to $2 \mathrm{~m}$, is located immediately downstream from this site and forms the main geomorphic feature of the area. In general, the site is flatter at its upper end, increasing in gradient as it drops down towards the Colorado River (fig. 32). Four small gullies (fig. 33) traverse the site, parallel in flow direction to the larger arroyo, and drain directly to the Colorado River. The gullies begin directly in the aeolian sediments (G1 and G2) or in the upper slope wash deposits (G3a and G3b) and cut directly through some of the roasting features at the site. A check dam has been built on one of the gullies (G1) to mitigate against further erosion. Pederson and others (2003) performed detailed geomorphic studies in this area to evaluate the erosion control effort.

Vegetation cover consists of a mix of both small grasses and shrubs and larger ocotillo (Fouquieria splendens), sagebrush (Artemisia species), cholla (Cylindropuntia acanthocarpa), and mesquite (Prosopis glandulosa var. torreyana). Overall, very few open, unvegetated areas are present, and in some cases the gullies themselves traverse the site through and under dense shrubs and trees.

Although comparison of the entire site $\left(1,380 \mathrm{~m}^{2}\right)$ was possible using the May 2006 and September 2007 data, only a smaller area $\left(1,000 \mathrm{~m}^{2}\right.$; table 2$)$ could be used for topographic change detection with the May 2007 data because of corrupt digital data files from six scan locations. This reduced the size of the final model for this survey effort by about 25 percent (table 2) and only topography for the two gullies farthest upstream (G1 and G2) could be analyzed with the May 2007 data.

Overall, little change occurred at this site except for an area of sand sheet deposition at the bottom of G2 (fig. 34). The statistics of the May 2006 to September 2007 surface comparison show an average distance between the two modeled surfaces of $2.6 \mathrm{~cm}$ with a standard deviation of $3.4 \mathrm{~cm}$. The $2 \sigma$ confidence interval range, representing 95 percent of the data, is $-4.2 \mathrm{~cm}$ to $9.4 \mathrm{~cm}$. Thus, only change associated with deposition is outside the error bound range ( \pm 8 $\mathrm{cm}$ ). According to the histogram distribution (fig. 34C), 5.0 percent (about $40 \mathrm{~m}^{2}$ ) of the area underwent more than $8 \mathrm{~cm}$ of vertical deposition and 0.5 percent (about $4 \mathrm{~m}^{2}$ ) of the area underwent more than $8 \mathrm{~cm}$ of erosion. Our analyses attribute all measured erosion to processing difficulties with removal of vegetation.

Observations and measurements indicate that the deposition occurred as a result of aeolian sand transport and covered an area of approximately $38 \mathrm{~m}^{2}$ at the bottom of G2 (fig. 35). Thus, this area accounts for nearly all the identified deposition from the histogram analysis. Volume calculations using the model surfaces indicate that $3.5 \mathrm{~m}^{3}$ of material was deposited in this region between May 2006 and September 2007. Additional analysis of all surfaces, along with photo interpretation (fig. 36), show that the deposition began between May 2006 and May 2007 to a maximum depth of $5 \mathrm{~cm}$ and then continued between May 2007 and September 2007 to a total average depth of $12 \mathrm{~cm}$. 


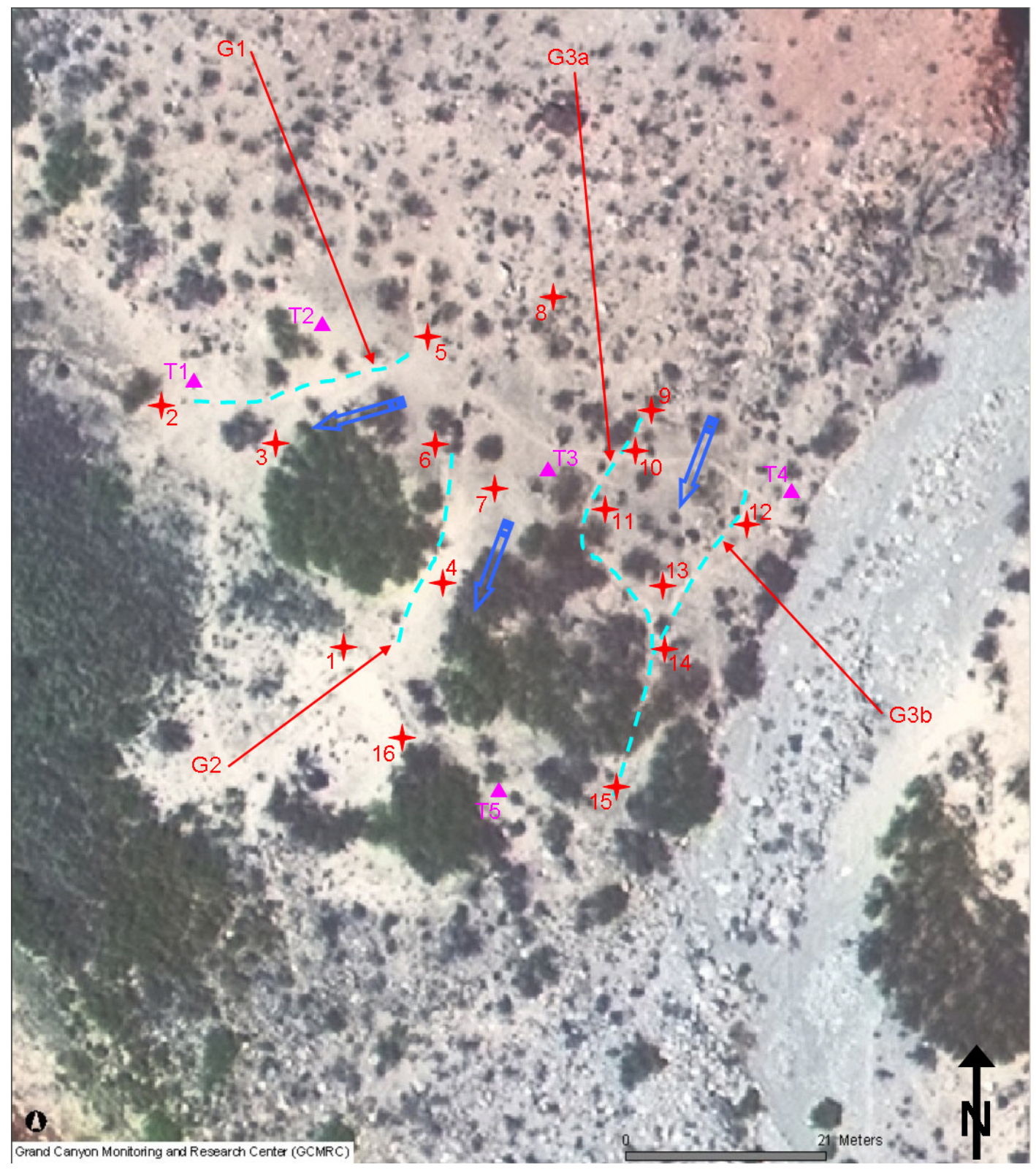

Figure 32. Site AZ:G:03:041 area showing main gullies (dashed lines), general downhill flow direction (blue arrows), and laser scan (red crosses) and laser control point (blue triangles) locations.
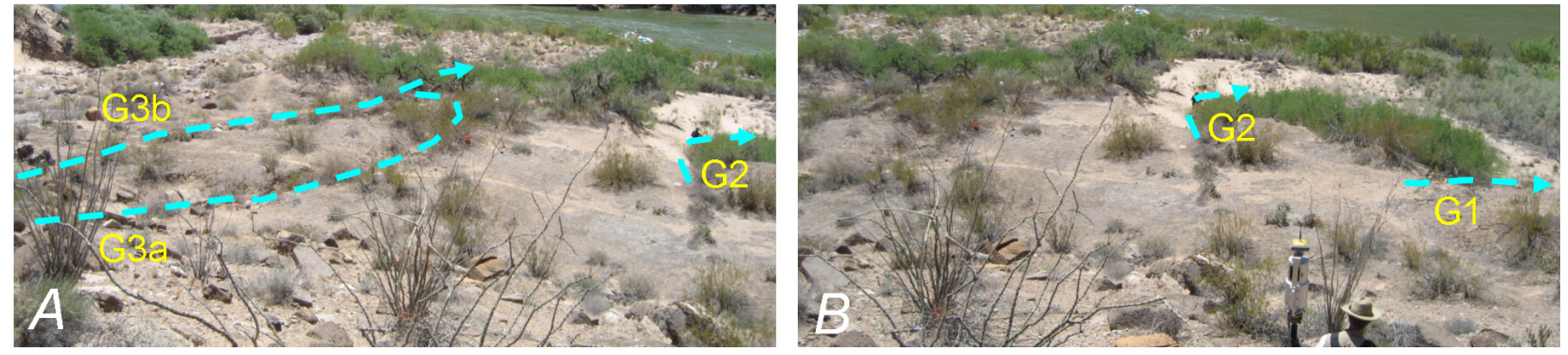

Figure 33. Site $A Z: G: 03: 041$ area showing gully locations (dashed lines): $A, G 3 b, G 3 a$, and $G 2 ; B, G 2$ and $G 1$. 


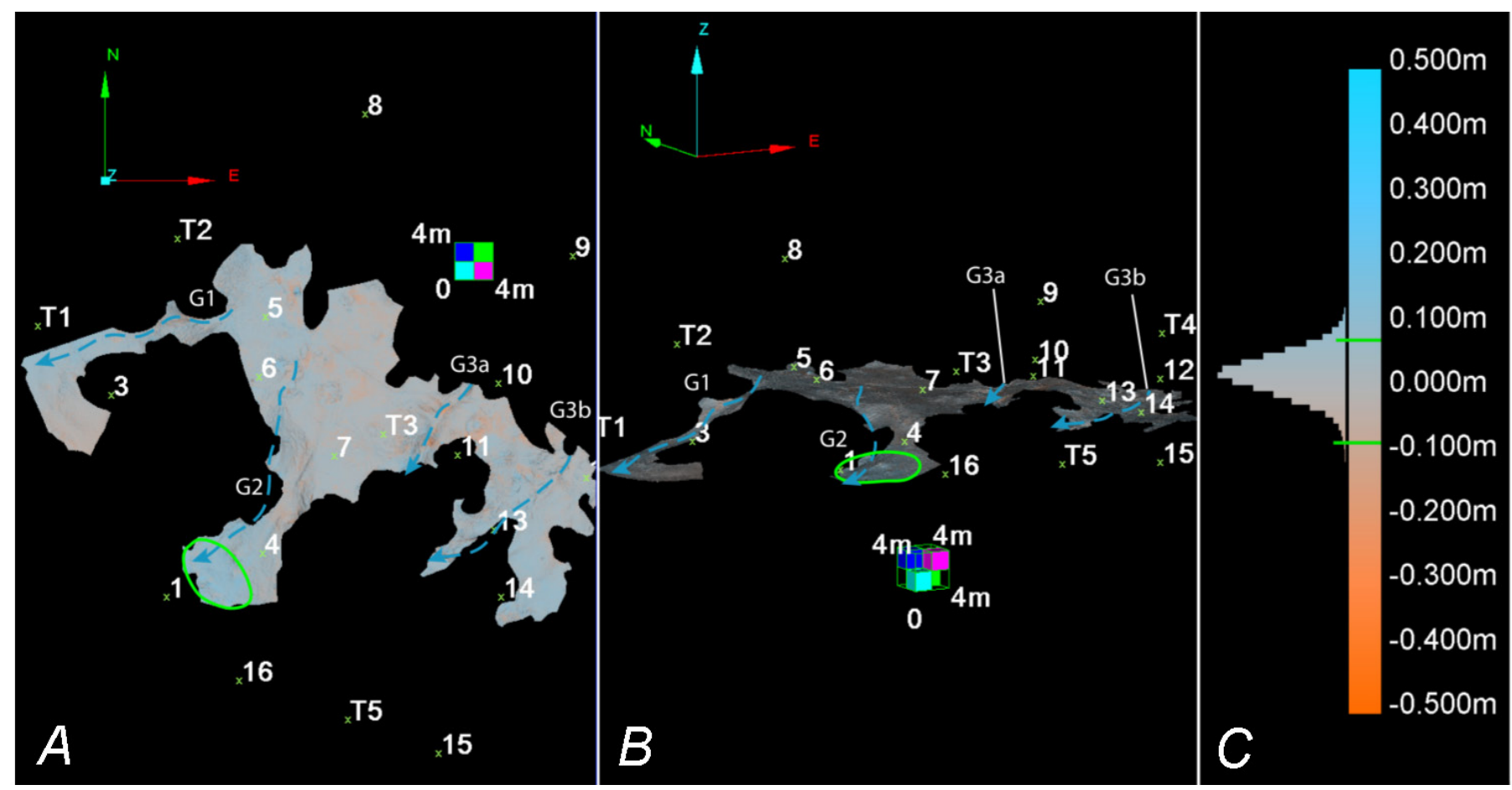

Figure 34. Site AZ:G:03:041-5-cm triangulated irregular network (TIN) output showing relative magnitude of surface comparison from May 2006 to September 2007. Laser scan and control point locations coincide with figure 32. One area of deposition at the base of G2 was identified (ovals). $A$, plan view; $B$, oblique view; and $C$, vertical change histogram distribution and color scale.

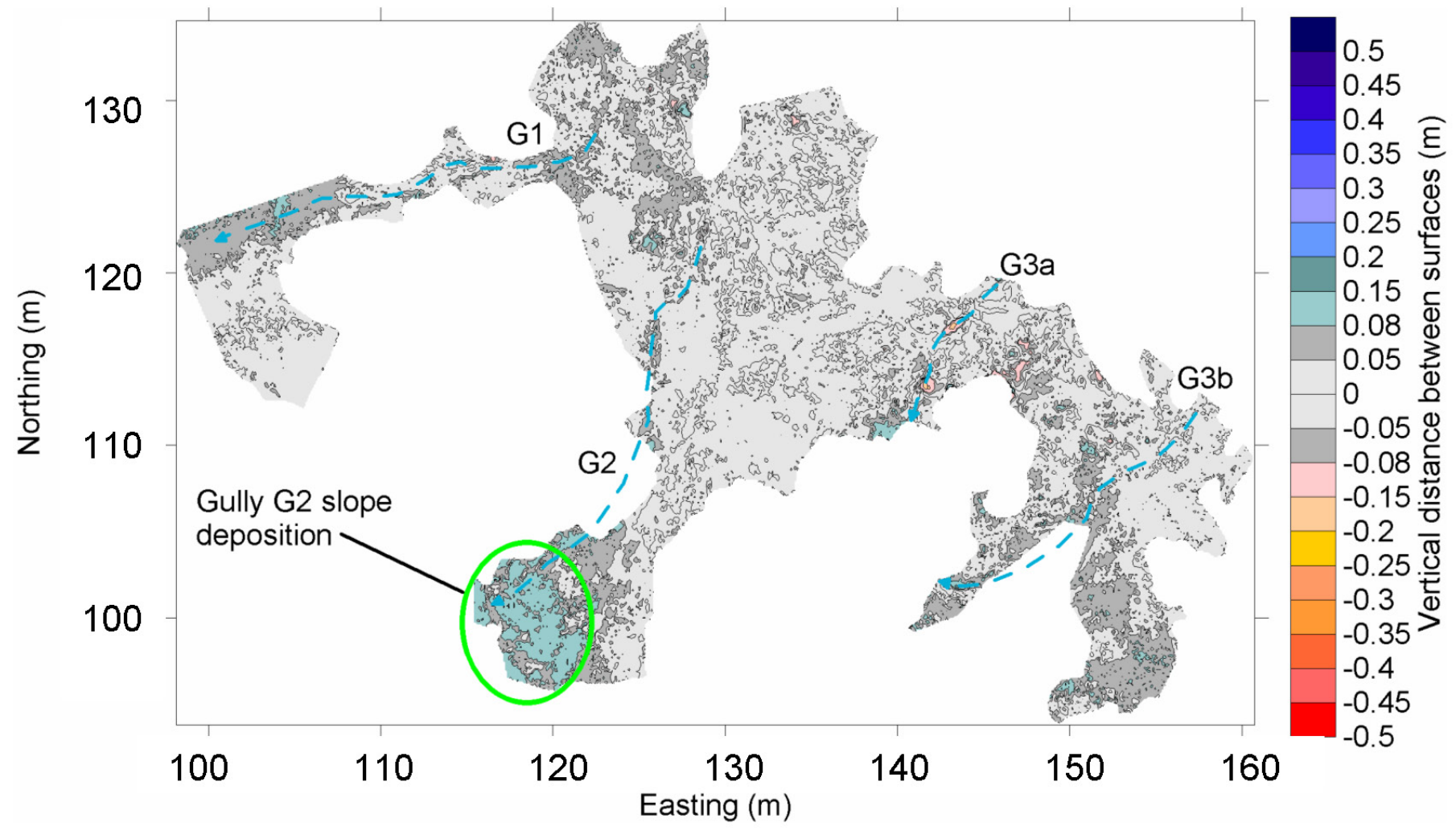

Figure 35. Site AZ:G:03:041 - 10-cm gridded output showing erosion (red, negative) and deposition (blue, positive) from May 2006 to September 2007 and approximate gully locations (dashed lines). One area of deposition at the base of gully G2 (oval) was identified. 

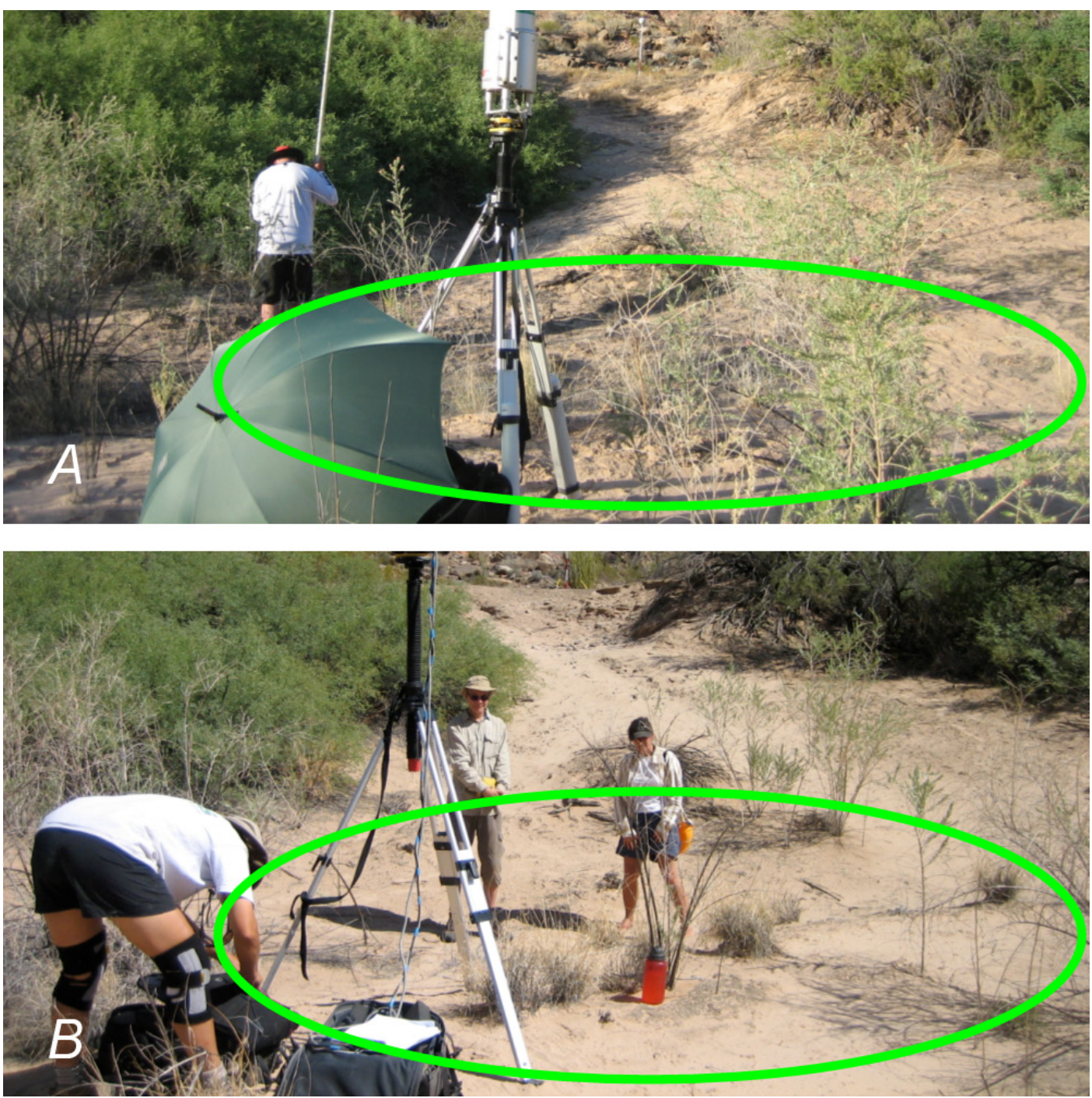

Figure 36. Site AZ:G:03:041—Images of gully G2 bottom slope area from $(A)$ May 2006 and $(B)$ September 2007 showing area of as much as $15 \mathrm{~cm}$ deposition (ovals). 


\section{Site AZ:G:03:002}

Site AZ:G:03:002 is located on a gently sloping alluvial terrace overlain with semistabilized aeolian sand deposits, as indicated by grasses and shallow (several centimeters) soil development (fig. 37). The terrace is located in a transition area between looser, fine-grained aeolian and alluvial deposits nearer to the river and coarser-grained slope wash derived from the canyon walls. The area contains evidence of protohistoric (A.D. 1500 to mid-1800) occupation by ancestors of Hualapai and Southern Paiute peoples. The occupation areas have been recorded by archeologists as two separate sites, although the division between the two sites is not distinct (Fairley and others, 1994). Archeological remains include several large roasting pit features in which charcoal and firecracked rocks are abundant.

One main gully (G1) traverses the site and is joined in its upper section by a smaller side drainage (G2). The main gully is of relatively low gradient until reaching the border of the site and the intersection with much looser dune sands (fig. 38A). Here, the gully plunges two meters through the sands (fig. 38B), forming a sizeable knickpoint before continuing its course towards the river. With the knickpoint possibly progressing towards areas of archeologic sensitivity, the drainage channel has been lined with rock to help stop erosion. Vegetation cover on the upper terrace consists of large (several meters) diameter and relatively well spaced shrubs and mesquite trees (Prosopis glandulosa var. torreyana) with only

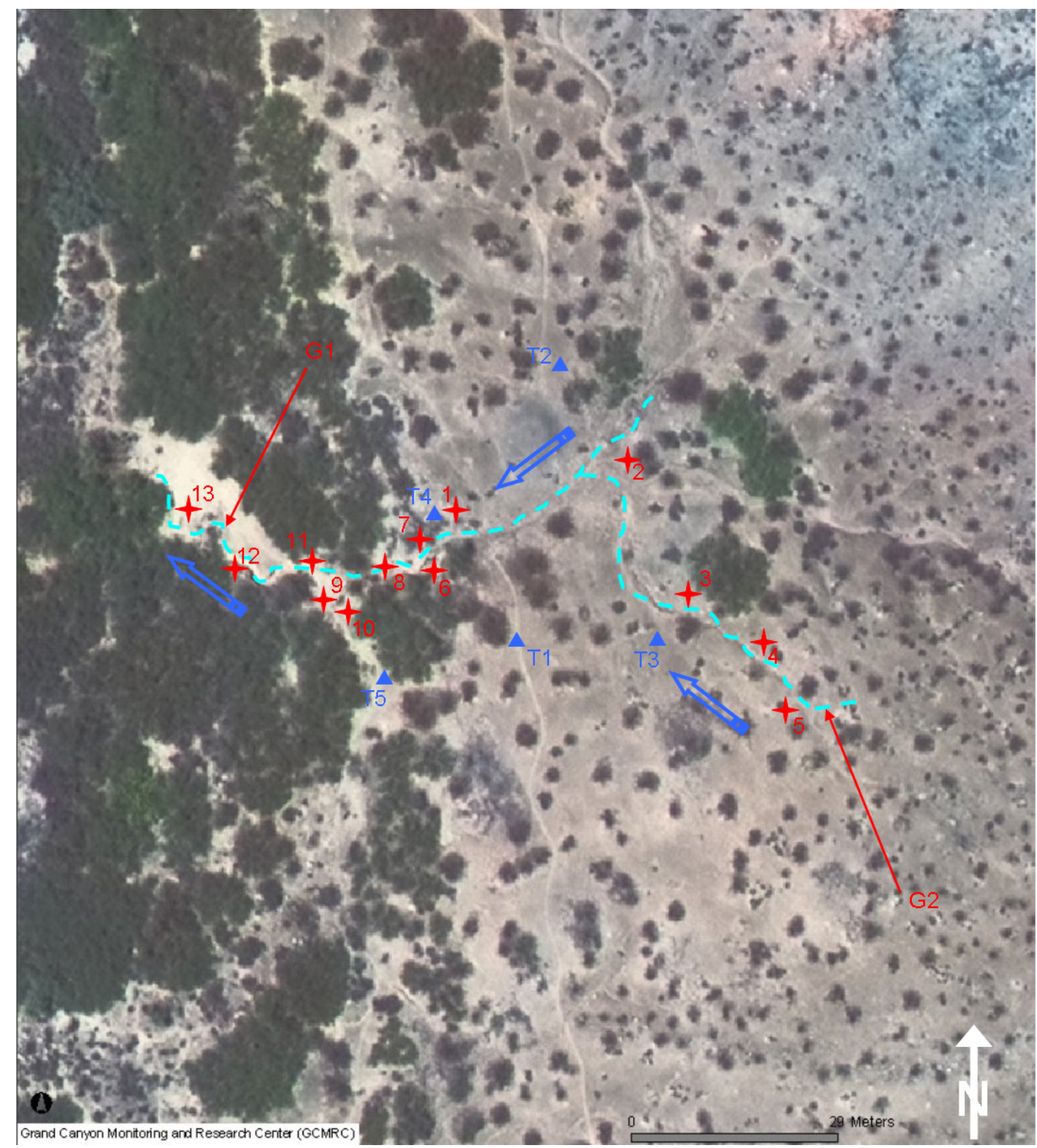

Figure 37. Site AZ:G:03:002 showing main gullies (dashed lines), general downhill flow direction (blue arrows), and laser scan (red crosses) and laser control point (blue triangles) locations. 

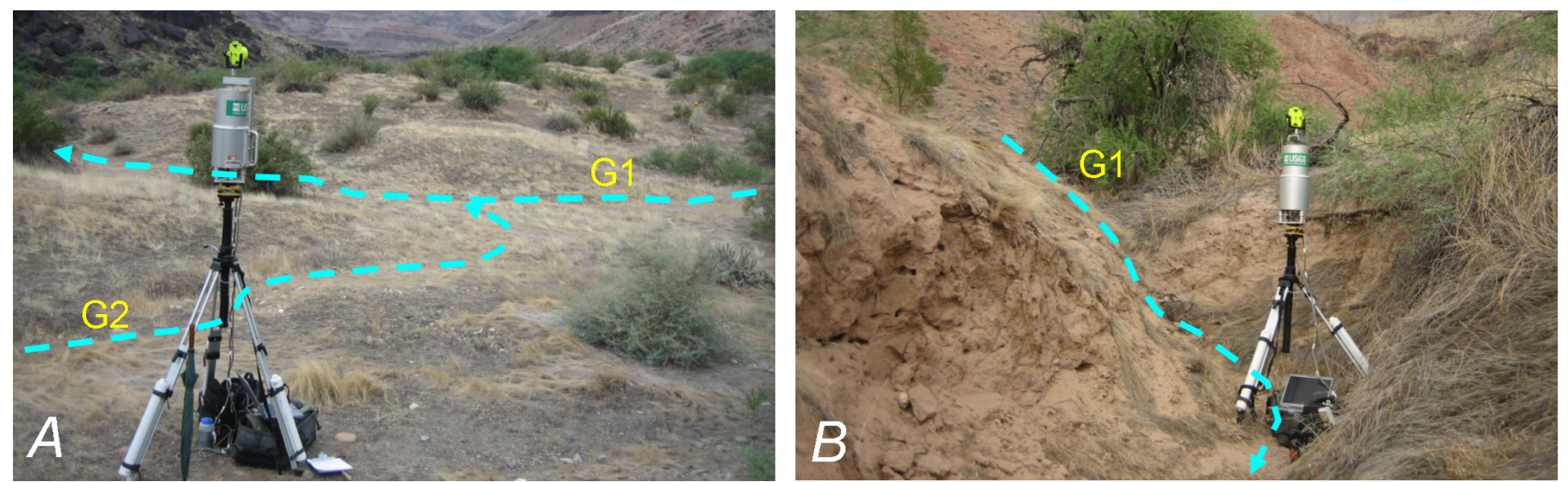

Figure 38. Site AZ:G:03:002 area showing gully locations (dashed lines): $A$, upper $\mathrm{G} 1$ and $\mathrm{G} 2$; $t$, lower $\mathrm{G} 1$.
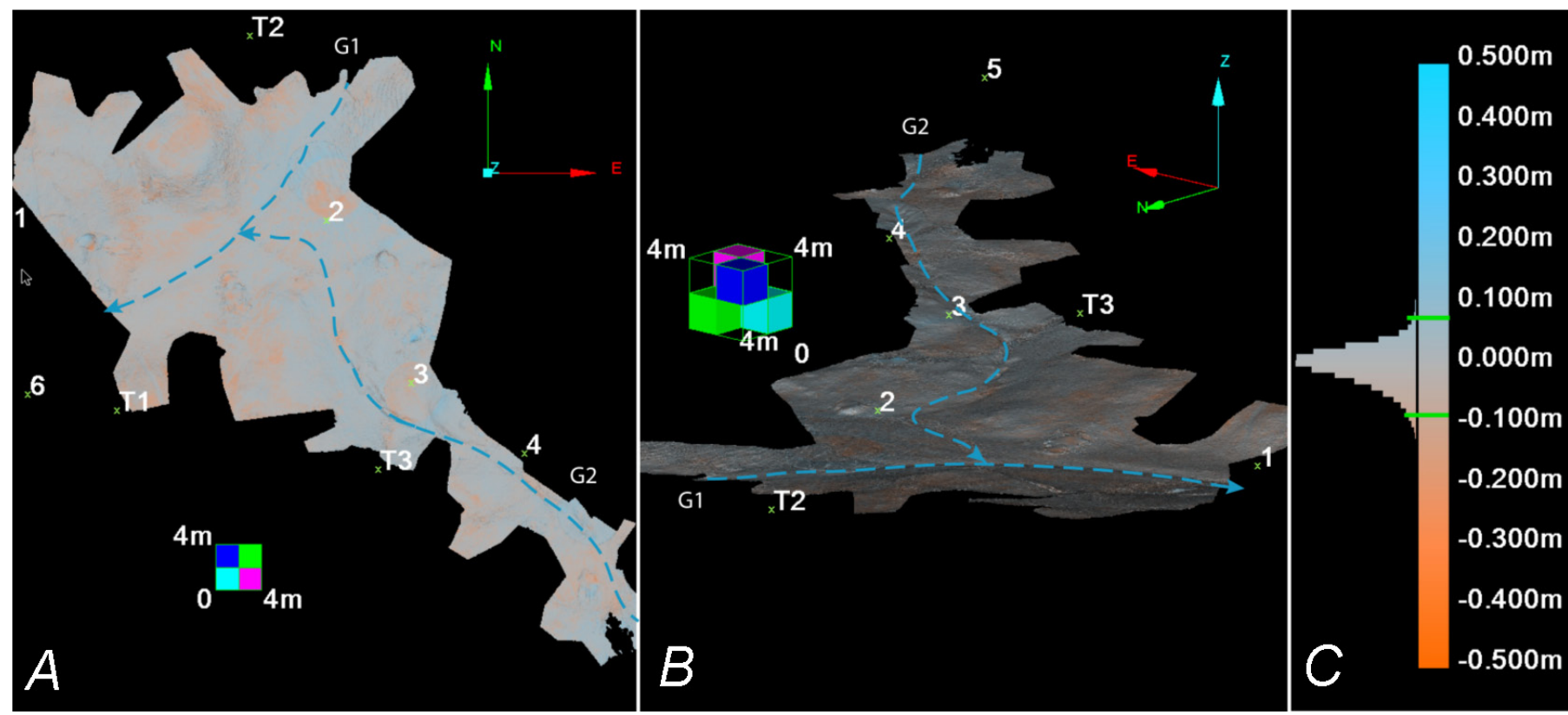

Figure 39. Site AZ:G:03:002 — 5-cm triangulated irregular network (TIN) output showing location and relative magnitude of surface comparison from May 2006 to September 2007 for the upper area. Laser scan and control point locations coincide with fig. 37. No significant topographic change was identified. $A$, plan view; $B$, oblique view; and $C$, vertical change histogram distribution and color scale.

minor smaller cacti. During the spring, grasses cover much of the site. Below the upper terrace and within the well-incised gully, vegetation becomes much denser and more riparian. In some places, it is not possible to walk between trees.

Although all three survey efforts allowed generation of detailed site topography models, the dense vegetation and narrow dimensions of the lower section of G1 prevented construction of complete surface models of this lower area. In many places, the lower gully is only $1.5 \mathrm{~m}$ wide, less than the 2-m minimum range required by the lidar unit. Vegetation grows very close to the edges of the gully, preventing the location of scan positions from farther away. As a result, the surface models we present here only examine topographic changes in the upper part of the site (scan locations 1 through
5; fig. 37). In the lower section (scan locations 6 through 13), we investigated changes by comparing only a smaller selection of manually filtered points that we could positively correlate with ground topography.

We found no statistically significant change in the upper gully area between May 2006 and September 2007 (fig. 39). Although the results indicate some minor, scattered erosion towards the boundary of the site (fig. 40), we attribute this to a coarser alignment of scan clouds caused by a lack of survey data for some scan locations during the May 2006 effort. Analysis of the May 2006 to May 2007 and May to September 2007 surfaces confirmed this analysis. The statistics of the May 2006 to September 2007 surface comparison calculate an average distance between the two modeled surfaces 


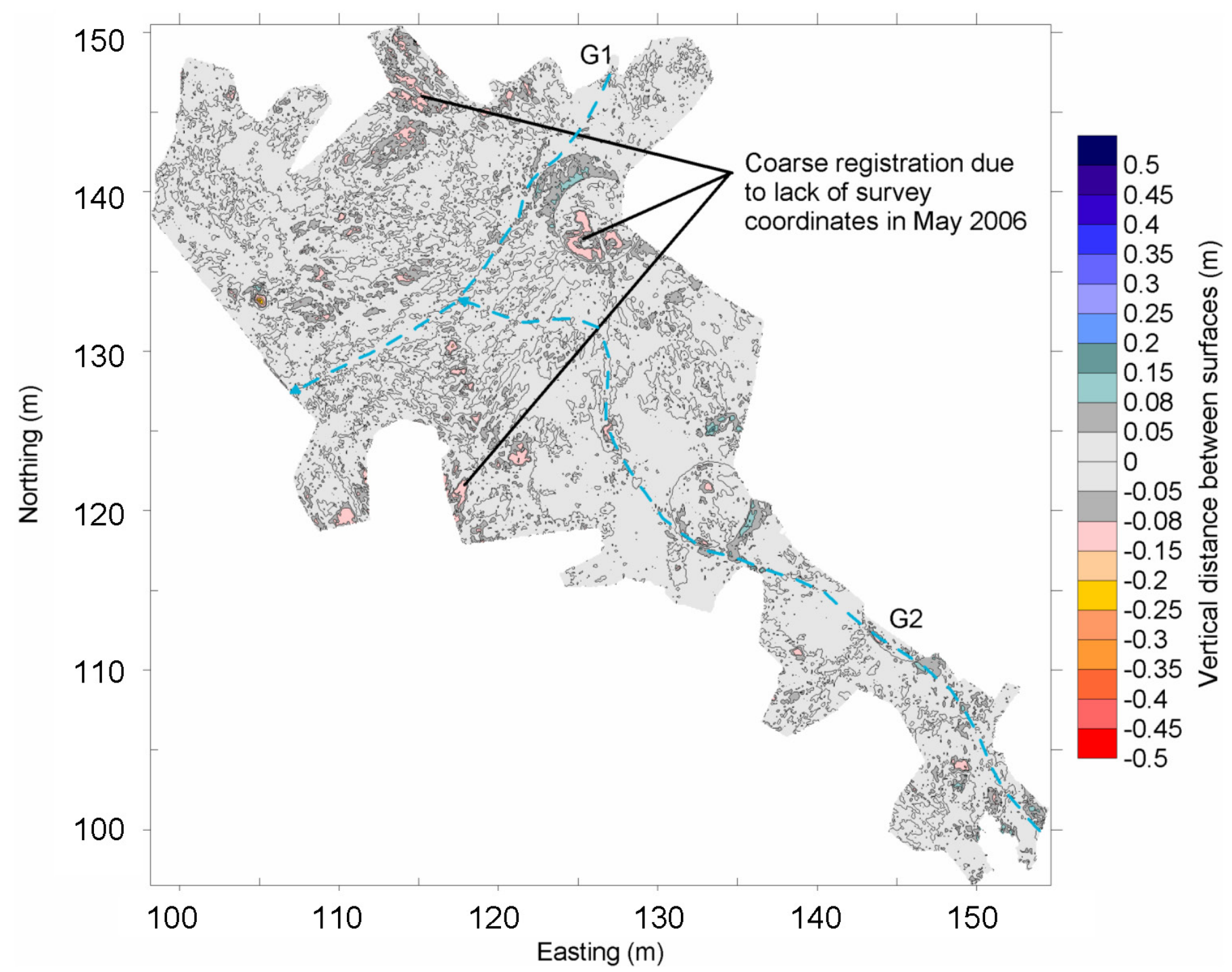

Figure 40. Site AZ:G:03:002-10-cm gridded output showing erosion (red, negative) and deposition (blue, positive) from May 2006 to September 2007 and approximate gully locations (dashed lines). No significant topographic change was identified. "Erosion areas" were attributed to poor registration of some areas of the May 2006 data as indicated.

of $0.1 \mathrm{~cm}$ with a standard deviation of $3.2 \mathrm{~cm}$ (fig. 39). The $2 \sigma$ confidence interval range, representing 95 percent of the data, is $-6.3 \mathrm{~cm}$ to $6.5 \mathrm{~cm}$. Thus, the vast majority of the data is within the error bound range $( \pm 8 \mathrm{~cm})$. According to the histogram distribution (fig. 39C), 0.5 percent (about $5 \mathrm{~m}^{2}$ ) of the area underwent more than $8 \mathrm{~cm}$ of vertical deposition and 1.8 percent $\left(18.4 \mathrm{~m}^{2}\right)$ of the area underwent more than $8 \mathrm{~cm}$ of erosion. As discussed, our analyses indicate that none of this change is statistically significant.

Our analysis of the point data in the lower gully area yielded no statistically significant change with the exception of one minor area. However, given the difficulties associated with the data collection in this narrow area and our inability to model the entire lower area effectively, we do not include this measured change in our final site change results. We performed cross-section analysis on two sections of the drainage, one in the immediate vicinity of the major gully knickpoint and another in the lowest section as the gully transitions out of the loose sand deposits. One small $\left(<0.5 \mathrm{~m}^{2}\right)$ section in the knickpoint area appears to have undergone very minor channel sidewall slumping and related gully bottom deposition, with as much as $10 \mathrm{~cm}$ of erosion and related deposition at the gully bottom. Given poor registration of the May 2007 data in this area, we were not able to determine whether this change occurred before or after this time. In the lower transition area, all measured change was within the error bounds (fig. 41). Given the difficulties associated with the data collection in such narrow confines, this area may not be well suited for whole-site monitoring using the presented terrestrial lidar methods. Instead, future surveys should focus on specific sections of the gully, with longer range scanner setup vantage points. 

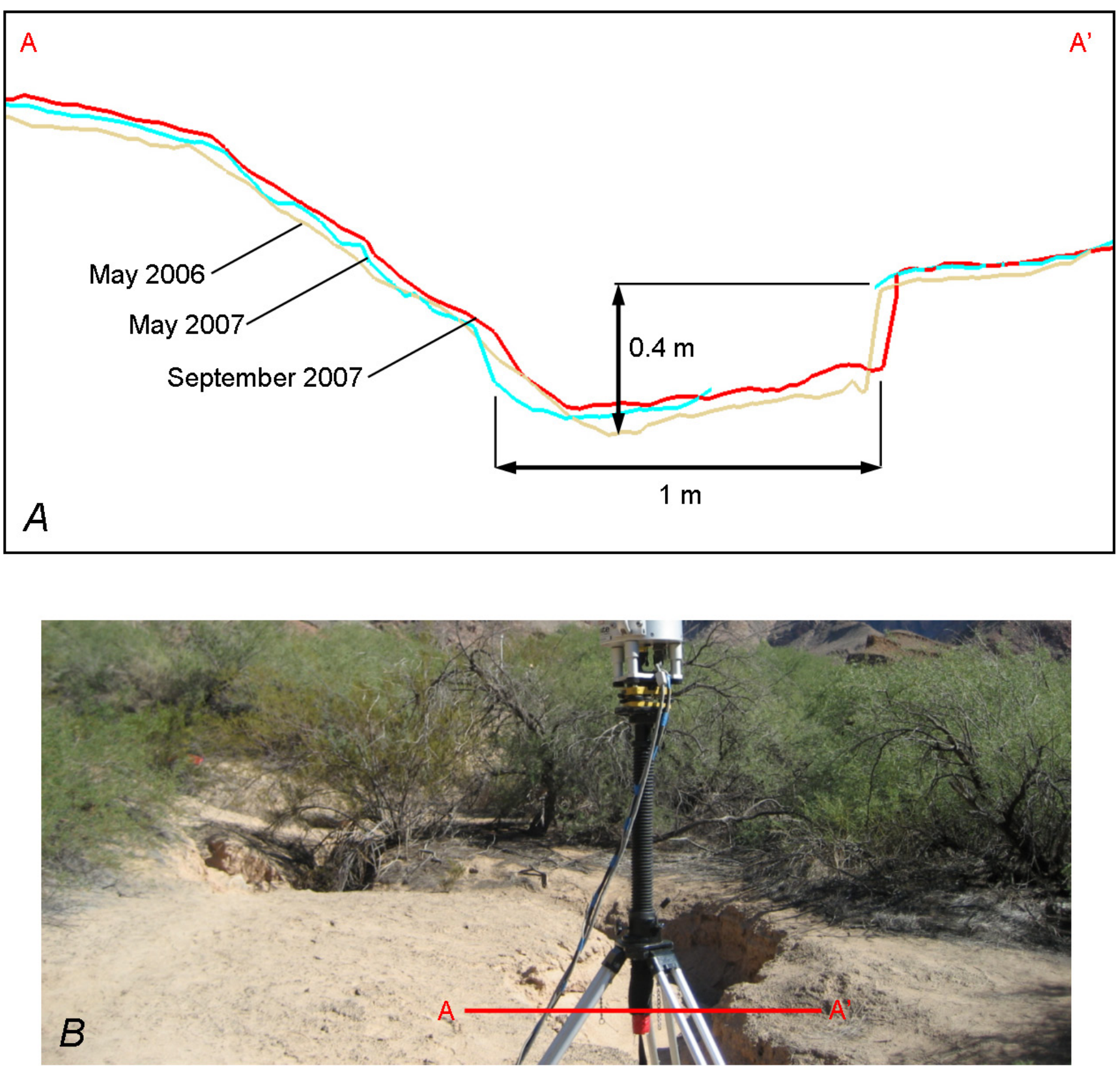

Figure 41. Site AZ:G:03:002- $A$, Cross-section analysis of lower $\mathrm{G} 1$ area from manual filtered point data. Average vertical distance between all sections is less than the error range $( \pm 8 \mathrm{~cm})$. $B$, Image showing cross-section location and narrow confines of this area. 


\section{Site AZ:G:03:072 US}

Site AZ:G:03:072 US (upstream) and site AZ:G:03:072 DS (downstream) form a single archeological site but were divided into two study areas (sites) because of their large spatial extent. The entire area is important as a prehistoric and protohistoric habitation site containing evidence of numerous roasting pits (Fairley and others, 1994). The sites are divided by a prominent large boulder-chocked drainage, and three small but well-developed gullies traverse each area (fig. 42). The downstream gullies are steeper in maximum gradient but generally show signs of less geomorphic activity due to incision to bedrock and better-stabilized soils. However, in many places, the archeological features are in close or direct proximity to the gullies, highlighting their vulnerability to future erosion and the importance of tracking topographic change.

Our observations indicate that the upstream site (AZ:G:03:072 US) consists of both active and stabilized aeolian dune areas. The gradient is generally constant over most of the site with the exception of several well-developed drainage knickpoints. Of the three gullies that cross this site, two are located in areas of generally stabilized vegetated and cryptobiotic crust (fig. $43 A, B$ ), although drainage knickpoints through the crust are visible in places and are the sites

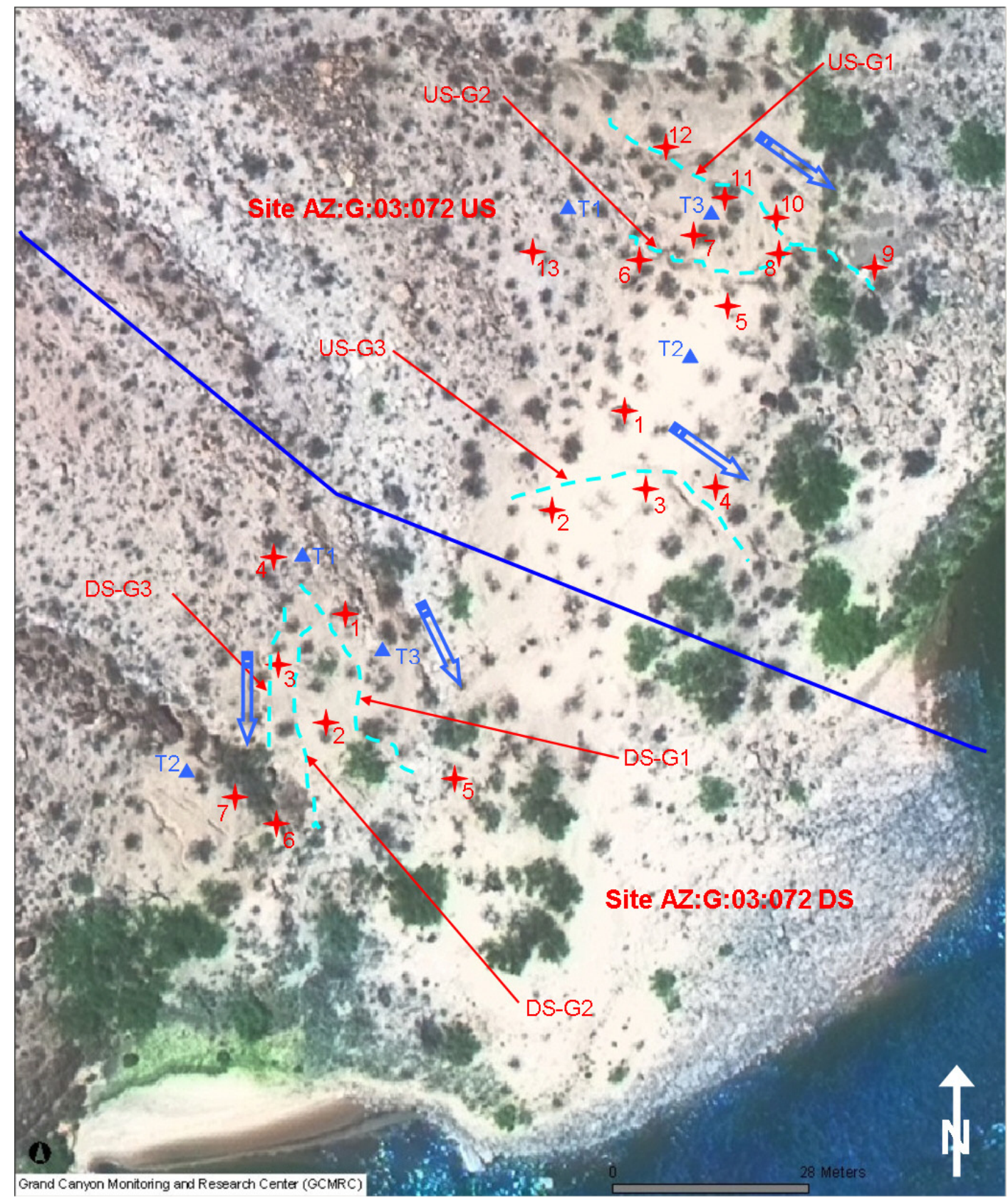

Figure 42. Site $A Z: G: 03: 072$ showing main gullies (dashed lines), general downhill flow direction, and laser scan (red crosses) and control point (blue triangles) locations for both upstream and downstream sites. 

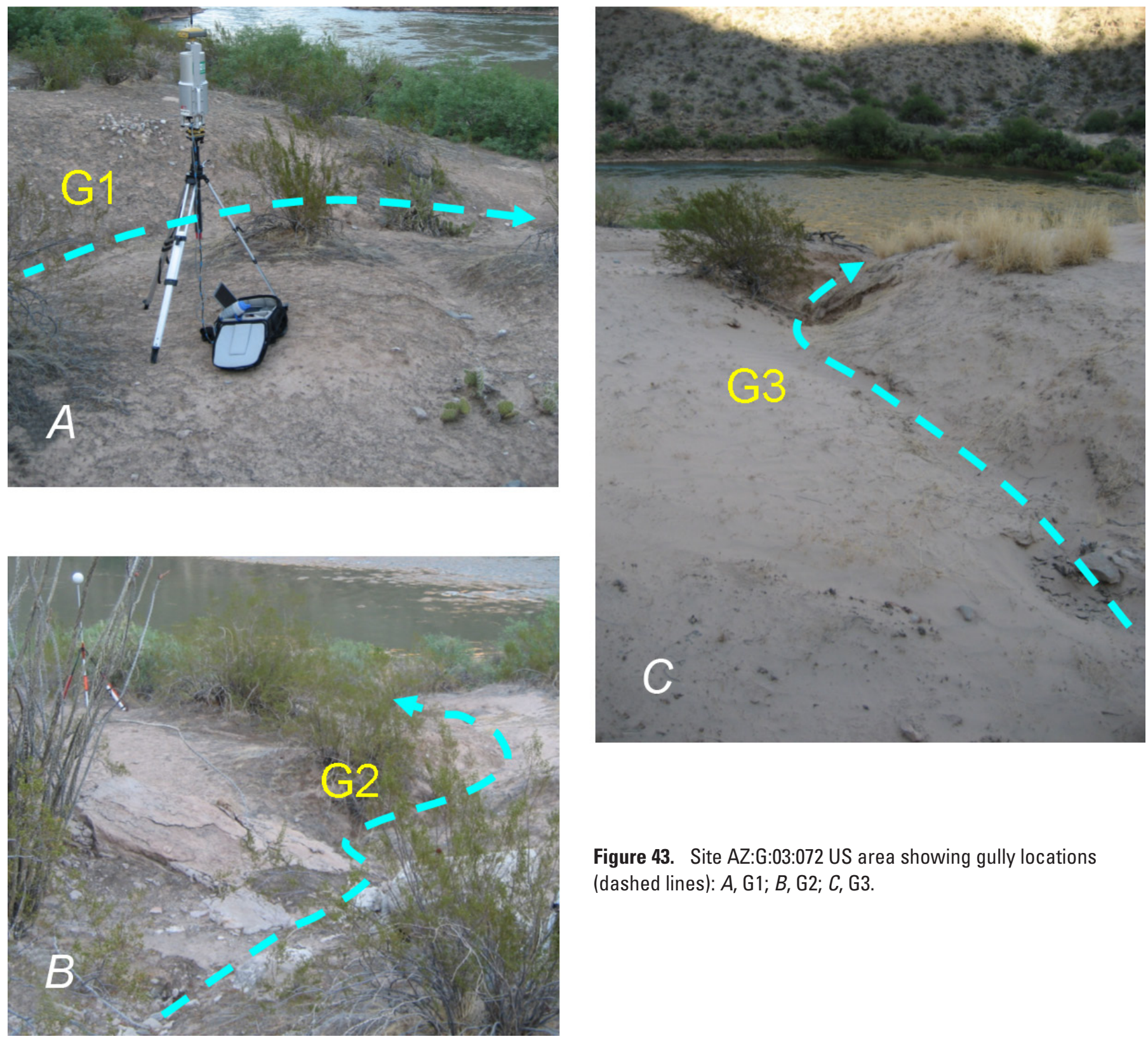

Figure 43. Site $A Z: G: 03: 072$ US area showing gully locations (dashed lines): $A, \mathrm{G} 1 ; B, \mathrm{G} 2 ; C, \mathrm{G} 3$.

of apparent recent erosion. The third is located in an area of active aeolian dune sand (fig. 43C); this gully appears to be actively downcutting through the dune field. All three gullies drain directly to the Colorado River which borders the site. Vegetation consists of clumps of grasses, smaller bushes, and prickly pear cactus (Opuntia basilaris), along with taller groups of ocotillo (Fouquieria splendens), cholla (Cylindropuntia acanthocarpa), and larger creosote (Larrea tridentata var. tridentata) and catclaw acacia (Acacia greggii) bushes several meters in height. Although vegetation generally clumps together, it is sufficiently dense to prevent line-ofsight visibility from one area to the next. Although individual gullies are sufficiently open to allow data collection, it is our opinion that this site is likely near maximum complexity for large-scale terrestrial lidar change detection studies.
Following the May 2006 data collection, we increased the number of scan locations and consequently the total area of scanning (table 2). During the subsequent May 2007 and September 2007 survey efforts, we saw visible change at identical locations within this site. As a result, we present separate change detection analyses for the May 2006 to May 2007 and May 2007 to September 2007 timeframes.

The May 2006 to May 2007 comparison shows only one area of significant topographic change linked to the headward erosion of G3 (figs. 44 and 45). The overall statistics indicate that the majority of the site did not undergo topographic change; the average distance between the two modeled surfaces is $1.1 \mathrm{~cm}$ with a standard deviation of $4.4 \mathrm{~cm}$. The $2 \sigma$ confidence interval range, representing 95 percent of the data, is therefore $-7.7 \mathrm{~cm}$ to $9.9 \mathrm{~cm}$. Thus, slightly more than 
5 percent of the data is outside the error bound range $( \pm 8 \mathrm{~cm})$. According to the histogram distribution (fig. $44 C$ ), 4.2 percent (about $37 \mathrm{~m}^{2}$ ) of the area underwent more than $8 \mathrm{~cm}$ of vertical deposition, but we attribute nearly all this change to processing difficulties with vegetation (fig 45). In terms of net erosion, the histogram distribution shows 2.5 percent of the total surface area (about $22 \mathrm{~m}^{2}$ ) underwent more than $8 \mathrm{~cm}$ of vertical erosion. Although some of this change is associated with processing difficulties with vegetation, the majority (13 $\mathrm{m}^{2}$ ) is linked to erosion and bank slumpage along an 11-m length of the drainage concentrated in and around gully G3 (fig. 45). The change is visible in both photo (fig. 46) and contour map (fig. 47) comparative analysis. Additional volumetric analysis between a best fit of the two surfaces in this region indicates a net sediment loss of $2.0 \mathrm{~m}^{3}$ from this area between May 2006 and May 2007.

The May 2007 to September 2007 comparison indicates that additional change occurred to this site and was distributed throughout the three gully areas. The overall surface comparison shows that the average difference between the two surfaces is $-0.9 \mathrm{~cm}$ with a standard deviation of $5.0 \mathrm{~cm}$. The $2 \sigma$ confidence interval range, representing 95 percent of the data, is therefore $-10.9 \mathrm{~cm}$ to $9.1 \mathrm{~cm}$. Thus more than 5 percent of the data is outside the error bound range $( \pm 8 \mathrm{~cm})$. The histogram distribution (fig. 48C) shows that 1.8 percent (about $22 \mathrm{~m}^{2}$ ) of the area underwent more than $8 \mathrm{~cm}$ of vertical deposition; however, we attribute nearly all of this change to processing difficulties with vegetation. In terms of net erosion, the histogram distribution (fig. 48C) shows 4.3 percent of the total surface area (about $52 \mathrm{~m}^{2}$ ) underwent more than $8 \mathrm{~cm}$ of vertical erosion. Although some of this change is associated with processing difficulties with vegetation, the majority $\left(30 \mathrm{~m}^{2}\right)$ is linked to erosion throughout the site and along all three gullies (fig. 49).

Five areas of erosion were identified. The first is located in a small length $(3.2 \mathrm{~m})$ of G1. Here, we measured an average of as much as $15 \mathrm{~cm}$ of erosion over a total area of $1 \mathrm{~m}^{2}$ (fig. 50) with maximum erosion of $20 \mathrm{~cm}$ and total sediment volume of $0.1 \mathrm{~m}^{3}$. In $\mathrm{G} 2$, we also measured an average of $15 \mathrm{~cm}$ of erosion over a longer length $(12.3 \mathrm{~m})$ and greater area $\left(2.5 \mathrm{~m}^{2}\right)$ with a total eroded sediment volume of $0.3 \mathrm{~m}^{3}$. Maximum erosion resulting in vertical lowering was about $25 \mathrm{~cm}$ (fig. 51). Two areas of erosion were identified outside of the gullies, one on a slope bordering G2 (fig. 52) and the other in an active sand dune area near G3 (fig. 53). At the slope near $\mathrm{G} 2$, a $3.2 \mathrm{~m}^{2}$ area underwent as much as $15 \mathrm{~cm}$ of erosion for a total eroded volume of $0.2 \mathrm{~m}^{3}$. At the G3 dune area, a $12.1-\mathrm{m}^{2}$ area also underwent as much as $15 \mathrm{~cm}$ of erosion and a total eroded volume of $0.8 \mathrm{~m}^{3}$. The final identified area of erosion was within the G3 channel (fig. 54), encompassing an $11.2 \mathrm{~m}^{2}$ area over a $28.4 \mathrm{~m}$ length of the drainage. Within this area, we measured maximum erosion depths of $50 \mathrm{~cm}$, averaging $25 \mathrm{~cm}$ over a 14-m-long section of the gully and shown by contour analysis in figure 55. Additional volumetric analysis of the two surfaces in this region indicates a net sediment loss of $4.7 \mathrm{~m}^{3}$ from this area between May 2007 and September 2007.
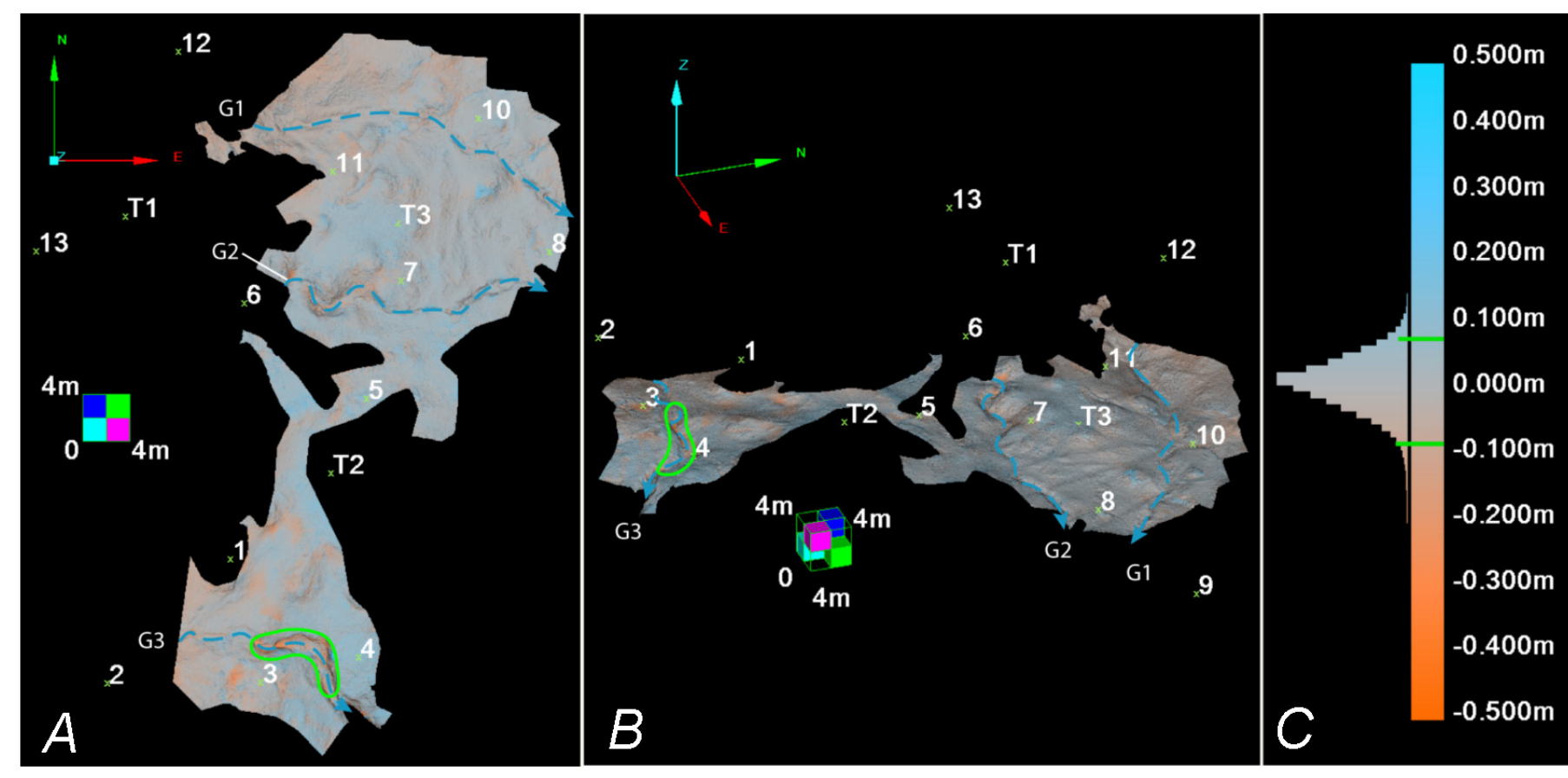

Figure 44. Site AZ:G:03:072 US—5-cm triangulated irregular network (TIN) output showing location and relative magnitude of surface comparison from May 2006 to May 2007. Laser scan and control point locations coincide with figure 42. Only one area of erosion (polygons) associated with gully $\mathrm{G} 3$ could be positively identified. $A$, plan view; $B$, oblique view; and $C$, vertical change histogram distribution and color scale. 


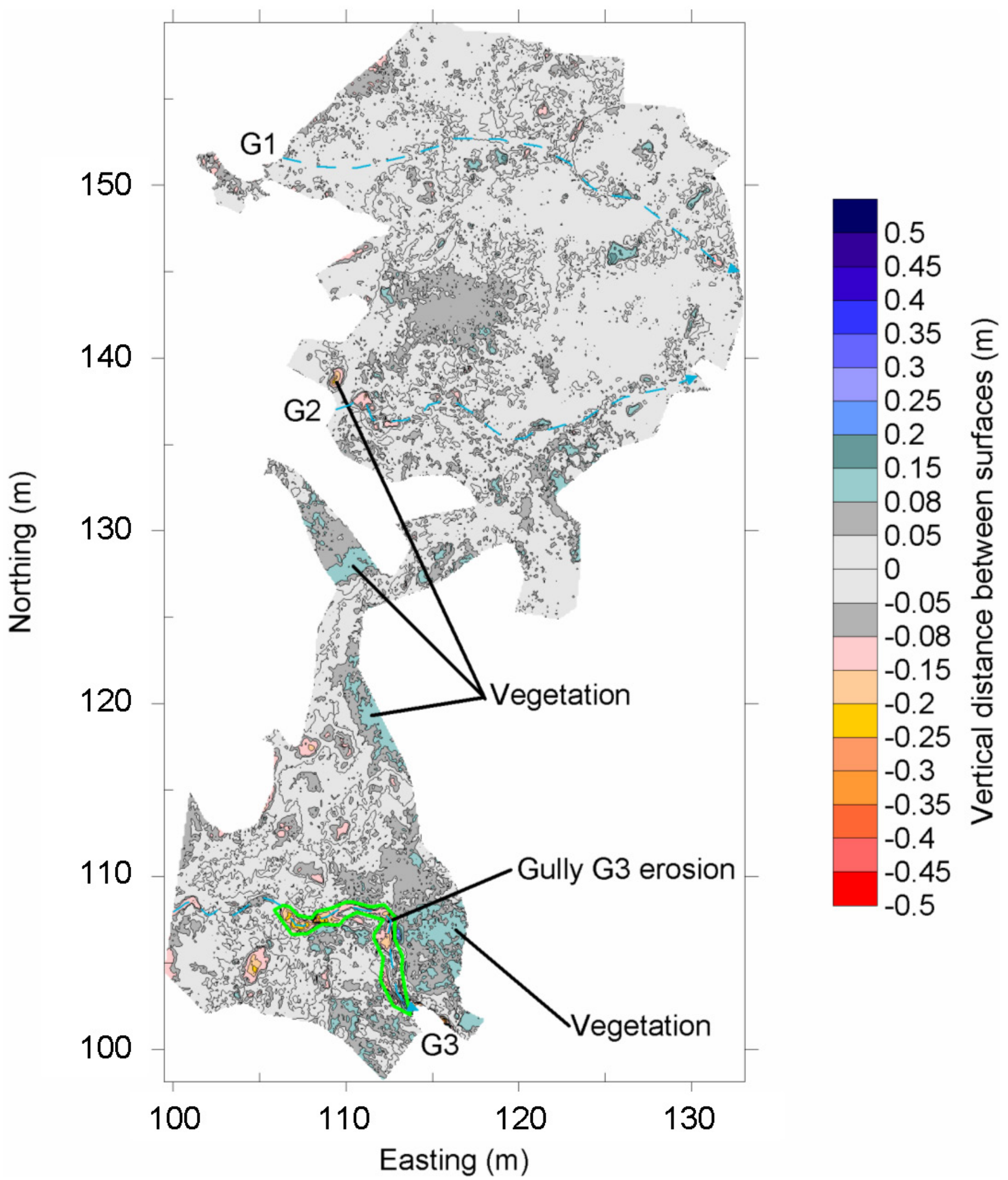

Figure 45. Site AZ:G:03:072 US—10-cm gridded output showing erosion (red, negative) and deposition (blue, positive) from May 2006 to May 2007 and approximate gully locations (dashed lines). Only one area of erosion (polygon) associated with gully G3 could be positively identified. 

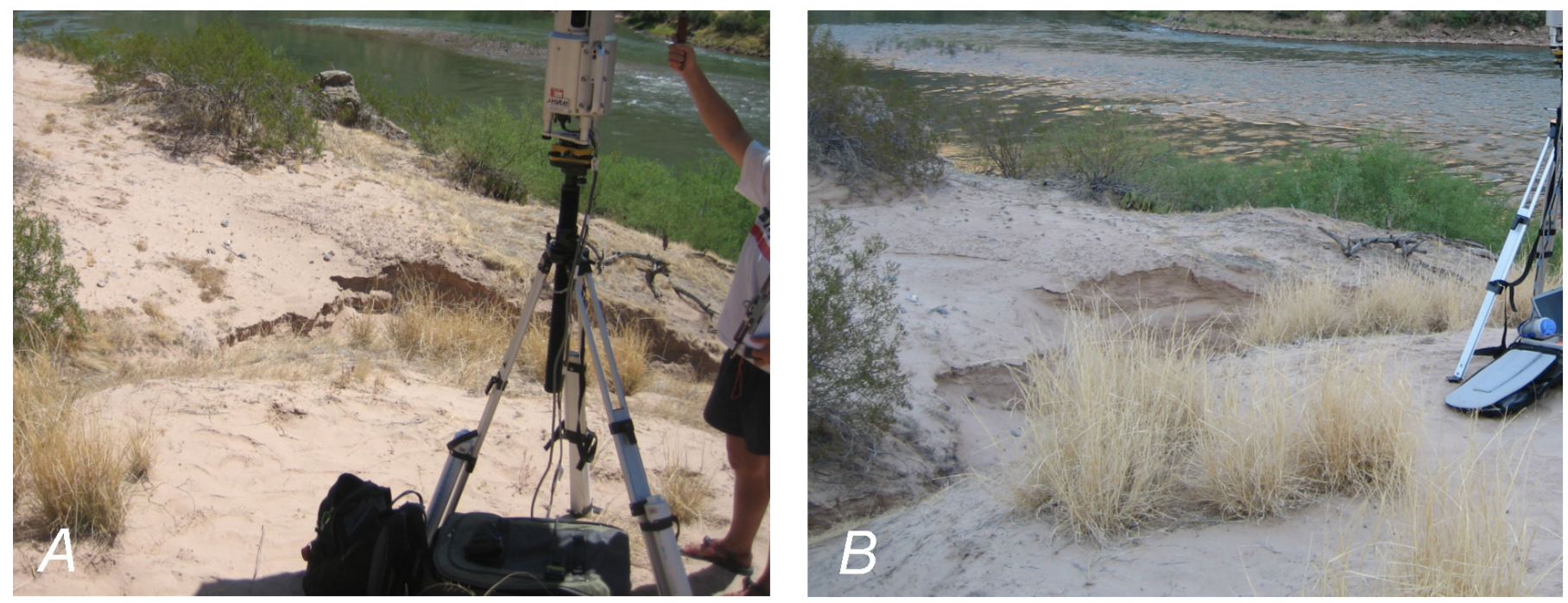

Figure 46. Site AZ:G:03:072 US_Photo comparison of G3 erosional area between ( $A$ ) May 2006 and (B) May 2007.
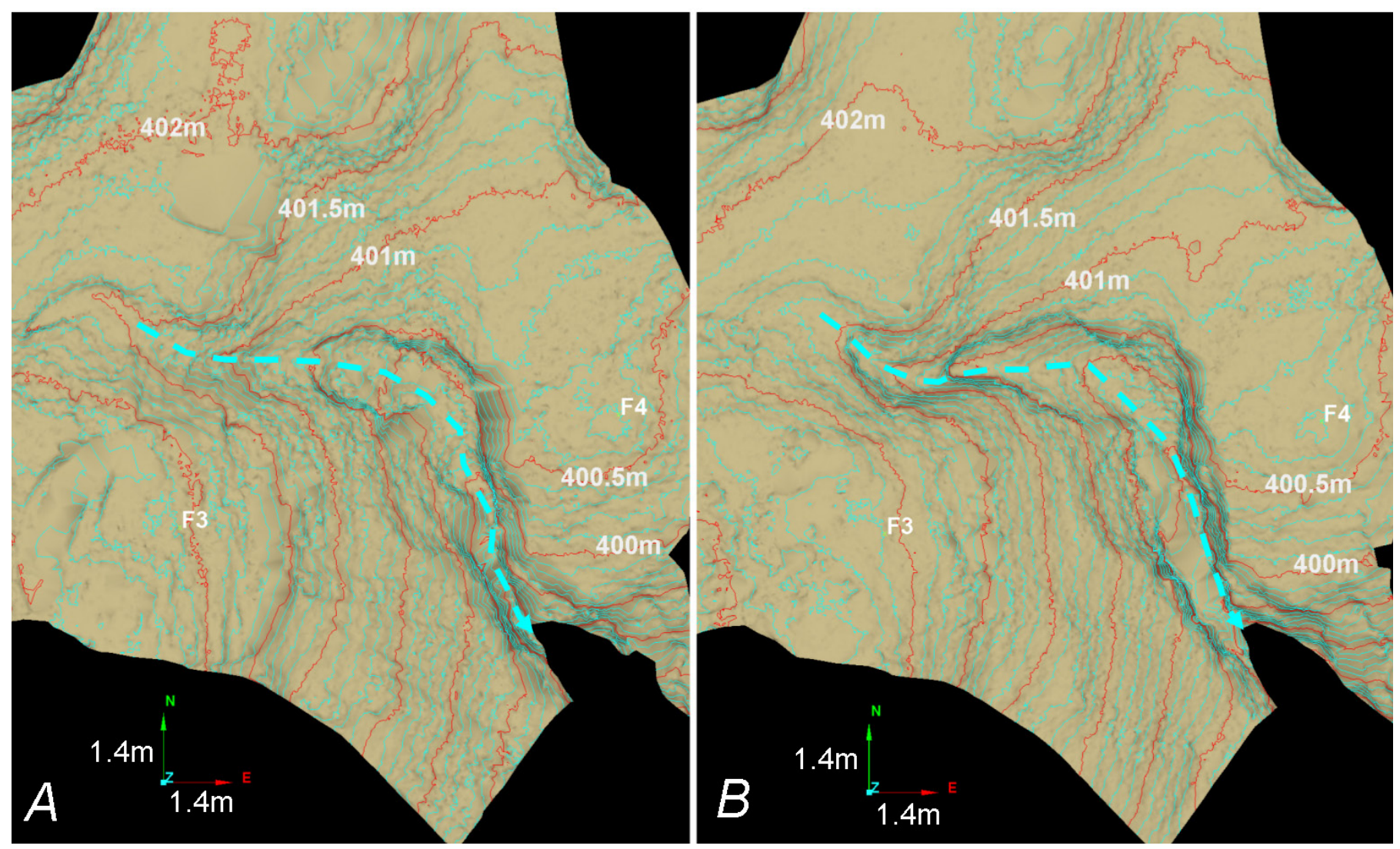

Figure 47. Site AZ:G:03:072 US—10-cm contour map comparison of G3 erosional area between ( $A$ ) May 2006 and (B) May 2007. Dashed line is approximate gully thalweg over the length of detected change (about $11 \mathrm{~m}$ ). 


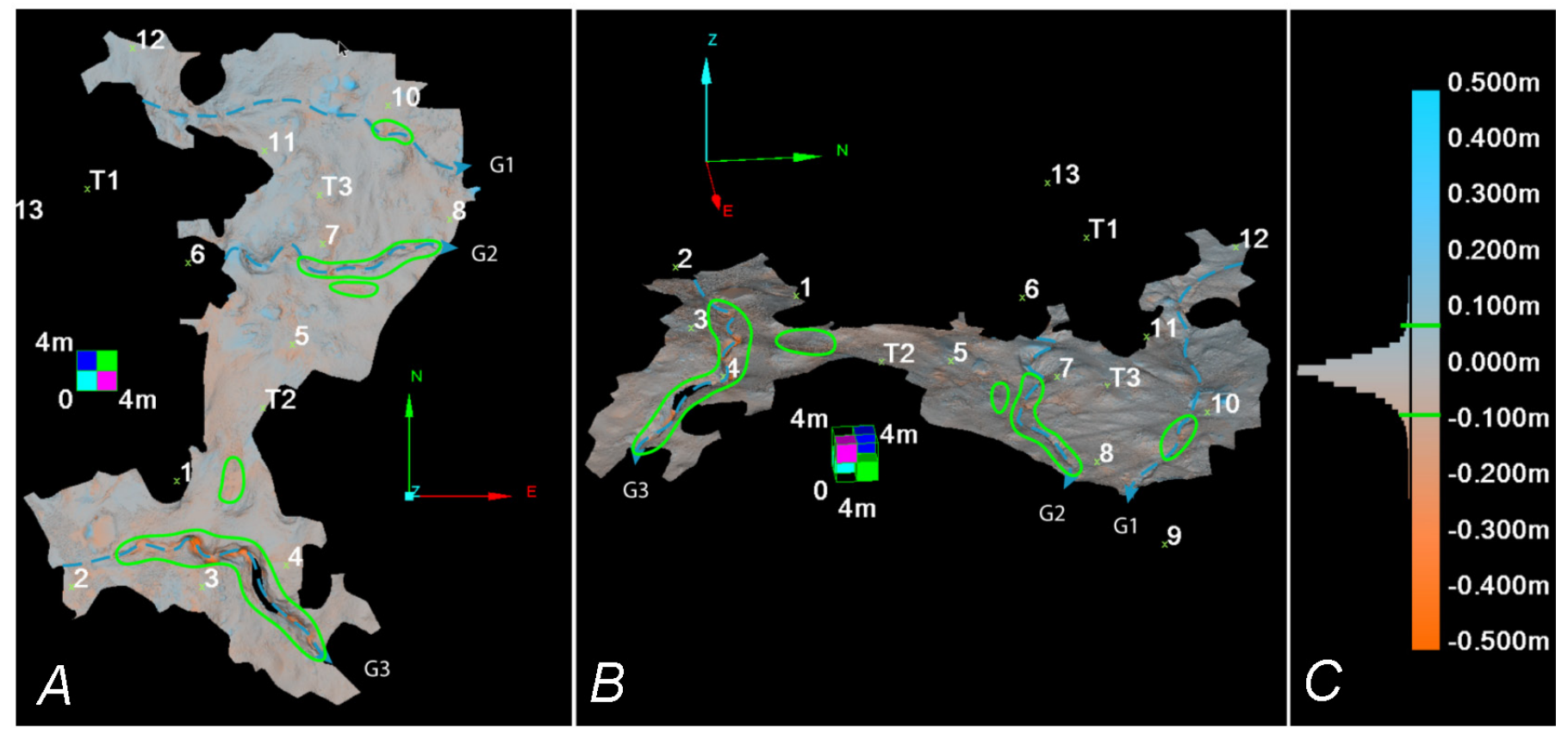

Figure 48. Site AZ:G:03:072 US — 5-cm triangulated irregular network (TIN) output showing location and relative magnitude of surface comparison from May 2007 to September 2007. Laser scan and control point locations coincide with figure 42. Topographic change (ovals and polygons) was identified in all three gullies. $A$, plan view; $B$, oblique view; and $C$, vertical change histogram distribution and color scale. "Hole" in G3 represents area not imaged in September 2007 because of the mislocation of the scanner. 


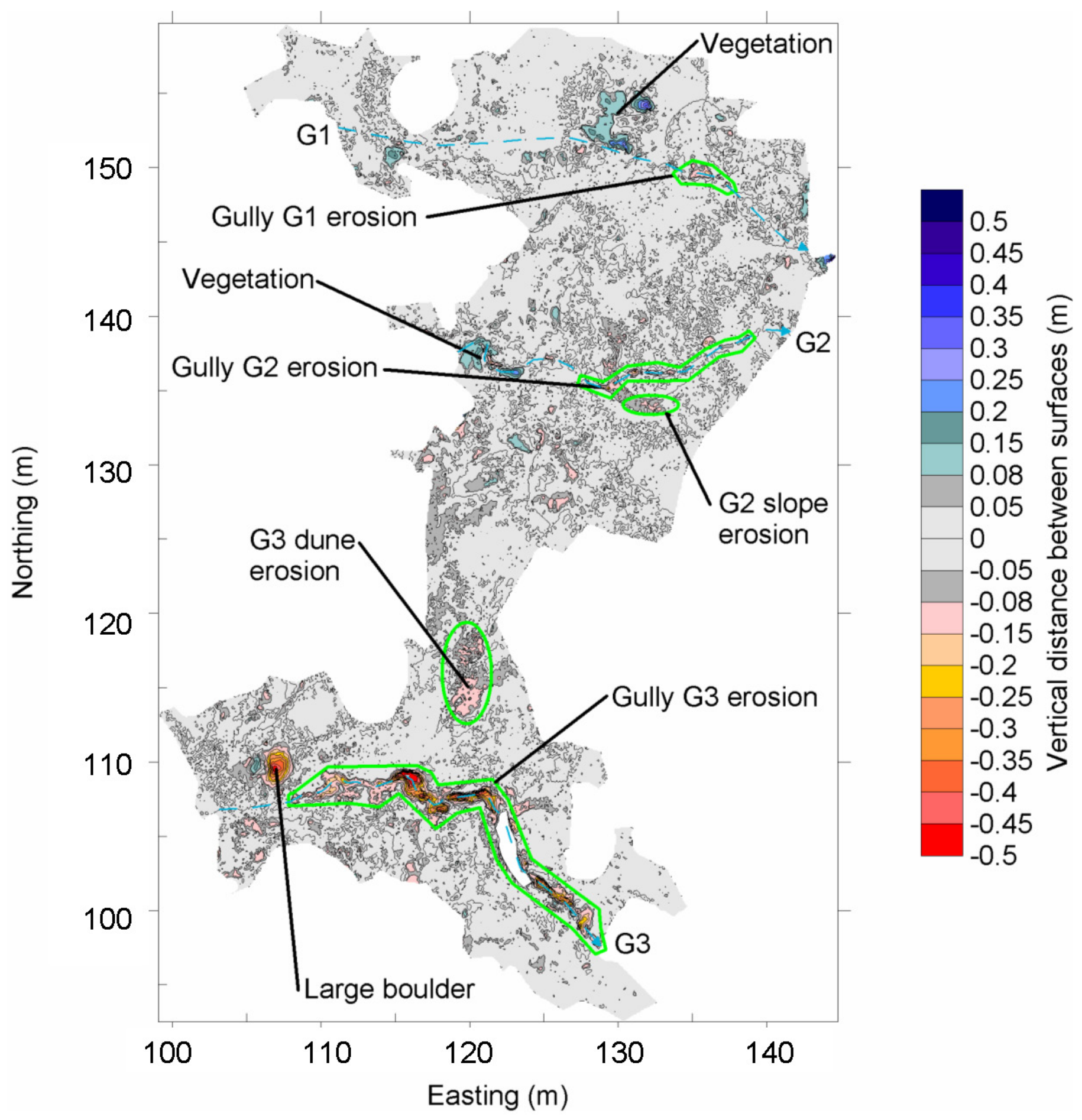

Figure 49. Site AZ:G:03:072 US-10-cm gridded output showing erosion (red, negative) and deposition (blue, positive) from May 2007 to September 2007 and approximate gully locations (dashed lines). Erosion was identified at five locations (ovals and polygons), including in all three gullies. Data points of large boulder were filtered inconsistently between model surfaces and therefore show up as false erosion. 


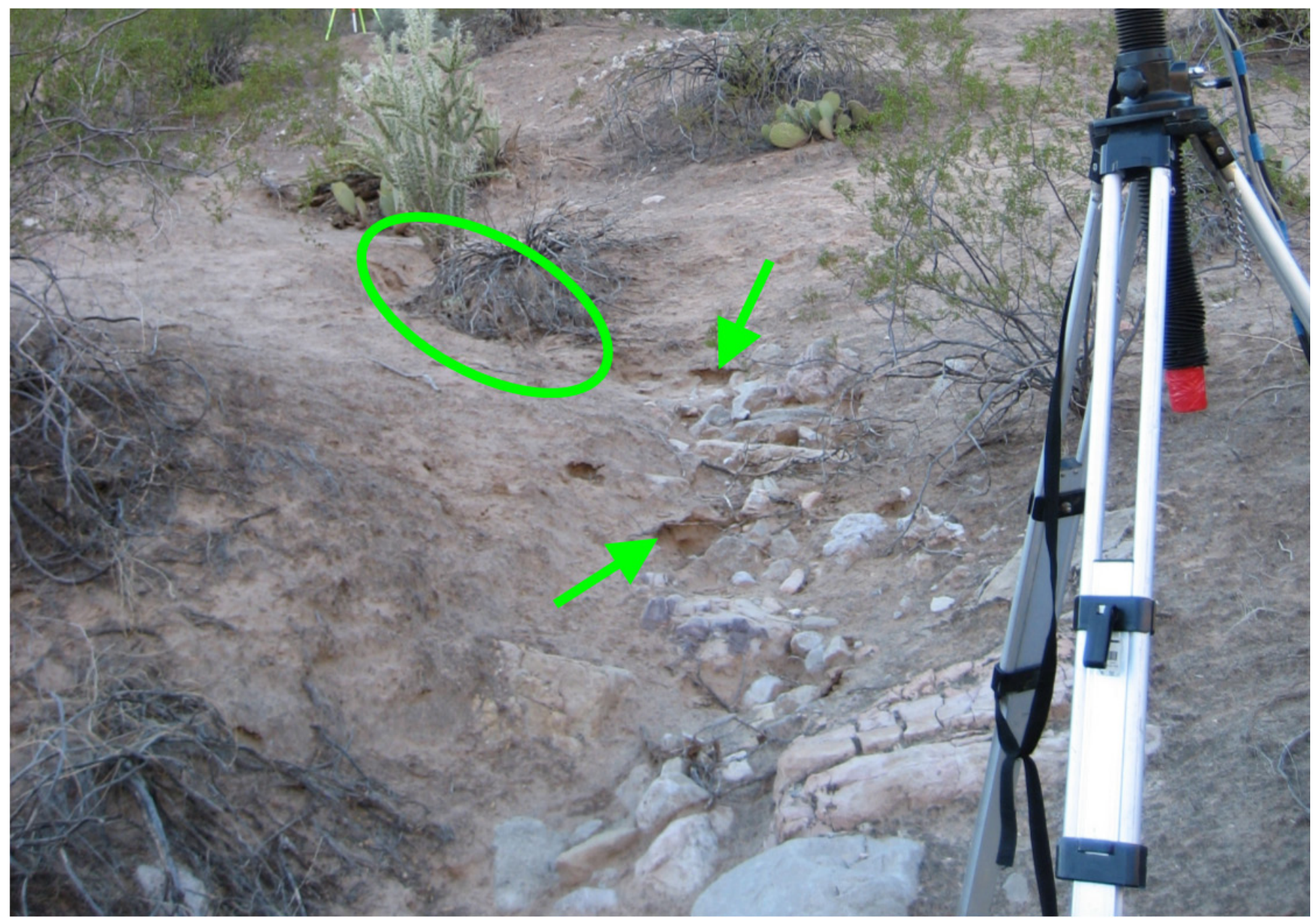

Figure 50. Site AZ:G:03:072 US-Photo of G1 erosional area (oval) in September 2007. Additional erosion lower in the gully (arrows) likely occurred but was within the error bounds of the data (change less than $8 \mathrm{~cm}$ ) and therefore not detected in the comparison. 

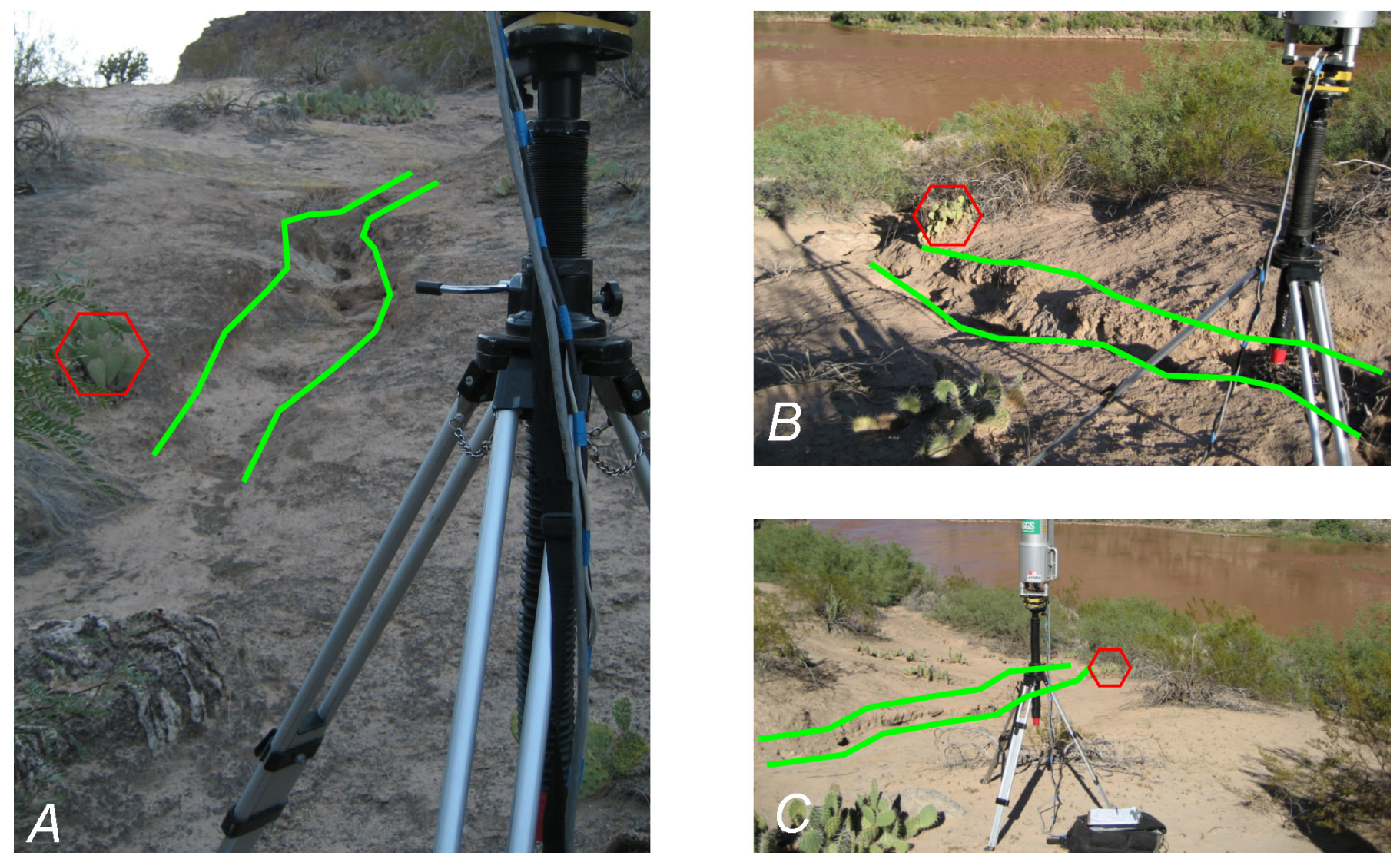

Figure 51. Site AZ:G:03:072 US—Photo comparison of G2 erosional area (parallel lines) between (A) May 2007 looking updrainage and $(B$ and $C)$ September 2007 looking downdrainage. Identical prickly pear cactus (hexagon) is highlighted in all photos for orientation.

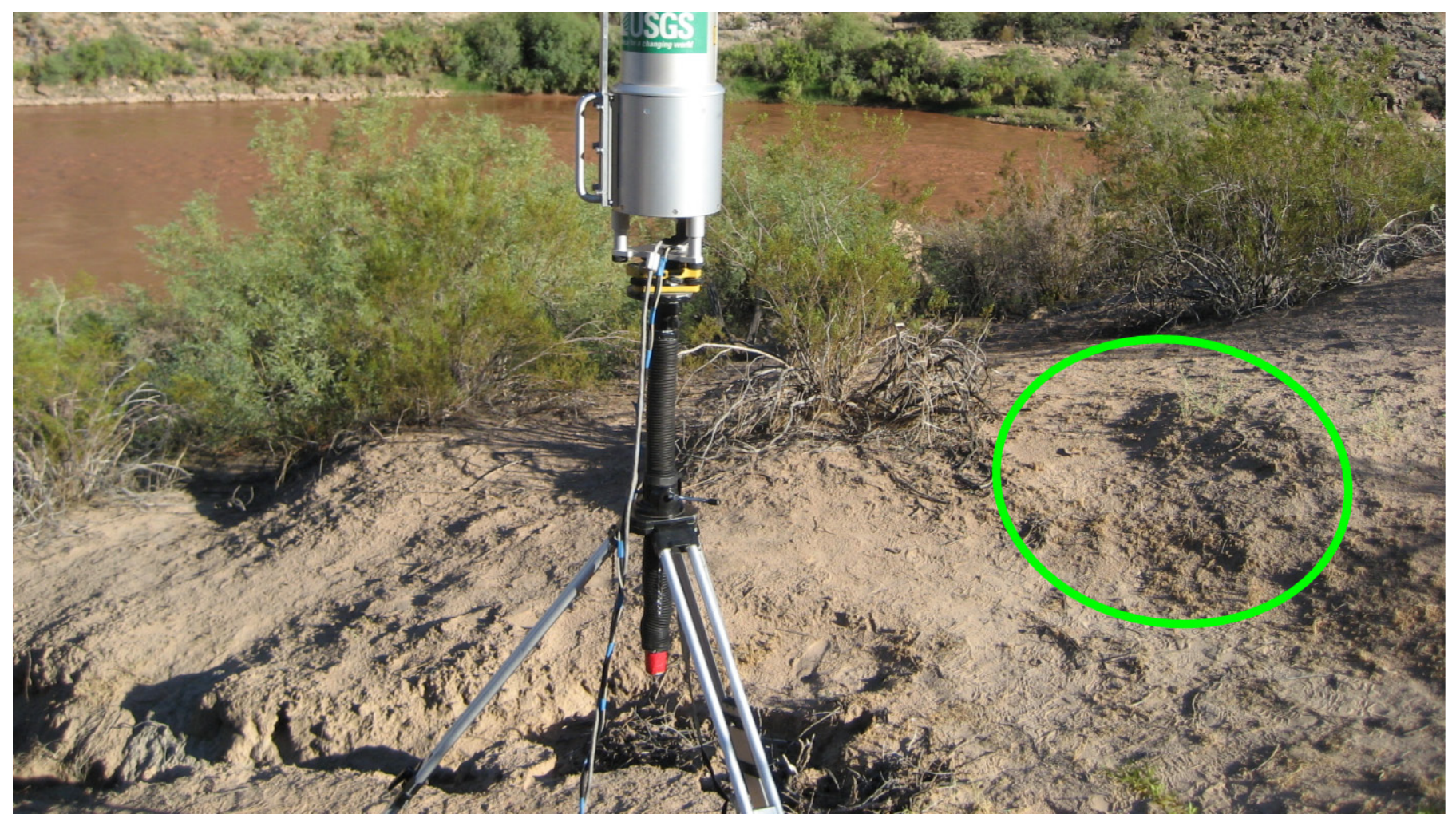

Figure 52. Site AZ:G:03:072 US—Photo of G2 slope erosional area (oval) in September 2007. 


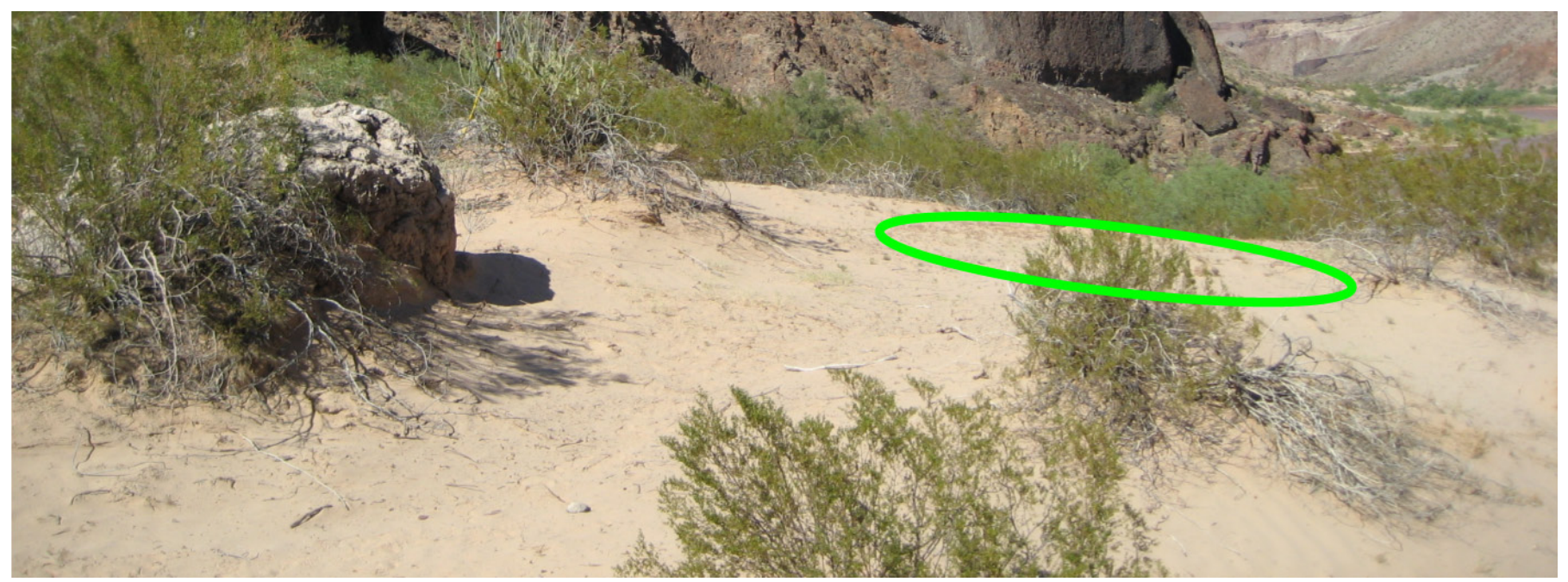

Figure 53. Site AZ:G:03:072 US—Photo of G1 dune erosional area (oval) in September 2007.
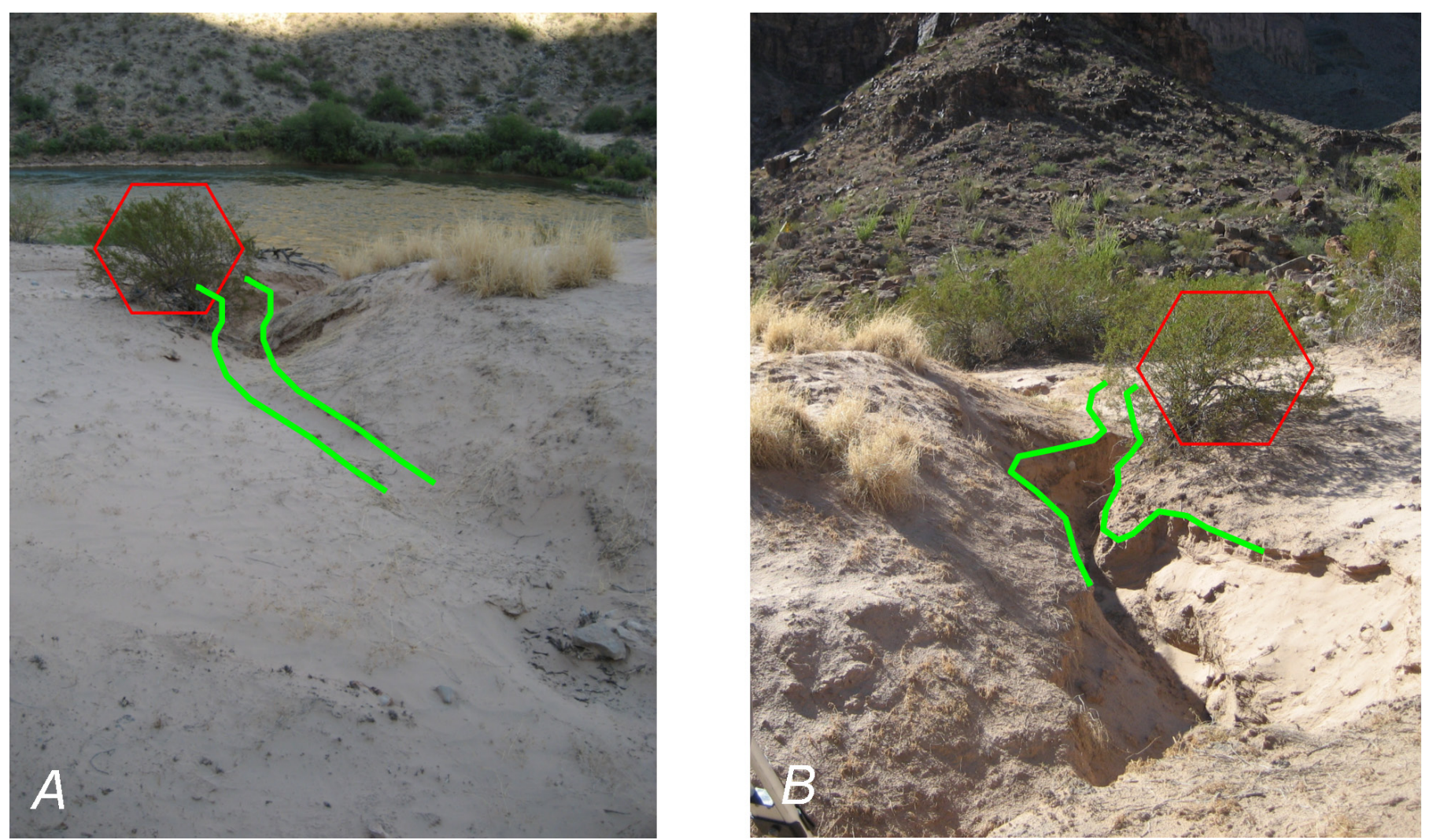

Figure 54. Site AZ:G:03:072 US—Photo comparison of G3 erosional area (parallel lines) between $(A)$ May 2007 looking downdrainage and $(B)$ September 2007 looking updrainage. Small creosote bush (hexagon) is highlighted in both photos for orientation. 


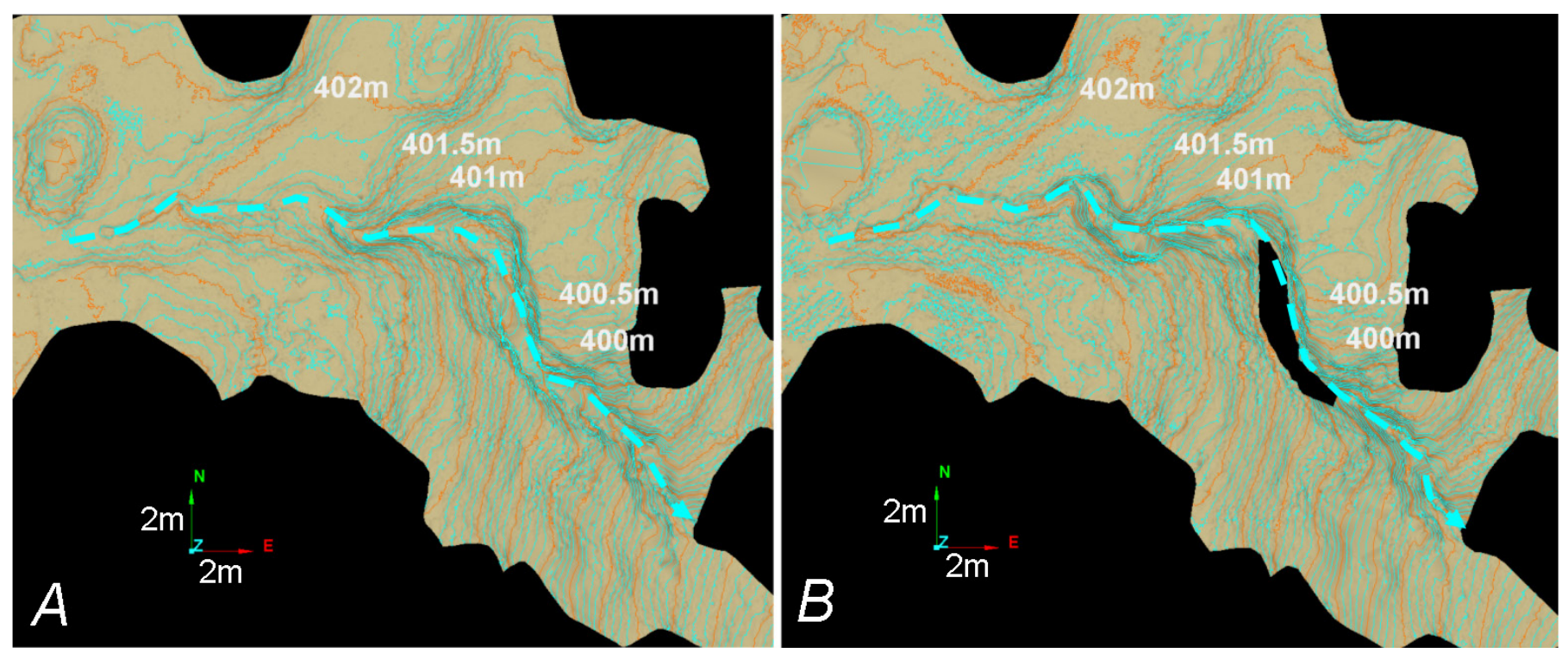

Figure 55. Site AZ:G:03:072 US-10-cm contour map comparison of G3 erosional area between ( $A$ ) May 2007 and ( $B$ ) September 2007. Dashed line is approximate gully thalweg over the total length of detected change (about $28 \mathrm{~m}$ ).

\section{Site AZ:G:03:072 DS}

Site AZ:G:03:072 DS forms a triangular shaped area bounded by large (several meters in width) drainages on two sides and a significant change in slope on the other (fig. 42). The area is generally of increasingly convex gradient with three gullies (G1, G2, G3) in various stages of development traversing the site (fig. 56). The gullies begin in an area of generally flat topography but dramatically increase in gradient as they reach the edge of the site. The gullies lead into the two larger bordering drainages which then converge and drain to the Colorado River, some $40 \mathrm{~m}$ downstream. Two gullies are being actively monitored for annual change caused by monsoon rains. The third (G3) has already incised to bedrock and does not exhibit significant change. Vegetation includes a broad mix of cacti, including prickly pear (Opuntia basilaris) and ocotillo (Fouquieria splendens), as well as several larger mesquite (Prosopis glandulosa var. torreyana) and catclaw acacia (Acacia greggii) trees. In the gullies, vegetation is generally absent. Site soils generally appear stabilized by both vegetation and cryptobiotic crust.

We focused our survey efforts on the G1 and G2 gully locations, so there is minimal data available for the G3 gully bottom. All three efforts were successful in allowing the generation of detailed site topography, but an experiment with new scan locations in September 2007 resulted in a lack of sufficient data in the primary study area to construct a full detailed model. As a result, we were only able to compare the original site area (460 $\mathrm{m}^{2}$; table 2) between May 2006 and May 2007 (fig. 57). A somewhat different area (about $450 \mathrm{~m}^{2}$ ) was compared for the May 2007 and September 2007 data sets.

The May 2006 to May 2007 comparison shows that no statistically significant change occurred during this period (figs. 57 and 58). The average distance between the two modeled surfaces is $-0.8 \mathrm{~cm}$ with a standard deviation of $3.6 \mathrm{~cm}$. The $2 \sigma$ confidence intervals $(-8.0 \mathrm{~cm}$ and $6.4 \mathrm{~cm})$, representing 95 percent of the data, are within the error range bounds $( \pm 8 \mathrm{~cm})$. According to the histogram distribution (fig. 57C), 3.0 percent of the total surface area (about $14 \mathrm{~m}^{2}$ ) underwent more than $8 \mathrm{~cm}$ of vertical erosion and 0.8 percent (about $4 \mathrm{~m}^{2}$ ) underwent more than $8 \mathrm{~cm}$ of vertical deposition. After additional investigation, we attributed the change in these areas to difficult-to-filter, tall vegetation in the case of the deposition and the dying off of grasses (figs. 56 and 58) in the case of the erosion.

The May 2007 to September 2007 comparison also showed no statistically significant topographic change, although it is not immediately apparent from the results (figs. 59 and 60). Because of the different alignments of the scan positions, we found discrepancies with how the data was filtered to remove vegetation and other nonbare ground objects. Thus, several areas that show deposition were determined to represent difficult-to-interpret ground areas such as small bushes of prickly pear cacti and jumbled cobble-sized rocks (fig. 60). The average distance between the two modeled surfaces was $2.4 \mathrm{~cm}$ with a standard deviation of $4.2 \mathrm{~cm}$. The $2 \sigma$ confidence intervals $(-6.0 \mathrm{~cm}$ and $10.8 \mathrm{~cm})$, representing 95 percent of the data, are just outside the error range of the data $( \pm 8 \mathrm{~cm}$ ). According to the histogram distribution (fig. $59 \mathrm{C}$ ), 5.2 percent of the total surface area (about $23 \mathrm{~m}^{2}$ ) underwent more than $8 \mathrm{~cm}$ of vertical deposition and 1.1 percent (about $5 \mathrm{~m}^{2}$ ) underwent more than $8 \mathrm{~cm}$ of vertical erosion. The six areas highlighted in figure 60 represent approximately 75 percent of the detected deposition; we assume the other 25 percent to be related to similar difficulties with data collection and processing at this site. Similarly, the vegetation "erosion" area indicated in figure 60 also represents the majority of the detected change. 

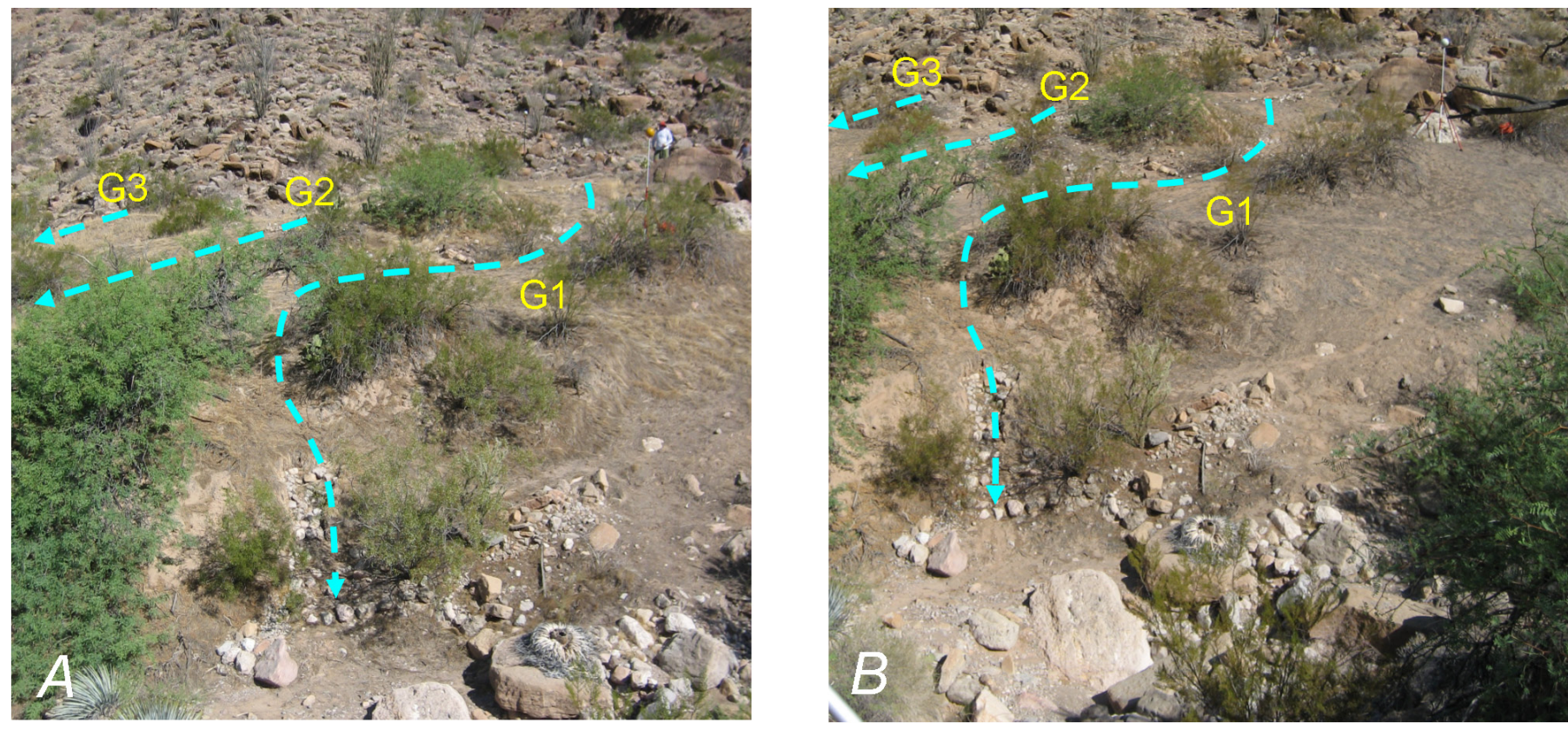

Figure 56. Site AZ:G:03:072 DS area showing gully locations (dashed lines) in $(A)$ May 2006 and ( $B)$ May 2007. Note longer grasses present in the May 2006 image.
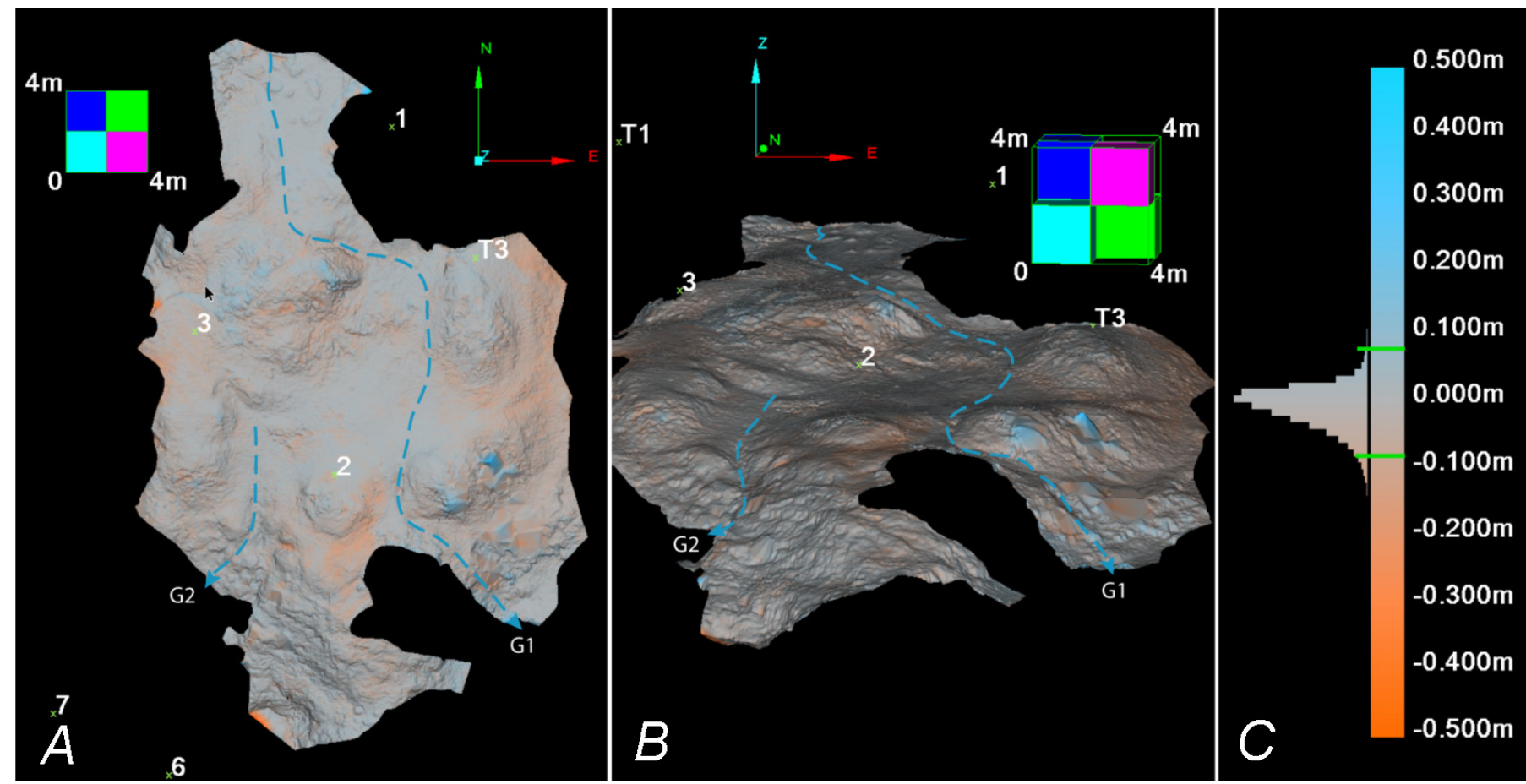

Figure 57. Site AZ:G:03:072 DS-5-cm triangulated irregular network (TIN) output showing location and relative magnitude of surface comparison from May 2006 to May 2007. Laser scan and control point locations coincide with figure 42. No significant topographic change was identified. $A$, plan view; $B$, oblique view; and $C$, vertical change histogram distribution and color scale. 


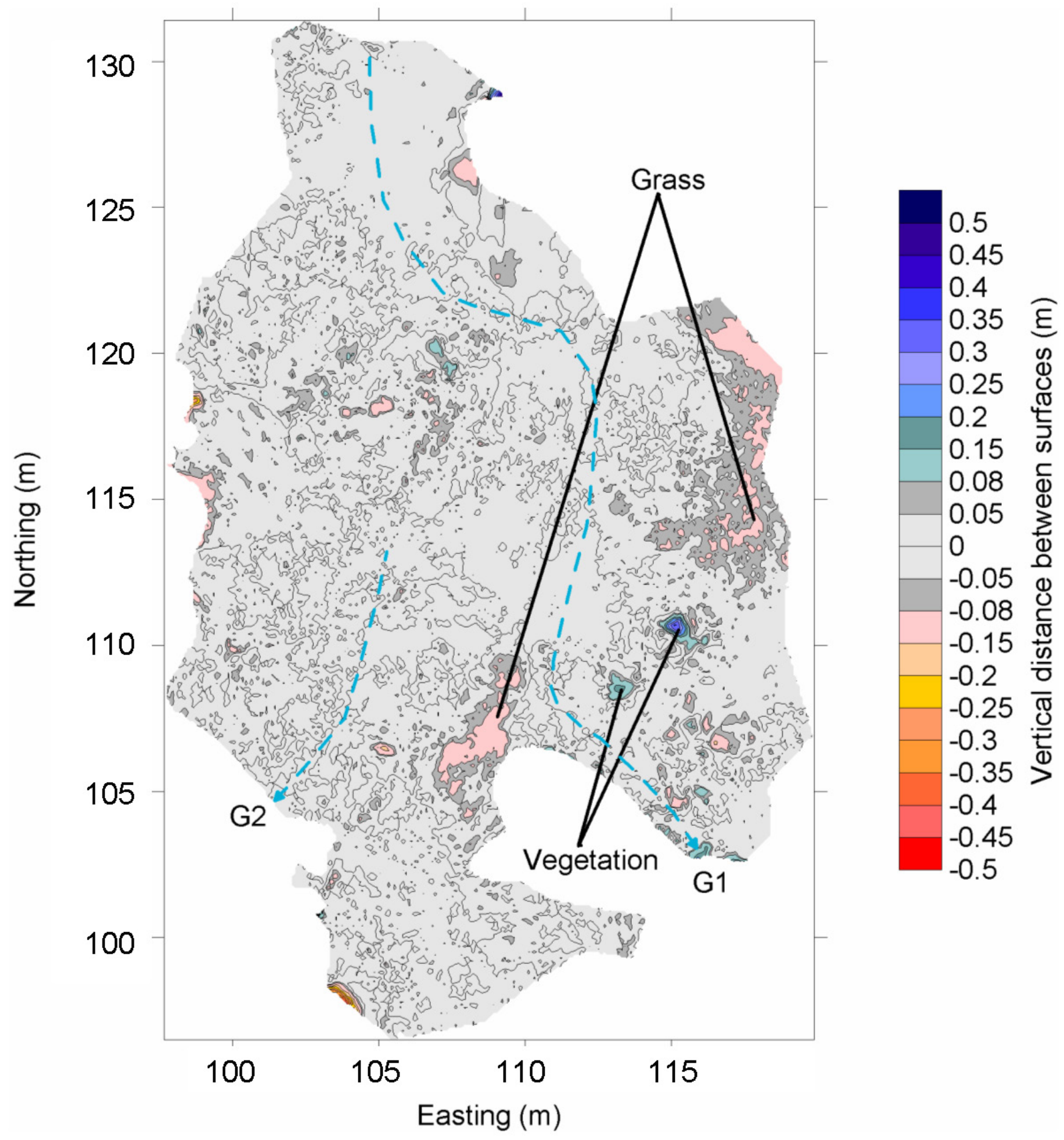

Figure 58. Site AZ:G:03:072 DS—10-cm gridded output showing erosion (red, negative) and deposition (blue, positive) from May 2006 to May 2007 and approximate gully locations (dashed lines). No significant change was detected during this time period. 

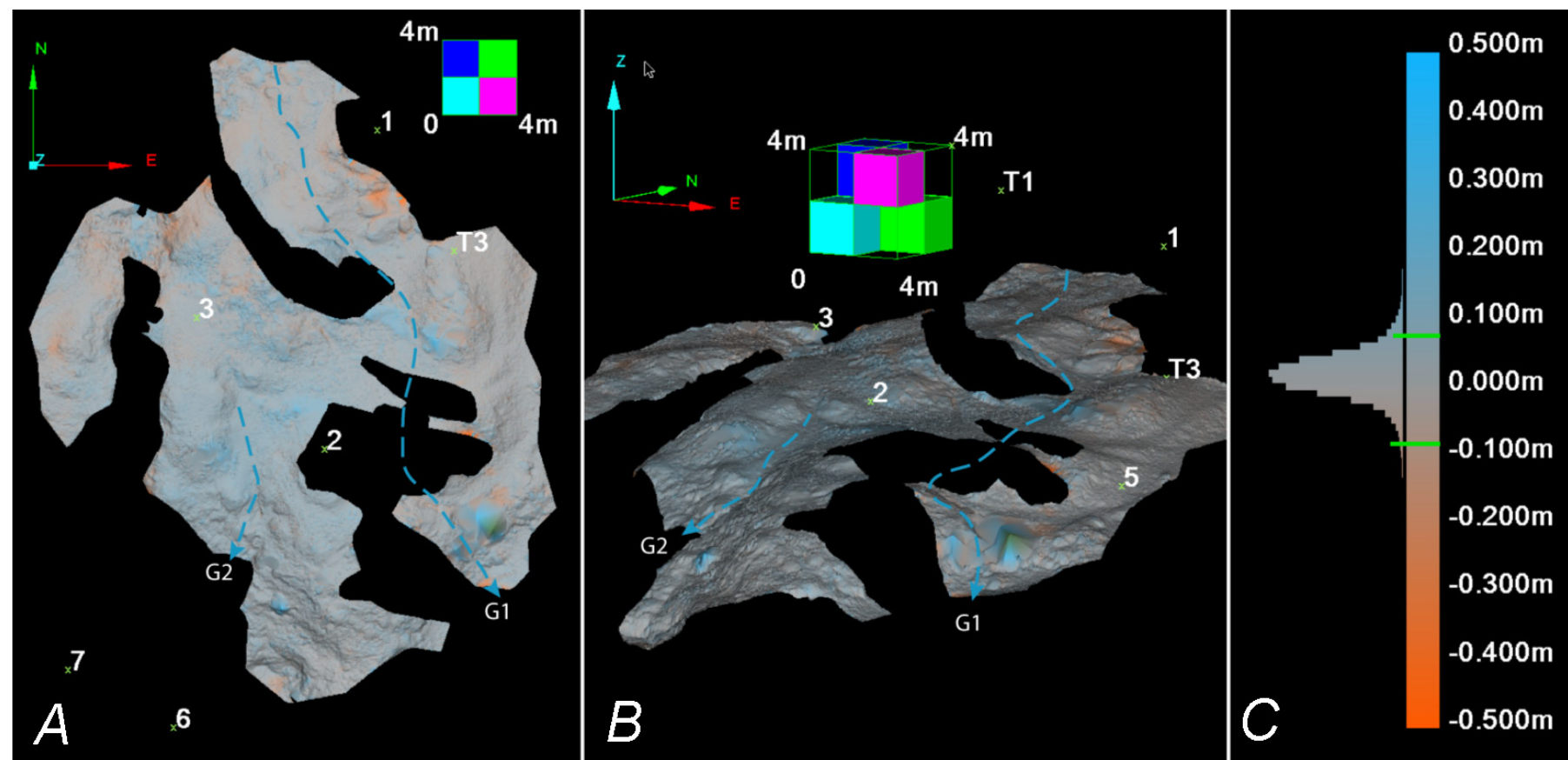

Figure 59. Site AZ:G:03:072 DS—5-cm triangulated irregular network (TIN) output showing location and relative magnitude of surface comparison from May 2007 to September 2007. Laser scan and control point locations coincide with figure 42. No significant topographic change was identified. $A$, plan view; $B$, oblique view; and $C$, vertical change histogram distribution and color scale. 


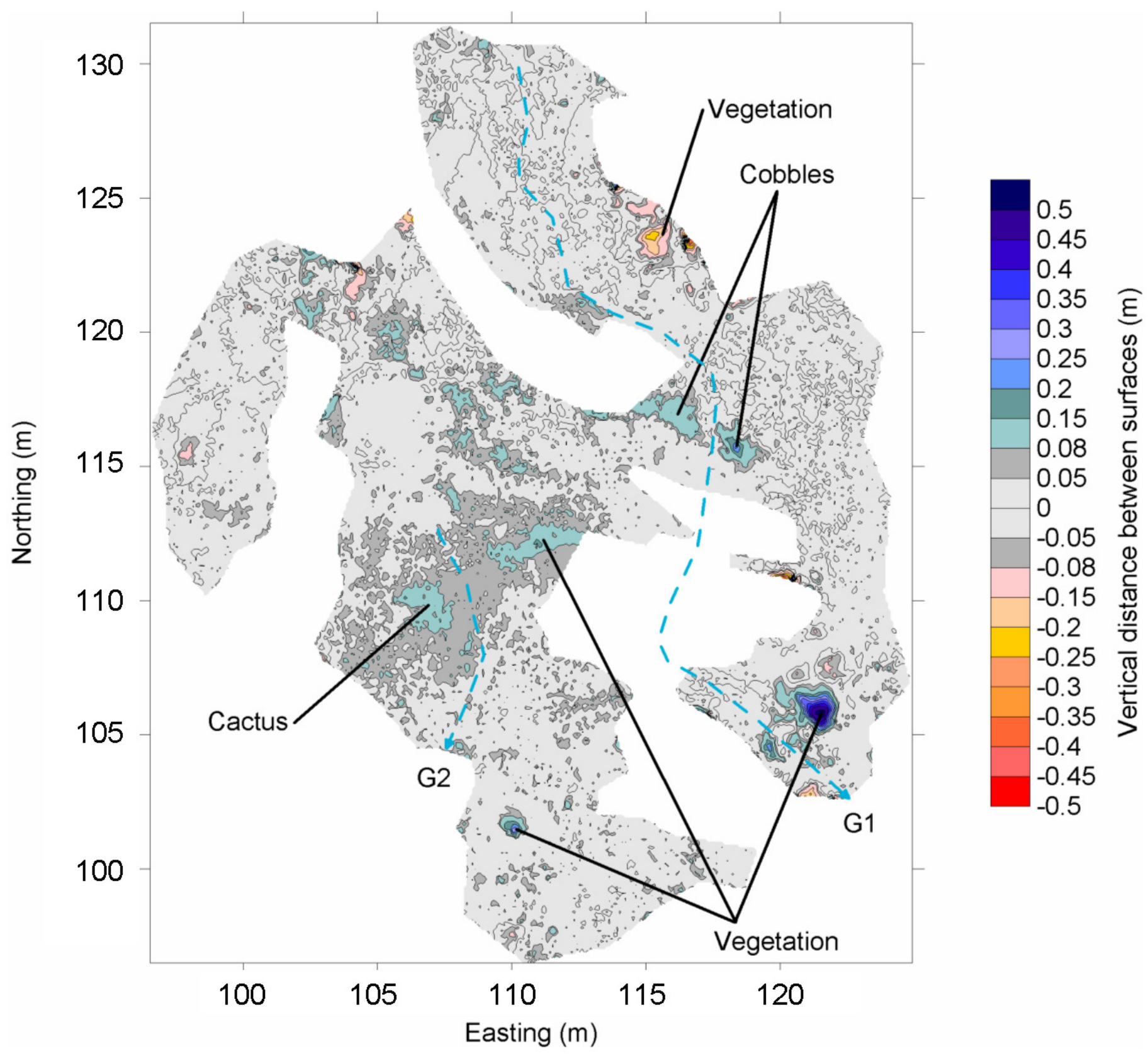

Figure 60. Site AZ:G:03:072 DS-10-cm gridded output showing erosion (red, negative) and deposition (blue, positive) from May 2007 to September 2007 and approximate gully locations (dashed lines). Despite indications of deposition, no significant change was detected during this time period. 


\section{Discussion}

This investigation provides new information about the amount and types of topographic changes that are currently affecting archeological sites within the Colorado River corridor in Grand Canyon National Park. We detected statistically significant change (greater than $\pm 8 \mathrm{~cm}$ ) at six of the nine sites investigated in this study (table 3 ) and possible change at two of the other sites. In general, change was detected on less than 5 percent of the total surface area modeled for each site, with the exception of site AZ:C:13:006, which showed deposition over almost 20 percent of the site area. Where detected, maximum erosion depths were between $12 \mathrm{~cm}$ and $50 \mathrm{~cm}$ and averaged between $12 \mathrm{~cm}$ and $17 \mathrm{~cm}$. Similarly, maximum deposition depths were between $15 \mathrm{~cm}$ and $35 \mathrm{~cm}$ and averaged between $12 \mathrm{~cm}$ and $15 \mathrm{~cm}$. While reinforcing the utility of methods used for this investigation and providing the ability to perform highly specific topographic change modeling, the results also highlight several points to be considered for additional geomorphologic and monitoring studies.

When detected, erosion was typically associated with surface water processes concentrated in drainages, whereas deposition was typically associated with aeolian sand transport outside drainage channels. This confirms the importance of studying gully geomorphology to understand potential effects of erosion at archeological sites. The identified change at sites AZ:C:13:006 and AZ:G:03:072 US are stand-out examples. However, measurements of aeolian sand deposition at several sites (for example, AZ:C:13:006 and AZ:G:03:041) also provide important information on surface aggradation and the potential for gully infilling, and thus topographic monitoring in areas outside already developed gullies is also important. At site AZ:C:13:006, the large depositional area detected between G2 and G3 may in fact be keeping erosion from occurring in this area. However, we also note that these processes may be competing and taking place concurrently over varying time spans. Regardless, we conclude that it is important to monitor for change not only in areas of present-day erosion but also in areas of either potential new erosion or deposition. At a minimum, monitoring should occur for baseline change detection purposes. Simple geomorphic drainage models that calculate the potential for concentrated stream flow could be used for initial assessment of these areas.

The importance of using highly regimented and accurate data collection and processing methods should also be emphasized. In general, we found it extremely important to maintain the same set-up geometry and "look" angles for the topography of interest, regardless of the type of terrain being investigated (for example, flat, steep, or hummocky ground). This resulted in similar data point density and, consequently, highly comparable surface models. One specific limitation of the data collection and processing methodologies was the sometimes poor or inconsistent filtering of vegetation from the point- cloud data. The remedy to this issue is not simple. In fact, vegetative filtering problems are common to all "lineof-sight" data collection methods, including both aerial and terrestrial lidar. Several automated methods are available, but we still propose that additional, rigorous manual checking of the data be performed, as was implemented in this study, to ensure that poor filtering does not lead to false positives of detected change. Because the false positives may take the form of either erosion (the more recent surface has been more

Table 3. Summary of net topographic change between May 2006 and September 2007.

\begin{tabular}{|c|c|c|c|c|c|c|}
\hline Site Number & $\begin{array}{l}\text { Area w/ mea- } \\
\text { sured erosion } \\
\qquad\left(\mathrm{m}^{2}\right)\end{array}$ & $\begin{array}{l}\text { Area w/ mea- } \\
\text { sured deposi- } \\
\quad \text { tion }\left(\mathrm{m}^{2}\right)\end{array}$ & $\begin{array}{l}\text { Total percent of site } \\
\text { area modeled w/ } \\
\text { topographic change } \\
\text { (percent) }\end{array}$ & $\begin{array}{l}\text { Average, maxi- } \\
\text { mum height of } \\
\text { erosion } \\
\text { (cm) }\end{array}$ & $\begin{array}{l}\text { Average, maxi- } \\
\text { mum height of } \\
\text { deposition } \\
\text { (cm) }\end{array}$ & $\begin{array}{c}\text { Total site volume } \\
\text { of erosion }(-) \text { and } \\
\text { deposition }(+) \\
\left(\mathbf{m}^{3}\right)\end{array}$ \\
\hline AZ:C:13:006 & 12.0 & 260 & 21.3 & 15,30 & 15,35 & $-0.7 /+26.9$ \\
\hline AZ:C:13:336 & 0 & 0.9 & 0.1 & 0,0 & 12,15 & $0 /+0.1$ \\
\hline AZ:C:13:099 playa area & 0.4 & 0 & $<0.1$ & 12,12 & 0,0 & $-0.1 / 0$ \\
\hline AZ:C:13:348 & 0 & 0 & 0 & 0,0 & 0,0 & $0 / 0$ \\
\hline AZ:G:03:041 & 0 & 38 & 4.8 & 0,0 & 12,15 & $0 /+3.5$ \\
\hline AZ:G:03:072 DS & 0 & 0 & 0 & 0,0 & 0,0 & $0 / 0$ \\
\hline
\end{tabular}


Topographic Change Detection at Select Archeological Sites in Grand Canyon National Park, Arizona, 2006-2007

rigorously filtered) or deposition (the less recent surface has been more rigorously filtered), neither false positive can be ruled out — both must be investigated. In this study, quality control for both of these issues was obtained through the use of photographs taken of each site at the time of data collection. Despite the high accuracy of the lidar data, we still found photographs indispensable for positively verifying areas of topographic change. We therefore strongly recommend that this type of data be gathered concurrently with terrestrial lidar surveys. The latest generation of laser instruments with built in high-resolution digital cameras capable of point-cloud photo draping will likely prove highly worthwhile in this regard.

Finally, we recommend that additional geomorphic studies be performed to understand the role of alluvial and aeolian sediment transport for maintaining relative topographic conditions at archeological sites in the Colorado River corridor. The data presented here only partly address this question. We plan to use this data collaboratively with other researchers who have gathered information on weather and geomorphic variables to arrive at conclusions on the effects of river levels and long-term climate patterns on archeological site preservation.

\section{Conclusions}

The deterioration of archeological sites from gully erosion within the Colorado River corridor of Grand Canyon National Park poses an ongoing management problem. Several questions exist including the location and magnitude of the changes occurring in relation to archeological resources, the rate of the changes, and the relative contribution of several potential causes including sediment depletion associated with managed flows from Glen Canyon Dam, site-specific weather patterns, visitor impacts, and long-term climate change. To answer these questions, highly accurate, spatially specific data are needed from sites undergoing change. Previous survey technologies have not been able to efficiently and accurately collect this data. Using terrestrial lidar data collection techniques and new post-processing methods, we analyzed topographic data for nine archeological sites, collected using three separate data collection efforts spanning 16 months.

Our results indicate that six of the nine sites showed positive signs of either erosion, deposition, or both during this time interval. Two other sites also showed possible signs of change. Erosion was concentrated in established gully drainages and averaged $12 \mathrm{~cm}$ to $17 \mathrm{~cm}$ in depth with maximum depths of $50 \mathrm{~cm}$. Deposition was also concentrated at specific locations outside of drainages, but generally was spread over larger areas. Maximum depths of deposition averaged $12 \mathrm{~cm}$ to $15 \mathrm{~cm}$ and reached up to $35 \mathrm{~cm}$. Overall, we found that the spatial distribution and magnitudes of surface change are specific to each site, and a thorough understanding of the geomorphology, weather, and sand supply is requisite for a complete understanding of the data. Additional work in combining these results with site-specific weather, hydrology, and geomorphology data will assist in the development of working models for determining the causes of the documented topographic changes.

\section{Acknowledgments}

Funding for this research was provided by a cooperative work agreement between the USGS Grand Canyon Monitoring and Research Center and the USGS Geologic Division initiated by Helen Fairley, Sociocultural Program Manager at the GCMRC. We thank Ms. Fairley for her vision and continuing commitment to this project. Kristin Brown, formerly of the GCMRC, provided field survey support and logistical assistance with all three data collection efforts, and her assistance is gratefully acknowledged. We thank Kevin Schmidt (USGS) and two anonymous reviewers whose comments improved this report. The authors would also like to thank the following individuals for their assistance with the data collection efforts: Jennifer Dierker and Lisa Leap, Grand Canyon National Park; Joel Pederson, Gary O'Brien, Ben Dejong, Mike Keller, Chris Tressler, and Tim Andrews, Utah State University; Richard Jonasse, USGS volunteer; Brian Dierker, Humphrey Summit Support, and the many other Grand Canyon river guides who participated in the field trips.

\section{References}

Bellian, J.A., Kerans, C., and Jennette, D.C., 2005, Digital outcrop models - Applications of terrestrial scanning lidar technology in stratigraphic modeling: Journal of Sedimentary Research, v. 75 , no. 2, p. 166-176.

Boehler, W., Vicent, M.B., and Marbs, A., 2003, Investigating laser scanner accuracy: Presented at the XIX International Committee for Documentation of Cultural Heritage (CIPA) Symposium, Antalya, Turkey, 2003, 9 p. [http:/cipa.icomos.org/fileadmin/papers/antalya/189.pdf, accessed February 23, 2009].

Collins, B.D., Brown, K.B., and Fairley, H.C., 2008, Evaluation of terrestrial LIDAR for monitoring geomorphic change at archeological sites in Grand Canyon National Park, Arizona: U.S. Geological Survey, Open-File Report 2008-1384, 60 p. [http://pubs.usgs.gov/of/2008/1384/, accessed February 1, 2009].

Collins, B.D., and Kayen, R., 2006, Applicability of terrestrial LIDAR scanning for scientific studies in Grand Canyon National Park, Arizona: U.S. Geological Survey, Open-File Report 2006-1198, 27 p. [http://pubs.usgs.gov/ of/2006/1198/, accessed August 1, 2008].

Collins, B.D., Kayen, R., and Minasian, D., 2006, Registration procedures for terrestrial laser scanning in geomorphologic studies: Eos Transactions, American Geophysical Union, v. 87, no. 52, Fall Meeting Supplement, Abstract G53C-0920.

Collins, B.D., and Sitar, N., 2002, Monitoring of coastal bluffs using 3-D laser scanning and conventional mapping: Eos Transactions, American Geophysical Union, v. 83, Fall Meeting Supplement, Abstract H12D-0952. 
Collins, B.D., and Sitar, N., 2008, Processes of coastal bluff erosion in weakly lithified sands, Pacifica, California, USA: Geomorphology, v. 97, p. 483-501.

Davis, P.A., 2004, Review of results and recommendations from the GCMRC 2000-2003 remote-sensing initiative for monitoring environmental resources within the Colorado River ecosystem: U.S. Geological Survey Open-File Report 2004-1206, 73 p. [http:/www.gcmrc.gov/library/reports/ Remote_Sensing/Davis2004.pdf, accessed August 1, 2008].

Doneus, M. and Neubauer, W., 2005, Laser scanners for 3D Documentation of Stratigraphic Excavations, in Recording, Modeling and Visualization of Cultural Heritage, Baltsavias et al., [eds.], Taylor \& Francis, 193-203.

Draut, A.E., and Rubin, D.M., 2008, The role of aeolian sediment in the preservation of archeological sites along the Colorado River corridor Grand Canyon National Park, Arizona: U.S. Geological Survey Professional Paper 1756, 71 p. [http://pubs.usgs.gov/pp/1756, accessed March 5, 2009].

Draut, A.E., Rubin, D.M., Dierker, J.L., Fairley, H.C., Griffiths, R.E., Hazel, J.E., Jr., Hunter, R.E., Kohl, K., Leap, L.M., Nials, F.L., Topping, D.J., and Yeatts, M., 2005, Sedimentology and stratigraphy of the Palisades, Lower Comanche, and Arroyo Grande areas of the Colorado River corridor, Grand Canyon, Arizona: U.S. Geological Survey Scientific Investigations Report 2005-5072, 68 p. [http:// pubs.usgs.gov/sir/2005/5072/, accessed August 1, 2008].

Fairley, H.C., 2005, Cultural resources in the Colorado River corridor, in Gloss, S.P., Lovich, J.E., Melis, T., eds., The state of the Colorado River ecosystem in Grand Canyon: U.S. Geological Survey Circular 1282, p. 177-192.

Fairley, H.C., Bungart, P.W., Coder, C.M., Huffman, J., Samples, T.L., and Balsom, J.R., 1994, The Grand Canyon river corridor survey project: Archaeological survey along the Colorado River between Glen Canyon Dam and Separation Canyon: Cooperative Agreement No. 9AA-40-07920, Grand Canyon National Park, Prepared in cooperation with the Bureau of Reclamation, Glen Canyon Environmental Studies, Flagstaff, Ariz.

Fairley. H. C., Collins, B.D., Draut A., Leap, L., and O’Brien, G., 2007, FY07-FY11 Archaeological Site Monitoring and Research Development Project: Research proposal dated February 28, 2007, submitted to Grand Canyon National Park and National Park Service Research Permit Application System, March 5, 2007, copy on file at the U.S. Geological Survey, Grand Canyon Monitoring and Research Center, Flagstaff, Ariz., 49 p.

Grand Canyon Monitoring and Research Center, 2008, Survey control operations for the Colorado River Ecosystem: U.S. Geological Survey Grand Canyon Monitoring and Research Center [http://www.gcmrc.gov/about/programs/isp/dasa/ survey/operations.aspx, accessed August 11, 2008].
Golden Software, 2008, Surfer, version 8, contouring, gridding, and surface mapping software [http://www. goldensoftware.com/products/surfer/surfer.shtml, accessed August 1, 2008].

Hazel, J.E., Jr., Kaplinski, M., Parnell, R.A., and Fairley, H.C., 2008, Aggradation and degradation of the Palisades gully network, 1996 to 2005, with emphasis on the November 2004 high-flow experiment, Grand Canyon National Park, Arizona: U.S. Geological Survey Open-File Report 20081264, 14p. [http://pubs.usgs.gov/of/2008/1264/, accessed September 25, 2008].

Hereford, R., 1996, Map showing surficial geology and geomorphology of the Palisades Creek area, Grand Canyon National Park, Arizona: U.S. Geological Survey Miscellaneous Investigations Series Map I-2449, scale 1:2,000.

Hereford R., Fairley H.C., Thompson K.S., Balsom J.R., 1991, The effect of regulated flows on erosion of archaeologic sites at four areas in eastern Grand Canyon National Park, Arizona-A preliminary analysis: U.S. Bureau of Reclamation, Glen Canyon Environmental Studies, Flagstaff, Ariz.

Hereford, R., Fairley, H.C., Thompson, K.S., and Balsom, J.R., 1993, Surficial geology, geomorphology and erosion of archaeologic sites along the Colorado River, Eastern Grand Canyon, Grand Canyon National Park, Arizona: U.S. Geological Survey Open-File Report 93-517, 46 p.

Hereford, R., Burke, K.J., and Thompson, K.S., 1998, Map showing Quaternary geology and geomorphology of the Nankoweap Rapids area, Marble Canyon, Arizona: U.S. Geological Survey Miscellaneous Investigations Series Map I-2608, scale 1:2,000.

Hough, I., and Brennan, E., 2008, Architectural documentation and preservation of Havasupai and Navajo wooden pole structures in Grand Canyon National Park, in Berger, T.B., Reflections of Grand Canyon historians - Ideas, arguments, and first-person accounts: Grand Canyon Association, p. 81-88.

I-SiTE, Inc., 2008, I-Site Studio version 3.1, 3D laser scanning software [http://www.isite3d.com, accessed August 1, 2008].

Kayen, R., and Collins, B.D., 2005, Terrestrial LIDAR imagery and analysis of Hurricane Katrina levee failures in the city of New Orleans: Eos Transactions, American Geophysical Union, 86(52) Fall Meeting, Supplemental Abstract H42C-07.

Kintigh, K., Altschul, J., Lipe, W., and Urquhart, N.S., 2007, Legacy monitoring data review panel report to the Grand Canyon Monitoring and Research Center: Report on file at the US Geological Survey, Grand Canyon Monitoring and Research Center, Flagstaff, Ariz., 63 p. 
Labourdette, R,. and Jones, R.R., 2007, Characterization of fluvial architectural elements using a three-dimensional outcrop data set; Escanilla braided system, south-central Pyrenees, Spain: Geosphere, v. 3, no. 6, p. 422-434.

Leap, L.M., Andrews, N.B., and Kunde, J.L., 1996, 1996 summary report - monitoring of archaeological sites along the Colorado River Corridor in Grand Canyon National Park: River Corridor Monitoring Project Report No. 37, 117 p. [http://www.nps.gov/grca/historyculture/upload/FY1996. pdf, accessed August 1, 2008].

Leap, L.M., Andrews, N.B., Hubbard, D.C., and Kunde, J.L., 1997, 1997 summary report - archaeological site monitoring and management along the Colorado River Corridor in Grand Canyon National Park: River Corridor Monitoring Project Report No. 50, 103 p. [http://www.nps.gov/grca/ historyculture/upload/FY1997.pdf, accessed August 1, 2008].

Leap, L.M., Kunde, J.L., Hubbard, D.C., Andrews, N.B., Downum, C.E., Miller, A.R., and Balsom, J.R., 2000, Grand Canyon monitoring project 1992-1999-synthesis and annual report for FY99. Grand Canyon National Park River Corridor Monitoring Project Report No. 66: Submitted to Bureau of Reclamation, Upper Colorado Region, Salt Lake City, Utah, acquisition No. 99-AA-40-2340, 14 p. [http:// www.nps.gov/grca/historyculture/upload/FY1999.pdf, accessed August 1, 2008].

Lichti, D.D., Gordon, S.J., Stewart, M.P., Franke, J., and Tsakiri, M., 2002, Comparison of digital photogrammetry and laser scanning, in Scanning for Cultural Heritage Recording, International Society for Photogrammetry and Remote Sensing (ISPRS) Commission V Symposium, Corfu Greece, v. 2, p. 39-44 [http://www.isprs.org/commission5/ workshop02/, accessed February 23, 2009].

Nagihara, S., Mulligan, K.R., Xiong, W., 2004, Use of a threedimensional laser scanner to digitally capture the topography of sand dunes in high spatial resolution: Earth Surface Processes and Landforms, v. 29, no. 3, p. 391-398.

Pederson, J.L., Petersen, P.A., MacFarlane, W.W., Gonzales, M.F., and Kohl, K., 2003, Mitigation, monitoring, and geomorphology related to gully erosion of cultural sites in Grand Canyon: Cooperative Agreement No. 01 WRAG0074 between Utah State University and U.S. Geological Survey, Grand Canyon. Grand Canyon Monitoring and Research Center, Flagstaff, Ariz. 250 p. [http://www.gcmrc.gov/ library/reports/cultural/Archaeology/Pederson2003.pdf, accessed August 1, 2008].
Pederson, J.L., Petersen, P.A., and Dierker, J.L., 2006, Gullying and erosion control at archaeological sites in Grand Canyon, Arizona: Earth Surface Processes and Landforms, v. 31, p. 507-525.

U.S. Geological Survey, 2008a, Metadata for USGS Coastal and Marine Geology field activities L-G1-06-GC, L-G107-GC, and L-G2-07-GC [http://walrus.wr.usgs.gov/ infobank/programs/html/main/activities.html, accessed August 1, 2008].

U.S. Geological Survey, 2008b, Grand Canyon Monitoring and Research Center, internet map server [http://www. gcmrc.gov/products/ims/, accessed August 1, 2008].

Wawrzyniec, T.F., McFadden, L.D., Ellwein, A., Meyer, G., Scuderi, L., McAuliffe, J., and Fawcett, P., 2007, Chronotopographic analysis directly from point-cloud data-A method for detecting small, seasonal hillslope change, Black Mesa Escarpment, NE Arizona: Geosphere, v. 3, p. 550-567.

Wright, S.A., Melis, T.S., Topping, D.J., and Rubin, D.M., 2005, Influence of Glen Canyon Dam operations on Downstream Sand Resources of the Colorado River in Grand Canyon, in Gloss, S.P., Lovich, J.E., and Melis, T.S., eds., The state of the Colorado River ecosystem in Grand Canyon: U.S. Geological Survey Circular 1282, p. 17-31.

Wright, S.A., Schmidt, J.C., Melis, T.S., Topping, D.J., and Rubin, D.M., 2008, Is there enough sand? —evaluating the fate of Grand Canyon sandbars: Geological Society of America (GSA) Today, v. 18, no. 8, p. 4-10.

Yeatts, M., 1996, High elevation sand deposition and retention from the 1996 spike flow: an assessment for cultural resources stabilization, in Balsom, J.R., and Larralde, S., eds., Mitigation and monitoring of cultural resources in response to the experimental habitat building flow in Glen and Grand Canyons, Spring 1996: final report dated December 31, 1996 submitted to Grand Canyon Monitoring and Research Center, copy on file at the U.S. Geological Survey, Grand Canyon Monitoring and Research Center, Flagstaff, Ariz., 335 p. 
Produced in the Western Region, Menlo Park, California Manuscript approved for publication, June 1, 2009

Edited by James W. Hendley II

Layout by David R. Jones 


\section{$\frac{\mathbb{3}}{3}$}

㕄

$\cong$

암

$\frac{\bar{D}}{\mathrm{D}}$

움

음

亏.

홇

D

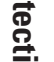

$\stackrel{2}{=}$

क्ष

국

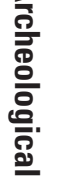

莡

$\Xi$

产

ه্잉

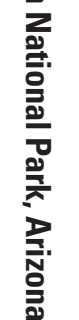

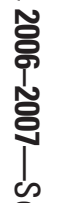

م.

ब.

言

胥

$\overrightarrow{0 .}$

훅.

7

ग

윽

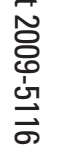

